\title{
Analyse de la verbalisation
}

\section{du travail illégal en 2017}

Présenté en juillet 2019

Direction Générale du Travail

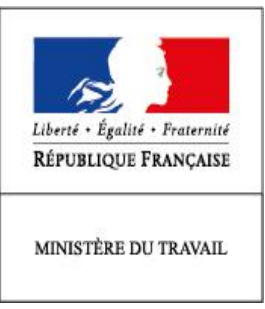




\section{SOMMAIRE}

Préambule

Observations Méthodologiques

Synthèse

1. Mobilisation des services

1.1 La mobilisation des services en matière de lutte contre le travail illégal en 2017

1.2 Près d'une procédure sur 3 est issue de contrôles conjoints

2. Procédures et établissements

2.1 Principales caractéristiques des procédures

2.2 Caractéristiques des établissements

3. Infractions constatées

3.1 En 2017, un peu plus de 11200 jnfractions ont été constatées 22

3.2 Près de huit infractions sur dix kessortent du travail dissimulé 24

3.2.2 Plus de 1400 infractions d'emploi d'étrangers sans titre de travail en 2017

3.2.3 Prêt illicite de main-d'œuvre et marchandage s'appréhendent difficilement 28

3.2.4 Fraude aux revenus de remplacement et cumuxirrégulier d'emplois 29

3.2.5 Les autres infractions liées au travail illégal

4. Auteurs et employés 31

4.1 Près de 7000 auteurs et co-auteurs présumés recensés en 2017

4.2 Plus de 27200 salariés sont concernés par les infractions de travail illéga

Annexe 36

Annexe 1 - Contours de l'enquête sur l'infraction d'emploi d'étrangers sans titre de travaix 36

Annexe 2 - Analyse sectorielle 



\section{Préambule}

Le travail illégal constitue une atteinte inadmissible aux droits sociaux fondamentaux des travailleurs qu'il s'agisse de leur juste rémunération, de conditions de travail décentes, de leur sécurité ou encore de leur protection sociale. En effet, il prive, en règle générale, les travailleurs des droits attachés au statut salarial accordés par la loi ou les conventions collectives concernant les droits individuels du contrat de travail comme les salaires, les congés, les conditions de travail, la formation professionnelle et les droits collectifs, mais également les allocations prévues par les régimes de sécurité sociale (chômage, maladie, invalidité, accident du travail et retraite). II les pénalise, d'une part, en les dépossédant de l'essentiel de la législation sociale, d'autre part, en les mettant ou les maintenant dans une situation de forte précarité et de vulnérabilité. En outre, les travailleurs non déclarés se trouvent parfois contraints de travailler dans les pires conditions en échange de faibles salaires, victimes de la traite des êtres humains par le travail.

Par ailleurs, le travail illégal favorise l'immigration irrégulière et les trafics de main-d'œuvre étrangère. Les employeurs sans scrupule disposent ainsi d'une main-d'œuvre étrangère clandestine particulièrement docile et peu exigeante car sans protection. Cette vulnérabilité a pour corollaire des conditions de travail difficiles voire parfois contraires à la dignité humaine.

Enfin, les auteurs de travail illégal, en éludant le paiement des sommes dues au titre de leur activité professionnelle ou de l'emploi de salariés, causent un préjudice considérable à l'ensemble de la collectivité en provoquant d'importantes évasions de recettes sociales et fiscales. Ils faussent également de manière inacceptable la concurrence à l'égard des entreprises qui respectent la réglementation et enfin nuisent gravement à l'image de leur secteur professionnel.

Pour toutes ces raisons, le gouvernement continu à faire de la lutte contre le travail illégal une priorité pour l'ensemble des services verbalisateurs. Le présent document retrace l'ensemble de leur activité de contrôle en 2017. 


\section{Observations Méthodologiques}

L'enquête annuelle sur la verbalisation du travail illégal recueille les données caractéristiques des procès-verbaux établis et clos avant le 31 décembre, dressés par l'ensemble des agents des corps de contrôle habilités et centralisés par les secrétaires permanents' des comités opérationnels départementaux anti-fraude (CODAF) en charge de la lutte contre le travail illégal. Les secrétaires ont la charge de saisir ces données dans le logiciel TADEES (Traitement Automatisé des DonnEEs Statistiques) dédié à cet effet ainsi que de transmettre les fichiers extraits de TADEES à la DGT au ler semestre de l'année $\mathrm{N}+1$ pour l'établissement du rapport national.

Cette enquête permet ainsi d'observer, à l'échelle nationale et régionale, les différentes formes du travail illégal identifiées et d'en évaluer l'ampleur et l'évolution.

Le plan 2016/2018, dans lequel s'inscrit cette enquête, entend avoir une approche globale et s'articule autour de cinq objectifs prioritaires : la lutte contre toutes les formes de travail dissimulé, la lutte contre les fraudes au détachement dans le cadre des prestations de service internationales, le contrôle des opérations de sous-traitance en cascade, le contrôle et la sanction du recours aux faux statuts, la sanction du recours à l'emploi d'étrangers sans titre de travail.

Du fait des mouvements des secrétaires, de la vacance du poste dans certains départements, de la non transmission des procès-verbaux de certains services de contrôle et de la période à laquelle la centralisation des données départementales est effectuée, la transmission des données relatives à la verbalisation du travail illégal pour une année donnée peut ne pas être totalement complète. Du fait de l'organisation de la transmission des données, ce reliquat est inéluctable et engendre, de fait, une très légère volatilité des chiffres présentés.

Ainsi, il peut résider une différence significative entre les données issues des systèmes internes des services de contrôle et celles issues du logiciel Tadees.

L'analyse de la verbalisation repose, par principe, sur les infractions verbalisées de travail illégal, c'est-àdire celles qui ont été constatées par les agents de contrôle dans un procès-verbal transmis au procureur de la République. Pour cette raison, elle ne reflète qu'une partie des pratiques de fraude car lui échappent toutes pratiques non constatées, toutes pratiques constatées mais ne donnant pas lieu à verbalisation et enfin toutes pratiques constatées mais incriminées sous d'autres infractions jugées plus opportunes (escroquerie, blanchiment d'argent, ou abus de vulnérabilité de la personne par exemple).

Note méthodologique

Les chiffres et conclusions énoncés ci-après ne sont pas exempts d'un contexte organisationnel et réglementaire. Ils sont aussi complètement indépendants des suites judicaires données aux procédures.

\footnotetext{
1 Cf. article 10 du décret du 25 mars 2010.
} 


\section{Synthèse}

En 2017, 5913 procès-verbaux de travail illégal ont été enregistrés par les secrétaires des CODAF, soit une diminution de $14 \%$ par rapport à 2016 (contre $+1 \%$ entre 2015 et 2016, - $12 \%$ entre 2014 et 2015). Près d'un tiers des procédures pénales résultent d'opérations conjointes inter-services en 2017 comme en 2016, soit respectivement 1782 et 2050 procédures. Cette baisse est à rapporter à la durée moyenne des procédures, sensiblement croissante et au nombre de salariés concernés par procédure également en hausse sensible.

$26 \%$ des procédures sont établis par l'inspection du travail, $24 \%$ pour les Urssaf, $23 \%$ pour la gendarmerie et $22 \%$ pour la police.

Les caractéristiques des procédures sont assez stables depuis 2013 : près des deux tiers des procédures sont réalisées à l'initiative des agents de contrôle (62\% en 2017 et 2016, $65 \%$ en 2015). La part des opérations initiées en comité de lutte anti-fraude (CODAF) s'élève à $20 \%$ en 2017 (18\% en 2016). La durée moyenne de constitution d'un PV est d'environ 6 mois en 2017 (5 mois en 2016). En 2017, 35 \% des procédures sont constituées dans les 2 mois suivant la date du constat, dont $12 \%$ en moins de 10 jours et un tiers des procès-verbaux ont une durée d'instruction comprise entre 2 et 6 mois. $32 \%$ des procès-verbaux ont une durée d'instruction de plus de 6 mois $(28 \%$ en 2016). Cette durée est très probablement un marqueur de la complexité croissante des fraudes auxquelles sont confrontés les agents de contrôle.

Le nombre d'établissements concernés, majoritairement des TPE, est, quant à lui, toujours un peu supérieur au nombre de procédures : 6 172. Près de 8 établissements sur 10 sont enregistrés au registre du commerce sous des statuts juridiques variables. $3 \%$ des établissements sont mentionnés comme implantés à l'étranger. Enfin, un peu plus de 6 établissements sur 10 appartiennent aux secteurs du BTP, du commerce ou des HCR.

En 2017, 11260 infractions ont fait l'objet d'une procédure pénale. Avec près de deux infractions en moyenne par procédure, ce taux est stable sur les dernières années (1,90 en 2017 et 2016, 1,81 en 2015 , 2,01 en 2014). La part des infractions liées au travail dissimulé en 2017 représente $\mathbf{7 8 \%}$ du total des infractions (79\% en 2016). La deuxième infraction la plus relevée est celle d'emploi d'étrangers sans titre de travail dont le poids est de $13 \%$ en 2017 (11\% en 2016). Viennent ensuite, le marchandage et le prêt illicite de main d'œuvre avec $2 \%$ des constats effectués $(2,5 \%$ en 2016), et les autres infractions comme les infractions contraventionnelles ou délits connexes associés régulièrement au travail illégal $(7,5 \%$ en 2017 et 2016).

Près de 7000 auteurs et co-auteurs présumés sont recensés en 2017, soit 1,18 auteur en moyenne par procédure. Près de 100 nationalités sont recensées en 2017.

Plus de 27200 travailleurs sont concernés par les infractions de travail illégal en 2017 ayant donné lieu à verbalisation. Le nombre moyen de salariés par procès-verbaux est de 4,61 salariés $(4,11$ en 2016). Près de 100 nationalités sont présentes dans l'ensemble des procédures. Sur l'ensemble des infractions constatées, $37 \%$ concernent des ressortissants de l'Union Européenne en 2017 (47 \% en 2016). 


\section{Mobilisation des services}

5913 procédures ont été enregistrées en 2017, soit une baisse de $14 \%$ par rapport à 2016 . Un peu moins d'1 procédure pénale sur 3 résulte d'opérations conjointes interservices $(30 \%)$, soit près de $1800(2050$ en 2016).

L'inspection du travail établit $26 \%$ des procédures en 2017. Les trois autres corps de contrôle les plus répressifs sont : les Urssaf avec $24 \%$; la gendarmerie avec $23 \%$ et la police avec $22 \%$ des procédures.

Les participations des administrations traditionnellement peu signataires des procédures passent d'un poids de $6 \%$ en 2009 à $16 \%$ en 2017.

\subsection{La mobilisation des services en matière de lutte contre le travail illégal en 2017}

\subsubsection{Une baisse du nombre de procès-verbaux}

En 2017, 5913 procès-verbaux de travail illégal ont été enregistrés par les services concernés par la lutte contre le travail illégal, soit une baisse de $14 \%$ par rapport à 2016.

Cette baisse du nombre de procès-verbaux en 2017 fait suite à une légère hausse en 2016 et à deux années de baisse en 2014 et 2015 (+1 \% entre 2015 et 2016,-12\% entre 2014 et 2015 et -16\% entre 2013 et 2014).

Plusieurs facteurs viennent expliquer un niveau comparable aux années 2014 et 2015 par rapport aux années précédentes:

- Le premier est lié au caractère de plus en plus complexe des affaires traitées qui rend leur détection plus difficile et leur instruction plus longue. Les agents de contrôle constatent moins d'infractions, mais s'attachent à démanteler des dispositifs frauduleux de plus grande envergure qui nécessitent des enquêtes longues, des recherches approfondies et des collaborations nombreuses y compris à l'étranger :

- Le second est la conséquence d'une montée en compétence rendue nécessaire par le développement des mécanismes de fraude à la prestation de services internationale alors même que la réglementation évolue très rapidement et se complexifie aussi. En 2017, $32 \%$ des procèsverbaux ont désormais une durée d'instruction supérieure à six mois ( $28 \%$ en $2016,27 \%$ en 2015 et $26 \%$ en 2014).

- Enfin, il semble, comme pour les années précédentes, qu'un nombre significatif de procédures n'a pas été transmis en 2017 aux secrétaires des Codaf en charge de la lutte contre le travail illégal, chargés de leur saisie dans le logiciel TADEES à partir duquel sont établies ces statistiques².

\footnotetext{
2 Cf. Observations méthodologiques en page 6.
} 
Graphe 1 : Nombre de procès-verbaux reçus depuis $2004^{3}$

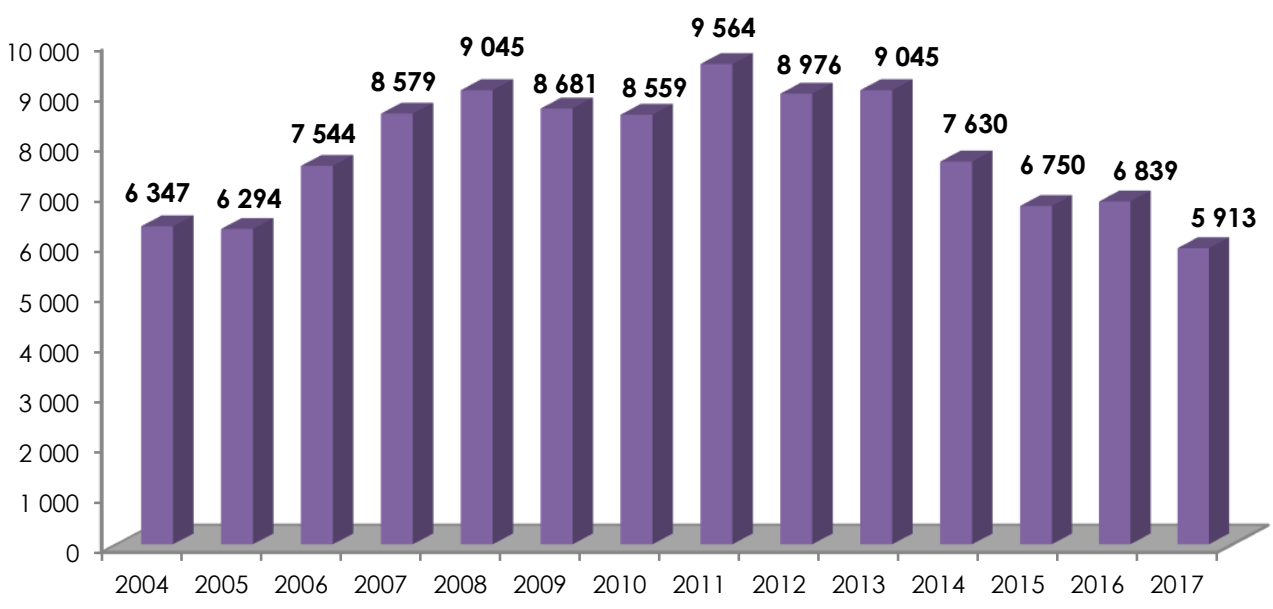

L'année 2011 enregistre le plus haut niveau de verbalisation en matière de travail illégal. Cela résulte probablement de l'objectif assigné aux régions d'établir 10000 procédures de travail illégal sur le territoire national ${ }^{4}$.

Les constats émis par les agents de contrôle et transcrits dans les rapports précédents continuent d'être d'actualité pour expliquer l'évolution de la verbalisation :

- d'une part, l'élargissement des missions d'investigation lors des contrôles au-delà des stricts contrôles de travail illégal dû à la fois au fait de l'intervention de services de plus en plus variés et d'un regard plus large donné aux conditions d'emploi (conditions d'hébergement indignes et manquements aux principes élémentaires de sécurité qui contribuent aux risques d'accidents graves ou mortels notamment) :

- d'autre part, la complexité croissante des activités délictueuses liées au travail illégal et conséquemment de la détection de leur fraude :

- concernant le travail dissimulé, à la dissimulation totale de salariés (« travail au noir ») semble se substituer une dissimulation partielle d'heures travaillées (" travail au gris »). En outre, le développement des recours abusifs à certains faux statuts d'emploi (bénévoles, stagiaires, auto entrepreneurs, indépendants détachés ou non...) est facilité par l'affaiblissement des frontières entre les divers statuts, nouveaux ou anciens, liés à l'évolution des organisations socio-productives. Ces évolutions transforment l'organisation des relations d'emploi, rendant notamment plus difficile la compréhension des formes de subordination ou d'indépendance.

- concernant la sous-traitance, l'infraction d'emploi d'étrangers sans titre de travail est de plus en plus souvent présente dans des cas de fausses prestations de service internationales. Les recours, d'une part, à la mise à disposition de personnel par une entreprise étrangère dans des conditions caractéristiques d'une fausse sous-traitance et, d'autre part, à des personnes dissimulées sous un faux statut étranger de travailleur indépendant perdurent.

\footnotetext{
3 Jusqu'en 2008, le nombre de procédures pénales était présenté depuis 1995, avec environ 10000 procédures annuel. La série n'étant pas homogène sur la période (modification des périmètres des données et des processus d'organisation de la remontée statistique notamment), il a été retenu depuis la publication 2009, 2003 comme point de référence, date à partir de laquelle les données ont été insérées dans un logiciel unique (Tadees).

${ }^{4}$ Cf. Plan d'action 2010/2011
} 


\subsubsection{Evolution de la part des administrations signataires}

Les procès-verbaux proviennent de toutes les administrations habilitées à verbaliser le travail illégal.

Il faut donc interpréter le niveau quantitatif de leurs contributions respectives en tenant compte des objectifs qui leur sont assignés, de leurs compétences institutionnelles et de leurs moyens humains.

En outre, l'analyse des données chiffrées par administration résulte des saisies dans le logiciel et peut se différencier, parfois nettement des volumes captés directement des systèmes internes propres à chaque corps de contrôle.
L'inspection du travail devient le premier corps verbalisateur avec $26 \%$ des procès-verbaux en 2017. Les Urssaf dressent $24 \%$ des procédures. La gendarmerie et la police en signent respectivement $23 \%$ et $22 \%$ des procédures.

Les corps de contrôle autres que les quatre cités cidessus représentent près de $4,5 \%$ des administrations signataires en 2017.

\section{Graphe 2 : Répartition des procès-verbaux par corps de contrôle depuis 2008}

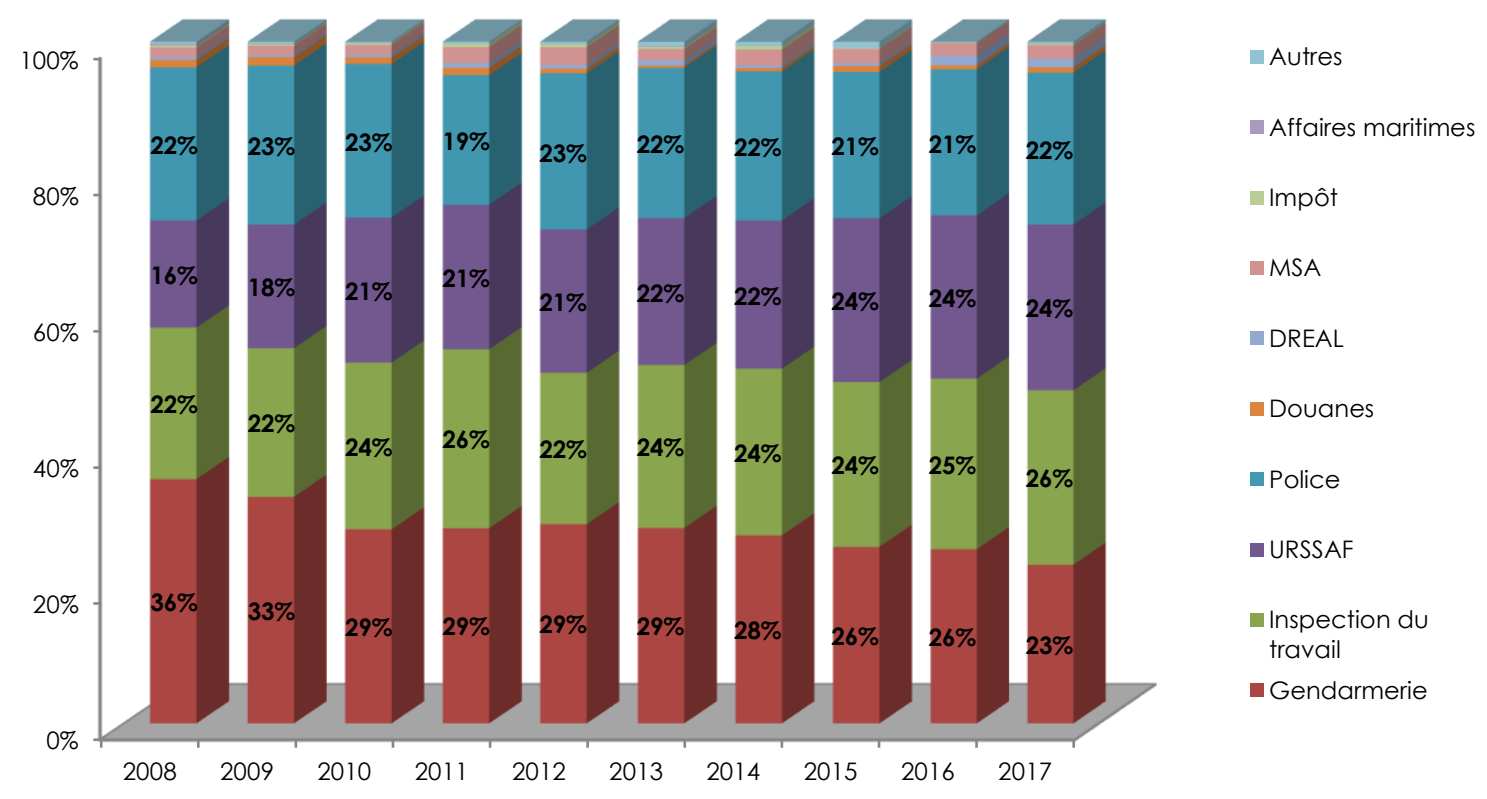

En 2017, Douanes : $0,8 \%$ (0,6\% en 2016) ; Equipement : $1,3 \%$ (1,4 \%) ; MSA : 2,0 \% (1,8 \%) ; Impôt : $0,2 \%(0,1 \%)$; Affaires maritimes : $0,1 \%(0,1 \%)$; Autres : $0,3 \%(0,1 \%)$. 


\subsection{Près d'une procédure sur 3 est issue de contrôles conjoints}

\subsubsection{Une part d'opérations conjointes stable entre 2016 et 2017}

L'enquête de la verbalisation permet de comptabiliser les contrôles décidés en comité de lutte anti-fraude spécialisé dans le travail illégal, les contrôles dit coordonnés et les contrôles effectués par la seule administration à l'origine du contrôle.

Le contrôle "coordonné ", désigne des actions communes faisant intervenir des agents de deux ou plusieurs corps habilités, que ce soit dans le cadre d'opérations décidées en Comité ou de leur propre initiative.
Terminologie

Contrôle coordonné, opération conjointe, action concertée, opération décidée en comité de lutte antifraudes (CODAF), contrôle d'envergure, opération « coup de poing », action exemplaire, contrôle commun, contrôle conjoint sur la lutte contre les étrangers en situation irrégulière sont un ensemble d'appellations indistinctement utilisées pour exprimer une collaboration de travail entre les services enquêteurs.

De l'ordre de $10 \%$ du total des procès-verbaux en 2004 et 2005, ces procédures issues de contrôles conjoints et transmises au parquet représentent plus d'un procès-verbal sur cinq entre 2006 (21 \%) et 2009 (23\%) et plus d'un procès-verbal sur quatre entre 2010 (27\%) et 2015 (26\%). En 2017, comme en 2016, la part des contrôles conjoints atteint 30 \%, soit 1782 contrôles conjoints en 2017 (2 050 en 2016 ).

Même si elle reste très majoritaire, la part relative du nombre des contrôles faits par une seule administration connaît une baisse tendancielle : de 90 \% en 2004 à 70 \% en 2017.

\section{Graphe 3 : Répartition des PV entre contrôle conjoint et non conjoint depuis 2004}

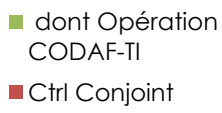

- Ctrl Conjoint

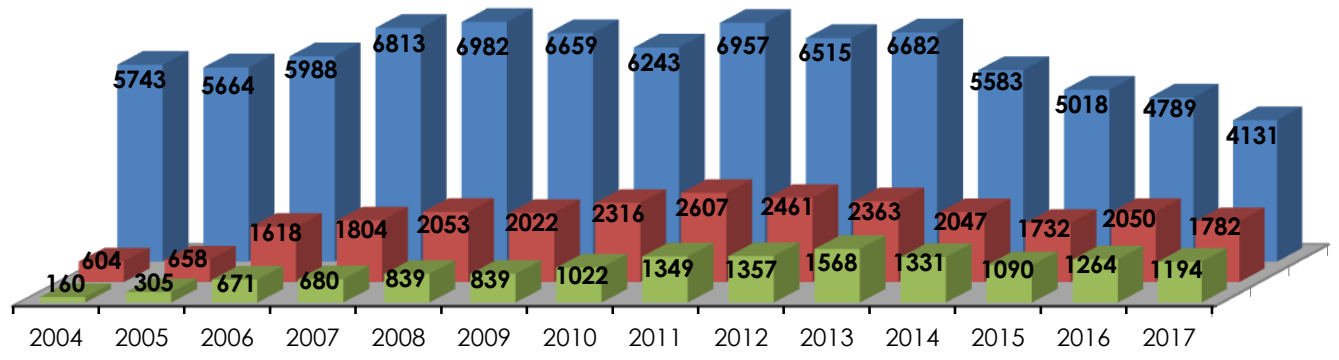

Parmi ces opérations conjointes, le nombre d'opérations décidées en comité de lutte anti-fraude donnant lieu à verbalisation représente près des deux tiers des opérations conjointes (67 \% en 2017, $62 \%$ en $2016,63 \%$ en 2015 et $65 \%$ en 2014 ). 
Selon les informations dont ils disposent, les agents doivent arbitrer entre les avantages et les inconvénients du mode opératoire qu'ils choisiront, à chaque étape de leurs investigations :

- d'un côté, un contrôle conjoint permet de mobiliser un grand nombre d'agents. Par exemple, dans les lieux ouverts tels que les chantiers de bâtiment, les champs agricoles, les lieux qui accueillent du public comme les discothèques ou les spectacles, il est nécessaire d'assurer la bonne réalisation du contrôle pour l'ensemble des personnes. La présence des forces de l'ordre permet à la fois de sécuriser le périmètre et de retenir les personnes qui seraient tentées de quitter de manière précipitée les lieux. Le contrôle conjoint permet également de combiner plus facilement des actions sur site et sur siège pour une même entreprise. Enfin, le contrôle conjoint (et coordonné) permet de mutualiser les missions, pouvoirs et compétences des agents, (dont la réquisition en qualité de "sachant» pour l'inspection fiscale ou du travail notamment) ;

- d'un autre côté, la complexité de la préparation et de la réalisation du contrôle croît avec le nombre de services impliqués, engendrant des délais, des coûts et également des risques de fuite des auteurs présumés d'infraction qui peuvent réduire l'efficacité du contrôle, voire le rendre caduc. Le contrôle fait en commun doit en outre répondre à des règles très précises de procédure, notamment pour les OPJ, instituées par le code de procédure pénale (CPP), au risque, à défaut, d'invalider le procès-verbal pour non-conformité. Enfin, notamment dans les opérations de lutte contre l'emploi des étrangers sans titre, les risques de confusion entre police de l'immigration et lutte contre le travail illégal nécessitent une définition préalable des rôles et le respect des identités professionnelles des services intervenants (circulaire du 20 décembre 2006).

La notion de contrôle concerté, quant à elle, peut permettre aux services d'orienter leurs actions plutôt sur tel ou tel type d'objectif ou même de comparer les résultats d'investigation ou les moyens en termes d'information. Cette coopération permet, notamment aux Etats communautaires dans les zones frontalières, d'effectuer des contrôles simultanément mais non conjointement dans le sens où elle ne s'accompagne pas de la participation directe d'un agent de contrôle étranger à une opération de contrôle sur le territoire national.

\subsubsection{La coopération inter-service}

Parmi les PV issus de contrôles conjoints, ceux résultant de deux ou trois administrations représentent près de 8 PV sur 10 et restent un des formats d'intervention les plus utilisés lorsque des administrations souhaitent réaliser un contrôle en commun efficace et dans des délais pertinents.

Tableau 1 : Répartition des PV par nombre d'administrations présentes lors du contrôle depuis 2011

\begin{tabular}{|c|c|c|c|c|c|c|c|c|c|c|c|c|c|c|}
\hline & \multicolumn{2}{|c|}{2011} & \multicolumn{2}{|c|}{2012} & \multicolumn{2}{|c|}{2013} & \multicolumn{2}{|c|}{2014} & \multicolumn{2}{|c|}{2015} & \multicolumn{2}{|c|}{2016} & \multicolumn{2}{|c|}{2017} \\
\hline $\begin{array}{l}\text { Deux } \\
\text { administrations }\end{array}$ & 1589 & $61 \%$ & 1468 & $60 \%$ & 1427 & $60 \%$ & 1214 & $59 \%$ & 1053 & $61 \%$ & 1219 & $59 \%$ & 1021 & $57 \%$ \\
\hline $\begin{array}{l}\text { Trois } \\
\text { administrations }\end{array}$ & 659 & $25 \%$ & 562 & $23 \%$ & 526 & $22 \%$ & 478 & $23 \%$ & 358 & $21 \%$ & 412 & $20 \%$ & 397 & $22 \%$ \\
\hline $\begin{array}{l}\text { Quatre } \\
\text { administrations }\end{array}$ & 279 & $11 \%$ & 246 & $10 \%$ & 218 & $9 \%$ & 211 & $10 \%$ & 160 & $9 \%$ & 202 & $10 \%$ & 173 & $10 \%$ \\
\hline $\begin{array}{l}\text { > Cinq } \\
\text { administrations }\end{array}$ & 80 & $3 \%$ & 185 & $8 \%$ & 192 & $8 \%$ & 144 & $7 \%$ & 161 & $9 \%$ & 217 & $11 \%$ & 191 & $11 \%$ \\
\hline
\end{tabular}

La part d'opérations conjointes réalisées par au moins cinq administrations atteint son niveau le plus élevé en 2016, niveau qui se maintient en 2017 (11\%). Ces derniers types de contrôle dit d'envergure, qui concentrent plusieurs moyens d'investigation et de sanction pluridisciplinaires, permettent le plus souvent de donner une lisibilité médiatique, par le relais de la presse régionale, à la lutte contre le travail illégal. 
Le graphique ci-après permet de mieux visualiser les coopérations les plus fréquentes en $2017^{5}$ :

- $\quad$ Police/Urssaf ont effectué 628 contrôles en commun (588 en 2016) ;

- $\quad$ Travail/Urssaf : 351 contrôles (418 en 2016);

- $\quad$ Police/Travail : 280 contrôles (332 en 2016);

- $\quad$ Urssaf/Gendarmerie : 250 contrôles (328 en 2016) ;

- $\quad$ Travail/Gendarmerie : 223 contrôles (333 en 2016) ;

- $\quad$ Services fiscaux/Police : 214 contrôles (213 en 2016) ;

- $\quad$ Police/Douanes : 177 contrôles (161 en 2016).

Dans une fréquence moindre mais récurrente, le tandem Gendarmerie/Services fiscaux a effectué 99 interventions communes (155 en 2016), et celui Travail/MSA 79 (74 en 2016).

Graphe 4 : Les alliances de collaboration des corps de contrôle en 2017

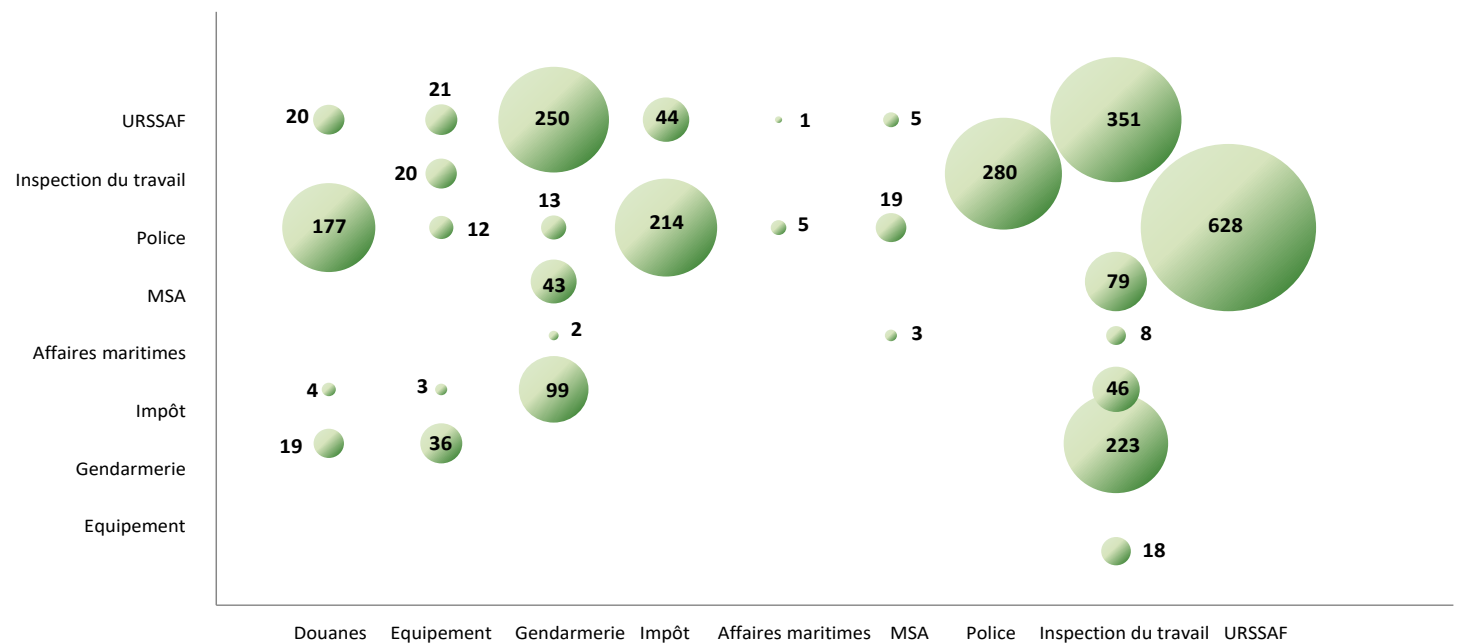

La participation des services de contrôle s'élève à un peu plus de 9000 sur les procédures issues de contrôle conjoint.

\section{Rappel}

La notion de "participation " d'une administration est utilisée depuis 2007 et se définit comme le "nombre d'administrations présentes lors des contrôles" et non plus seulement par les seules administrations signataires des procédures

La définition élargie de la notion de participation des services permet de mieux prendre en compte l'ensemble des interventions, notamment celles des corps d'inspection spécialisés dans la lutte contre les fraudes de type économique.

En 2017, les 5913 procès-verbaux dressés ont engagé 9015 participations des services, soit 1,52 administration présente en moyenne par contrôle donnant lieu à procédure.

Depuis 2010, la participation moyenne des administrations est stable (respectivement 1,52 en 2016, 1,43 en $2015,1,44$ en $2014,1,43$ en 2013, 1,46 en 2012, 1,43 en 2011, 1,41 en 2010).

\footnotetext{
${ }^{5}$ Note technique : chaque participation est comptée en binôme en référence à l'administration signataire de la procédure, même si le contrôle a été effectué par plusieurs administrations. Par exemple, un contrôle signé par la gendarmerie et effectué avec l'inspection du travail et la mutualité sociale agricole sera comptabilisé une fois au titre du binôme G/T et une fois au titre de G/MSA.
} 
Tableau 2 : Nombre de participations par administration depuis 2014

\begin{tabular}{|l|c|c|c|}
\cline { 2 - 4 } \multicolumn{1}{c|}{} & \multicolumn{3}{c|}{2017} \\
\cline { 2 - 4 } \multicolumn{1}{c|}{} & $\begin{array}{c}\text { Partipation } \\
\text { o aux Crtl }\end{array}$ & $\begin{array}{c}\text { avec PV } \\
\text { signé }\end{array}$ & $\begin{array}{c}\text { avec PV } \\
\text { non } \\
\text { signé }\end{array}$ \\
\hline Gendarmerie & 1560 & 1380 & 180 \\
\hline Police & 1752 & 1317 & 435 \\
\hline Douanes & 274 & 46 & 228 \\
\hline Inspection du travail & 1942 & 1512 & 430 \\
\hline Urssaf & 2291 & 1436 & 855 \\
\hline MSA & 206 & 116 & 90 \\
\hline Impôt & 421 & 12 & 409 \\
\hline DREAL & 135 & 74 & 61 \\
\hline Affaires maritimes & 21 & 4 & 17 \\
\hline Autres & 413 & 16 & 397 \\
\hline \multicolumn{4}{|l}{} \\
\hline Total & 9015 & 5913 & 3102 \\
\hline
\end{tabular}

\begin{tabular}{|c|c|c|}
\hline \multicolumn{3}{|c|}{2016} \\
\hline $\begin{array}{c}\text { Partip } \\
\text { aux Crtl }\end{array}$ & $\begin{array}{c}\text { avec PV } \\
\text { signé }\end{array}$ & $\begin{array}{c}\text { avec PV } \\
\text { non } \\
\text { signé }\end{array}$ \\
\hline 1999 & 1752 & 247 \\
\hline 1910 & 1464 & 446 \\
\hline 261 & 39 & 222 \\
\hline 2314 & 1710 & 604 \\
\hline 2537 & 1636 & 901 \\
\hline 251 & 125 & 126 \\
\hline 507 & 6 & 501 \\
\hline 166 & 97 & 69 \\
\hline 18 & 4 & 14 \\
\hline 414 & 6 & 408 \\
\hline & \multicolumn{3}{|c}{} \\
\hline 10377 & 6839 & 3538 \\
\hline
\end{tabular}

\begin{tabular}{|c|c|c|}
\hline \multicolumn{3}{|c|}{2015} \\
\hline $\begin{array}{c}\text { Partip } \\
\text { aux Crtl }^{\circ}\end{array}$ & $\begin{array}{c}\text { avec PV } \\
\text { signé }\end{array}$ & $\begin{array}{c}\text { avec PV } \\
\text { non } \\
\text { signé }\end{array}$ \\
\hline 1992 & 1753 & 239 \\
\hline 1812 & 1446 & 366 \\
\hline 292 & 59 & 233 \\
\hline 2051 & 1630 & 421 \\
\hline 2402 & 1621 & 781 \\
\hline 235 & 140 & 95 \\
\hline 396 & 13 & 383 \\
\hline 74 & 29 & 45 \\
\hline 8 & 1 & 7 \\
\hline 386 & 58 & 328 \\
\hline & & \\
\hline 9648 & 6750 & 2898 \\
\hline
\end{tabular}

\begin{tabular}{|c|c|c|}
\hline \multicolumn{3}{|c|}{2014} \\
\hline $\begin{array}{c}\text { Partip } \\
\text { aux Crtl }\end{array}$ & $\begin{array}{c}\text { avec PV } \\
\text { signé }\end{array}$ & $\begin{array}{c}\text { avec PV } \\
\text { non } \\
\text { signé }\end{array}$ \\
\hline 2386 & 2109 & 277 \\
\hline 2080 & 1666 & 414 \\
\hline 274 & 39 & 235 \\
\hline 2415 & 1864 & 551 \\
\hline 2591 & 1658 & 933 \\
\hline 374 & 175 & 199 \\
\hline 461 & 43 & 418 \\
\hline 55 & 29 & 26 \\
\hline 10 & 2 & 8 \\
\hline 370 & 45 & 325 \\
\hline \multicolumn{3}{|c|}{} \\
\hline 11016 & 7630 & 3386 \\
\hline
\end{tabular}

Participations aux contrôles $\rightarrow$ Total du nombre de participations du service de contrôle, qu'il soit signataire ou non du PV.

avec PV signé $\quad \rightarrow$ le service de contrôle a établi et signé le PV issu du contrôle ququel il a participé, qu'il soit conjoint ou non ;

avec PV non signé $\quad \rightarrow$ le service de contrôle n'a pas établi le PV issu du contrôle conjoint auquel il a participé.

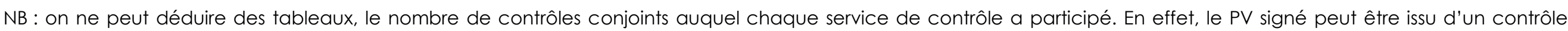
conjoint ou non.

Rappel

Les données chiffrées par administration résultent des saisies dans le logiciel TADEES et peuvent se différencier des volumes captés directement dans les systèmes internes propres à chaque corps de contrôle. 
L'indicateur taux de participation permet une lecture différente de l'activité des services

La comparaison entre le taux de signature des procédures et celui de participation aux contrôles donnant lieu à procédure montre une image différente de l'implication des services.

\section{Graphe 5 : Comparaison entre taux de signature et taux de participation en 2017}

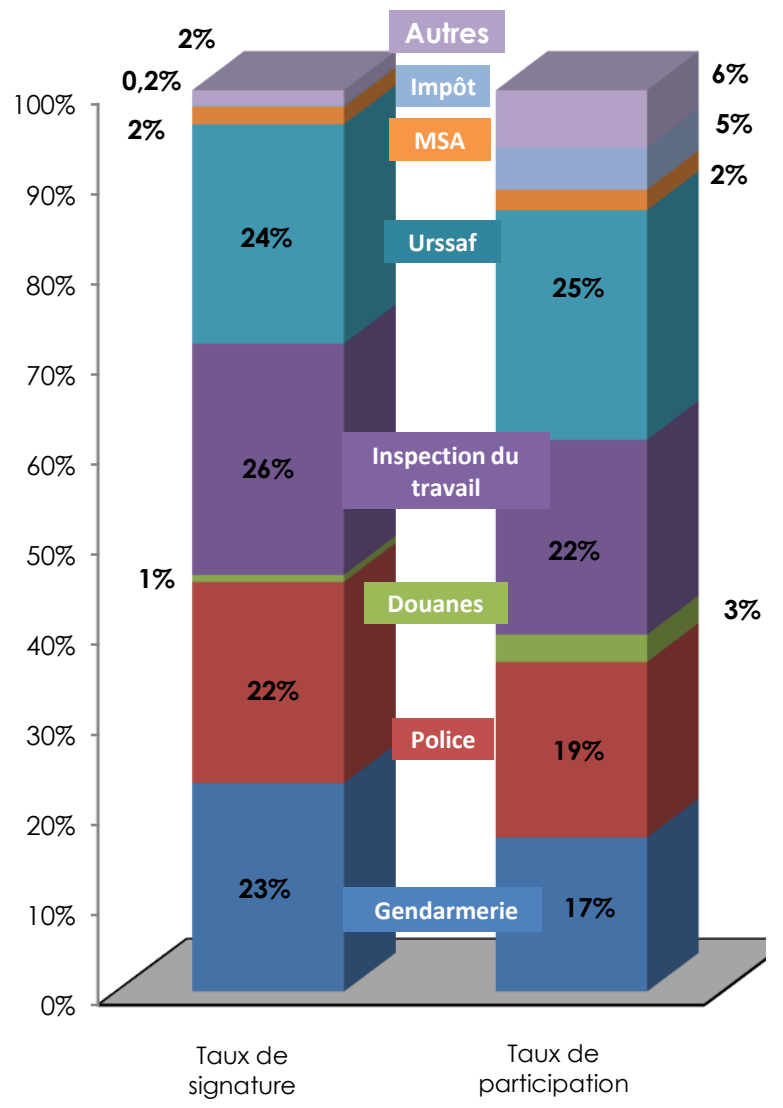

- Avec près de 2300 participations en 2017, les URSSAF ont un taux de participation légèrement supérieur au taux de signature de procédure, respectivement $25 \%$ et $24 \%$.

- Dans une proportion bien inférieure avec un peu plus de 400 participations, les services fiscaux ont une participation de $5 \%$ pour $0,2 \%$ des procès-verbaux signés.

- A contrario, la police et la gendarmerie, en signant la grande majorité de procédures issues du contrôle, possèdent un poids de signature supérieur à leur poids de participation.

- Identique par rapport à l'an passé, l'inspection du travail possède un poids de signature supérieur à son poids de participation (soit $26 \%$ contre $22 \%$ ), et effectue cette année près de 2000 participations.

- Les administrations qui ont participé à moins de 415 procédures en 2017 ont un taux de signature inférieur à celui de leur participation.

Ces pourcentages concernent une moyenne nationale. Au sein de chaque département, des mouvements très différents peuvent être observés selon les modalités de mise en œuvre du contrôle conjoint.

L'analyse de l'implication des services par participation confirme l'idée que la seule signature du procès-verbal n'est pas un indicateur suffisant pour appréhender l'engagement de chaque corps. Souvent, d'un commun accord entre les services et notamment ceux siégeant dans les comités, l'élaboration de la procédure est laissée au service le plus approprié ou celui qui est doté des moyens d'investigation les plus adaptés. Il bénéficie alors des informations de tous pour concrétiser la recherche des infractions ciblées.

Chaque administration, pendant la préparation du contrôle et lors du contrôle conjoint, doit pouvoir alors mieux faire valoir ses missions dans le procès-verbal sans chercher obligatoirement à en dresser la procédure (codification des infractions idoines, investigations complémentaires liées au donneur d'ordre, prise en compte des critères qui permettront ultérieurement d'engager de nouvelles procédures etc....).

Par ailleurs, la participation à un contrôle avec d'autres services représentent aussi un atout pour chaque participant en lui permettant de capter des informations qui pourront s'avérer utiles dans un autre cadre ou pour engager des procédures incidentes. En ce sens, les contrôles conjoints permettent un échange efficace d'informations entre les différents partenaires qui, souvent, se poursuit au-delà de l'opération conduite ensemble. 


\section{Procédures et établissements}

En 2017, près de 6 procédures sur 10 sont à l'initiative des agents de contrôle et la durée moyenne de constitution d'un PV est d'environ 6 mois.

Le nombre d'établissements, majoritairement des TPE, est, quant à lui, toujours un peu supérieur au nombre de procédures. Près de 8 établissements sur 10 sont enregistrés au registre du commerce sous des statuts juridiques variables. $3 \%$ des établissements sont mentionnés comme implantés à l'étranger en 2017. Enfin, un peu plus de 6 établissements sur 10 appartiennent aux secteurs du BTP, du commerce ou des HCR.

\subsection{Principales caractéristiques des procédures}

\subsubsection{L'initiative des services est à l'origine d'un peu moins des deux fiers des constats}

Comme les années précédentes, le fait générateur des contrôles donnant lieu à procédure est à l'initiative des services de contrôle (62 \% en 2017 et en 2016, 65 \% en 2015). En 2017, pour 12 \% des contrôles, il ressort d'un signalement exogène (plainte, dénonciation ou encore signalé par service) ${ }^{6}$.

\section{Graphe 6 : Répartition de l'origine des contrôles en 2017}

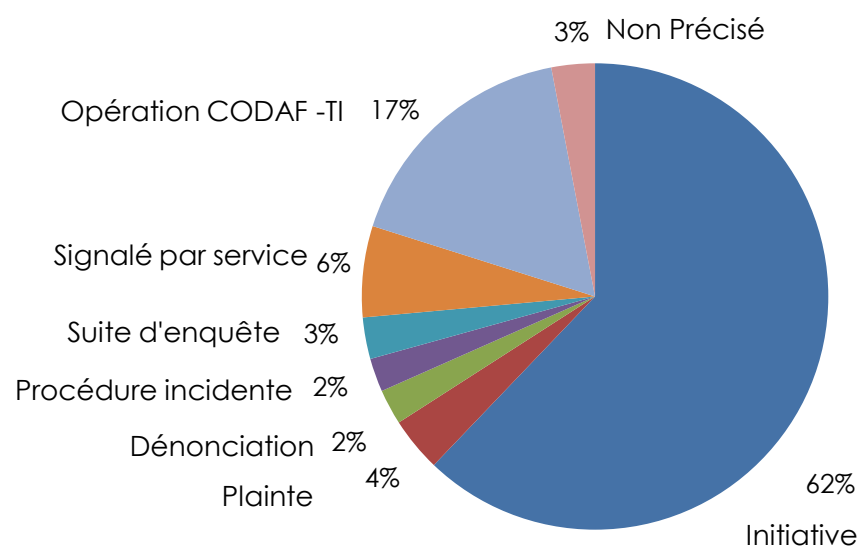

Le poids du «non précisé » est passé de 12 \% en 2009 à 5 \% en 2010, grâce à l'implantation du nouveau logiciel statistique et s'établit à $3 \%$ en 2017, permettant ainsi une analyse plus fine du poids des signalements venus de tiers professionnels.

La part des opérations initiées en comité de lutte anti-fraude dans le domaine du travail illégal s'élève à $17 \%$ en 2017 (16\% en 2016).

\footnotetext{
6 Outre le taux d'imprécision, cette analyse demeure complexe du fait des différentes combinaisons possibles entre les rubriques proposées (une opération en comité peut être combinée à une plainte et/ou une suite d'enquête), et de la confusion possible dans la fiche d'analyse du procès-verbal entre les modes de saisine qui est l'élément déclencheur de l'enquête (ex. initiative, plainte, dénonciation) et du mode opératoire des officiers de police judiciaire qui a lieu a posteriori (commission rogatoire, enquête préliminaire, flagrant délit).
} 


\subsection{2 $35 \%$ des procédures sont transmises en moins de deux mois}

L'amplitude de la distribution du nombre de jours de constitution des dossiers pour chaque procédure exprime clairement l'hétérogénéité des affaires rencontrées: de moins de 10 jours pour $12 \%$ des procédures à plus d'un an pour également $12 \%$ d'entre elles. En 2017, la durée moyenne de constitution d'un procès-verbal est de 182 jours, en augmentation de 17 jours par rapport à 2016.

Graphe 7 : Durée de constitution des procédures en 2017

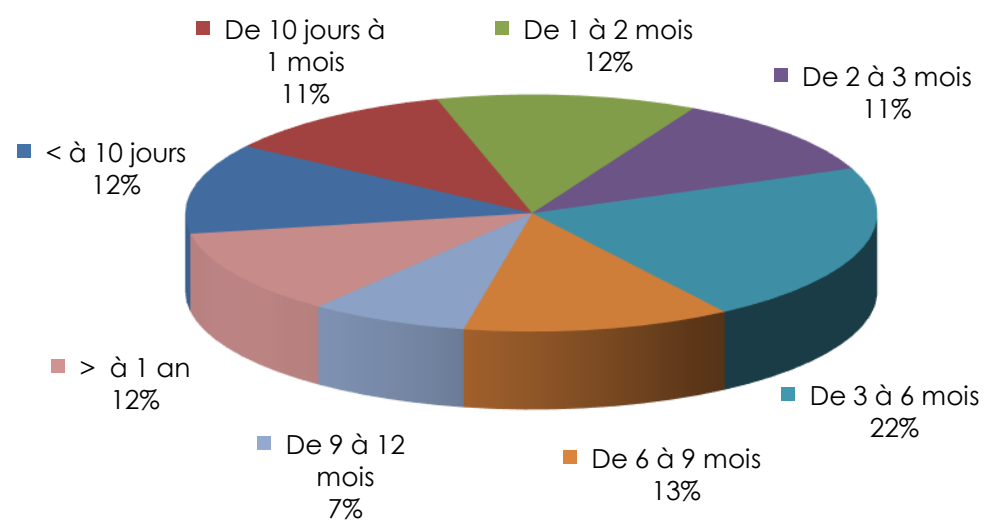

Passant de 248 en 2004 à 690 en 2017 (735 en 2016, 661 en 2015, 700 en 2014), le nombre de procédures nécessitant plus d'un an est en légère baisse par rapport l'année dernière et reste à un niveau élevé. Ce niveau peut traduire la complexité de certains processus de fraude.

\subsection{Caractéristiques des établissements}

\subsubsection{Près de 6200 établissements recensés}

En 2017, 6172 établissements contrôlés ${ }^{7}$ ont donné lieu à une procédure pénale incriminant le responsable pénal de l'infraction constatée. Ce nombre est inférieur à celui de 2016 (7 181, soit - 14 \%).

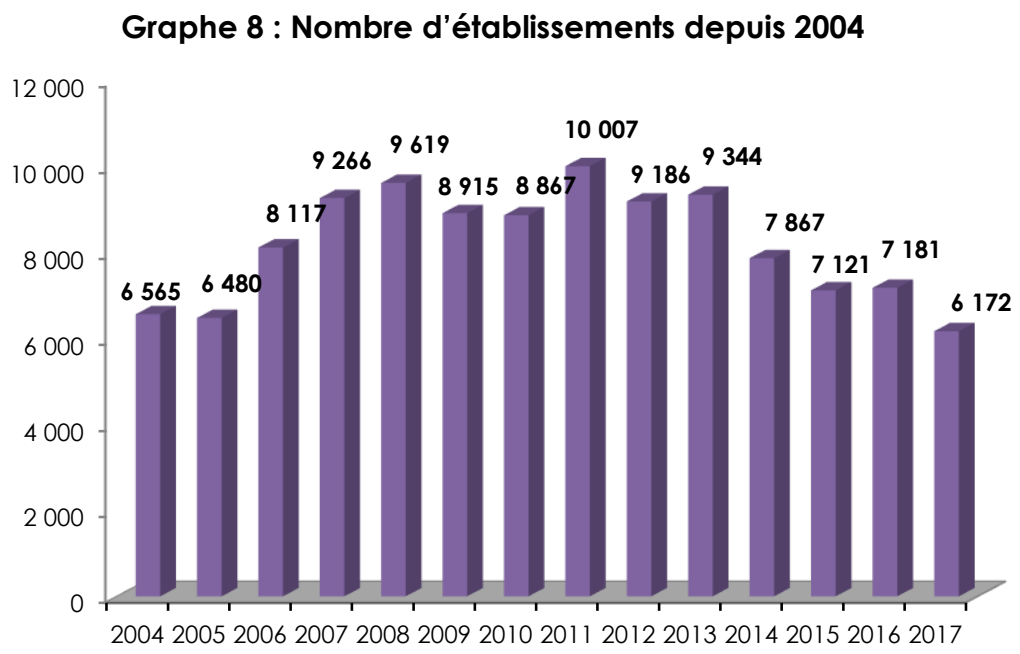

\footnotetext{
7 La notion d'établissement est à considérer dans une acception large dans ce sens où un particulier/employeur en situation d'infraction sera considéré comme un « établissement ».
} 


\subsubsection{Près de huit établissements sur dix sont enregistrés au registre du commerce et des sociétés (RCS)}

L'analyse des catégories juridiques où sont immatriculés les établissements contrôlés montre que $83 \%$ des établissements ont un enregistrement au registre du commerce et des sociétés, dont près de la moitié en SA ou SARL. Ces informations étant parfois difficilement vérifiables, les agents de contrôle décèlent cependant parfois des sociétés montrant une apparence de vraies immatriculations qui s'avèrent factices par l'usurpation de l'identité d'autres entreprises (faux nom, faux numéro de RCS ou Siret, ou fausse adresse d'implantation).

Outre les $2 \%$ pour lesquels il n'y a pas d'information, seuls $3 \%$ des établissements ne sont pas déclarés et $3 \%$ seraient des particuliers. $3 \%$ des établissements sont mentionnés comme implantés à l'étranger. ${ }^{8}$

L'auteur présumé, en régime d'auto-entrepreneur/employeur, est a priori positionné dans la catégorie " travailleurs indépendants» (voire "particulier» ou "non déclaré »). Cette catégorie représente $14 \%$ des établissements en 2017. Son taux reste relativement stable depuis le début de la période d'étude.

Graphe 9 : Catégorie juridique des établissements depuis 2004

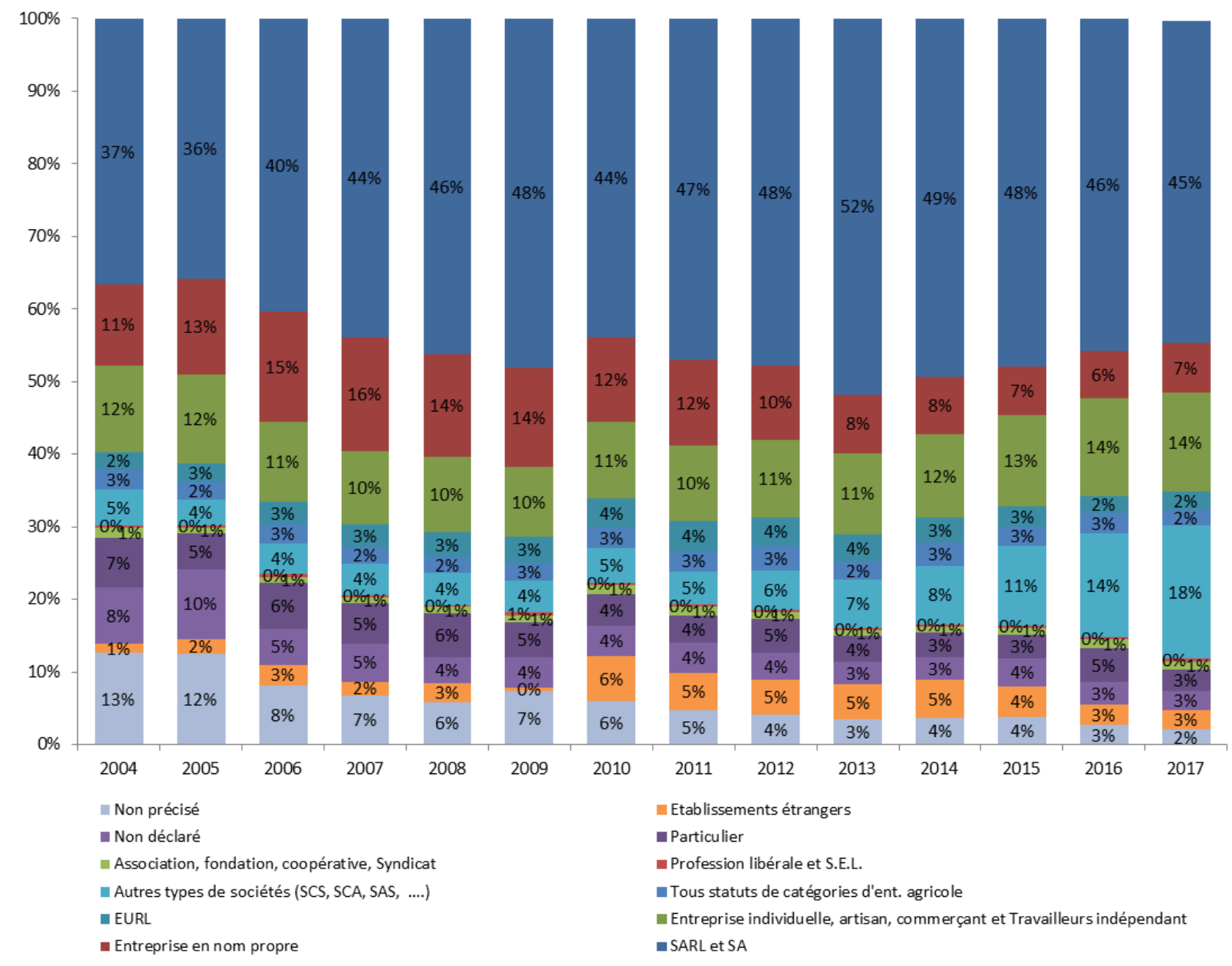

\footnotetext{
8 L'enquête ne permet pas de savoir si ces établissements sont réellement et régulièrement déclarés dans leur pays.
} 


\subsubsection{Près de six établissements sur dix appartiennent aux secteurs du BTP, du commerce ou des HCR}

\section{Graphe 10 : Répartition sectorielle des établissements en 2017}

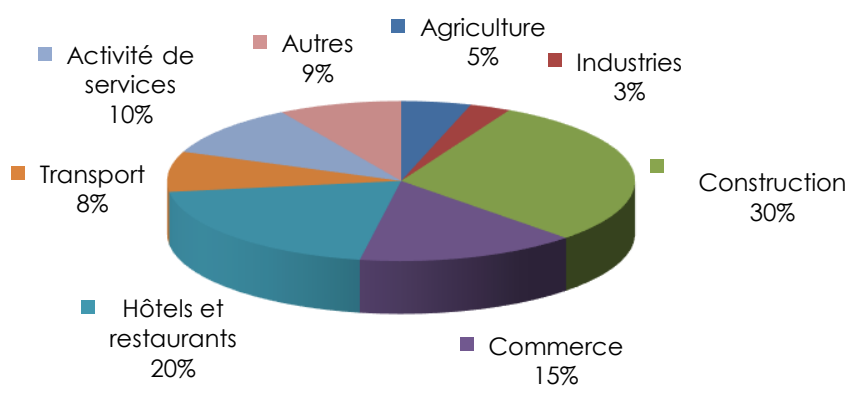

Avec $30 \%$ des établissements recensés, le secteur du BTP reste le secteur le plus verbalisé. Ce taux de verbalisation dans le BTP doit se lire en parallèle avec le nombre de contrôles effectués par les corps de contrôle. En effet, le BTP reste le secteur le plus contrôlé dans les secteurs prioritaires.

Le secteur des HCR est assez stable également, avec une part de $20 \%$ des PV (19\% en 2016). Le commerce représente le 3ème secteur avec $15 \%$. Chacun des autres secteurs représente une part de 3 à $10 \%$, dont l'agriculture avec une part de $5 \%$ et le transport à $8 \%$.

L'analyse sectorielle doit se lire en parallèle avec le nombre de contrôles effectués annuellement, qui ont une influence directe sur les procès-verbaux dressés pour les secteurs définis comme prioritaires dans le plan national d'action et, par suite, les plus contrôlés.

Dans le même esprit, les opérations en comité sont principalement centrées dans les secteurs prioritaires, même si le comité ne limite pas son action afin que tous les secteurs puissent être sensibilisés aux risques du travail illégal.

Si le poids sectoriel des interventions conjointes est sensiblement le même que pour l'ensemble des opérations conjointes, un axe est donné au secteur des HCR qui est le plus important $(27 \%$ en poids sur les procédures issues des opérations conjointes versus $20 \%$ pour l'ensemble de procédures) soit davantage que le secteur du BTP (respectivement $23 \%$ et $30 \%$ ).

Le commerce demeure le 3ème secteur, avec une part de $20 \%$ sur les procédures issues des opérations conjointes décidées en comité et $15 \%$ pour l'ensemble de procédures. Alors même que ce secteur n'est pas défini comme prioritaire par le plan national d'action, l'importance des opérations conjointes indique la vigilance des corps de contrôle à ne laisser aucun secteur en marge de la lutte contre le travail illégal.

\section{Graphe 11: Répartition sectorielle des opérations décidées en comité en 2017}

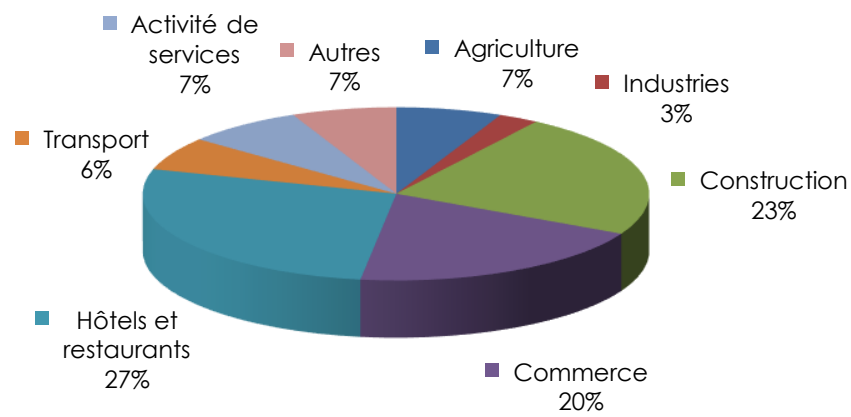




\subsubsection{Près des trois quarts des établissements ont leur lieu d'implantation similaire au lieu de contrôle}

En 2017, pour $77 \%$ des établissements, le département d'implantation de l'établissement est identique au département de constat de l'infraction (79\% en 2016 et $84 \%$ en 2015). Pour ceux-là, le rayonnement de la fraude semble donc être circonscrit au département dans lequel ils sont installés. En revanche, pour $23 \%$ des établissements, la localisation de l'établissement diffère du département où l'infraction est relevée (21\% en 2016).

\subsubsection{Huit établissements sur dix ont moins de 10 salariés}

La verbalisation porte pour l'essentiel sur de très petits établissements (moins de 10 salariés) qui représentent $79 \%$ du total des établissements, dont $19 \%$ d'entreprises à 0 salarié déclaré et $60 \%$ de 1 à 10 salariés.

Ensuite, viennent les entreprises de 11 à 49 salariés avec une part de verbalisation de $9 \%$. Enfin les entreprises de plus de 50 salariés représentent $3 \%$ de la verbalisation totale.

Le poids des établissements pour lesquels l'information n'est pas précisée traduit la qualité relative de cet indicateur (9\% en 2017).

Graphe 12 : La taille des entreprises verbalisées en 2017

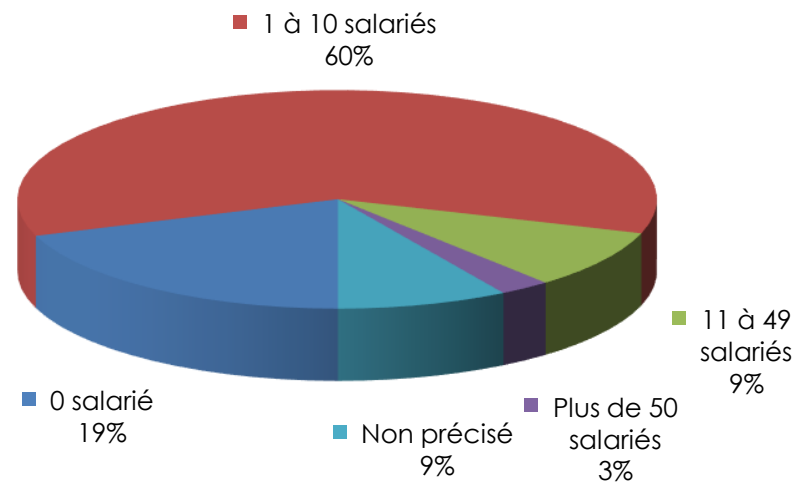




\section{Infractions constatées}

En 2017, un peu plus de 11200 infractions ont été relevées dans les procédures au titre de la lutte contre le travail illégal. Avec près de deux infractions en moyenne par procédure, ce taux est identique à celui de 2016.

Les infractions de travail dissimulé représentent 78 \% du total des infractions dont $54 \%$ pour la dissimulation totale ou partielle de l'emploi salarié. L'emploi d'étranger sans titre concentre $13 \%$ des infractions, et les infractions de prêt illicite de main d'œuvre et de marchandage 2 \%.

\subsection{En 2017, un peu plus de 11200 infractions ont été constatées}

\subsubsection{Le nombre d'infractions constatées est en baisse ...}

En 2017, 11260 infractions ont été constatées au titre de la lutte contre le travail illégal, soit une diminution de $13 \%$ par rapport à l'année 2016. Le nombre moyen d'infractions par procès-verbal est de 1,90 en 2017, comme en 2016.

Graphe 13 : Evolution du nombre d'infractions relevées depuis 2004

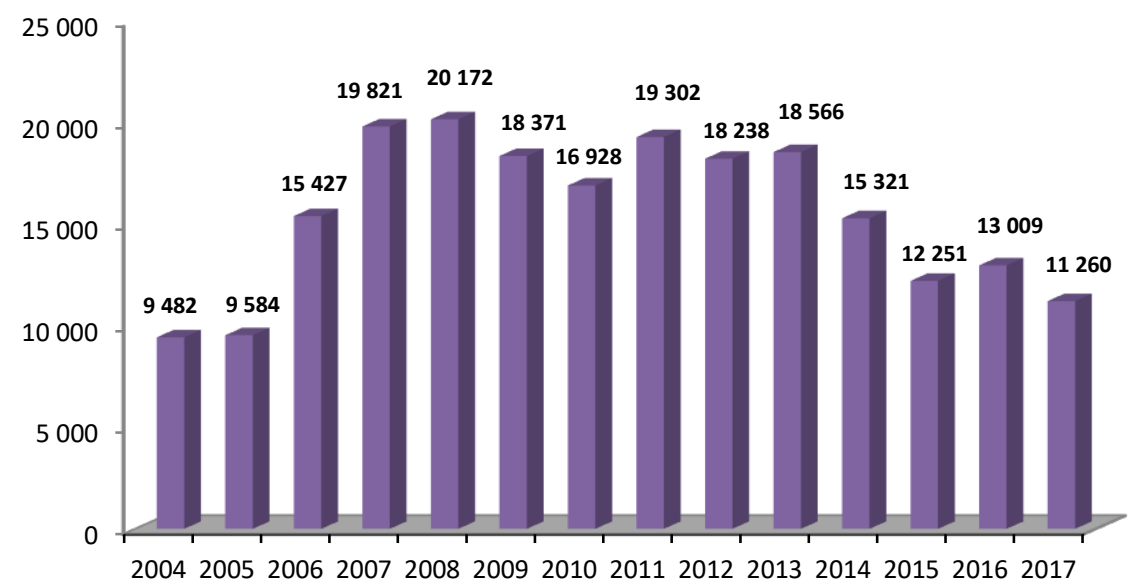

Note méthodologique

L'augmentation massive du nombre d'infractions relevées à partir de 2006 implique de manier les comparaisons avec les années antérieures avec grande précaution.

\subsection{2 … et la hiérarchie entre les infractions reste inchangée}

Le législateur définit les infractions de travail illégal selon six catégories :

1. le travail dissimulé9,

\footnotetext{
9 La Chancellerie ne distingue pas, dans la nomenclature des infractions Natinf, la dissimulation d'immatriculation de l'entreprise du défaut de déclaration fiscale ou du défaut de déclaration sociale, le tout étant agrégé dans le code 1508. L'enquête propose une distinction entre ces trois items qui ne repose donc pas sur une nomenclature communément utilisée et qui laisse donc le champ à l'interprétation du rédacteur de la fiche d'encodage de la procédure. (Cf. rapport de la verbalisation 2009 DGT/DNLF).
} 
2. le marchandage,

3. le prêtillicite de main d'œuvre,

4. I'emploi d'étrangers sans titre de travail,

5. le cumul irrégulier d'emplois

6. la fraude aux revenus de remplacement.

Dans l'enquête, une dernière catégorie « Autres infractions $\|^{10}$ vient compléter l'information disponible

10 En 2017, cette catégorie représente $8 \%$ du total des infractions constatées dont: entrée/aide au séjour irrégulier d'étrangers, défaut de tenue/ non présentation du RUP, responsabilité des personnes morales art.225-13 à 225-15 du code pénal, abus de vulnérabilité,... 
Graphe 14: La répartition des infractions en 2017

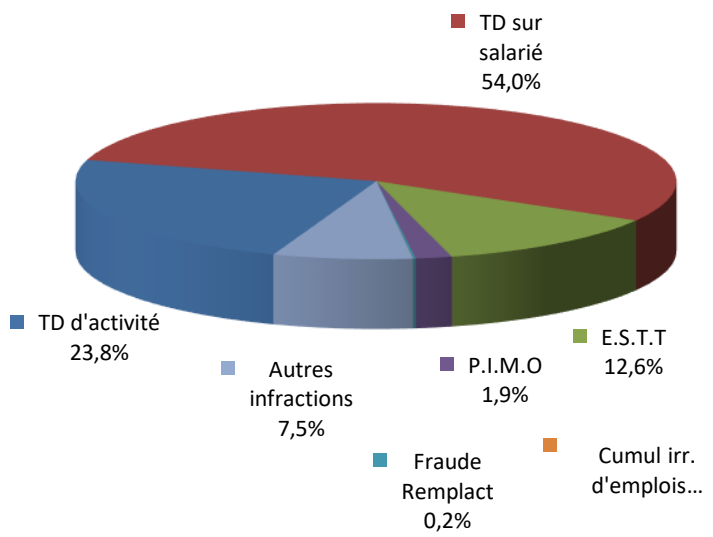

Largement majoritaire pour chacune des années, la part des infractions liée au travail dissimulé en 2017 est en légère diminution par rapport à 2016 et se situe à $78 \%$ du total des infractions (79\% en 2016).

La deuxième infraction la plus relevée concerne l'infraction d'emploi d'étrangers sans titre de travail dont le poids est de près de $13 \%$ (11\% en 2016). Viennent ensuite, le marchandage et le prêt illicite de main d'œuvre avec environ $2 \%$ des constats effectués $(2,5 \%$ en 2016$)$.

Les infractions de fraude au revenu de remplacement et de cumul irrégulier d'emplois représentent respectivement $0,2 \%$ et $0,02 \%$ du total des infractions.

7,5\% des infractions concernent les autres infractions dont infractions contraventionnelles ou délits connexes associés régulièrement au travail illégal en 2017, comme en 2016.

\subsection{Près de huit infractions sur dix ressortent du travail dissimulé}

En 2017, 8765 infractions liées au travail dissimulé ont été constatées, soit une diminution de $15 \%$ par rapport à l'année 2016. Ces infractions représentent $78 \%$ du total des infractions constatées, soit une part légèrement inférieure à celle de 2016 (79\%).

L'enquête permet de dissocier les infractions qui ressortent de la dissimulation d'activité de celles liées à la dissimulation d'emplois salariés.

\section{Formalités et obligations de l'entrepreneur}

L'exercice d'une activité de production, de fabrication, de prestation de services, de vente etc. impose l'accomplissement de plusieurs formalités et le respect d'obligations sociales et fiscales de la part de l'entrepreneur, c'est-à-dire de l'opérateur économique responsable de cette activité professionnelle. Il en est de même lors de l'embauche et de l'emploi de salariés.

L'omission volontaire et délibérée de ces formalités déclaratives et de ces obligations constitue le délit de travail dissimulé. 

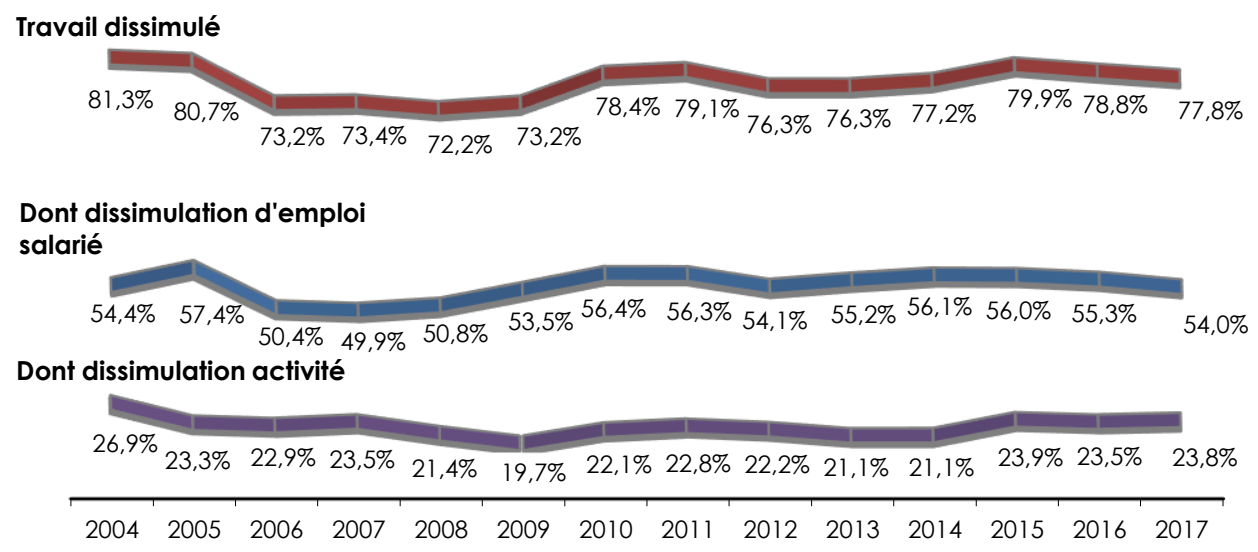

Graphe 15 : Evolution de la part de l'infraction de travail dissimulé depuis 2004

\subsubsection{La dissimulation de salariés représente plus de la moitié des infractions de travail illégal}

La dissimulation d'une activité économique consiste pour un entrepreneur à exercer une activité professionnelle en omettant volontairement d'effectuer des formalités déclaratives obligatoires liées à la création de l'entreprise ou au démarrage d'une nouvelle activité ou d'un nouvel exercice professionnel.
En matière de dissimulation totale ou partielle d'activité, 2682 infractions ont été constatées en 2017. Elles représentent près de $24 \%$ des infractions de travail illégal et $31 \%$ des infractions de travail dissimulé.

Le constat lié au défaut de déclaration sociale de l'établissement reste la première infraction constatée de dissimulation d'activité et représente $58 \%$ en $2017 \quad 52 \%$ en 2016), avec plus de 1500 cas référencés. Ce résultat est le reflet probable :

- d'une part de l'importance donnée à la lutte vers la fraude économique. Ainsi, l'orientation donnée aux corps de contrôle sur la plus grande vigilance à avoir sur la dissimulation d'activité alors même il n'y aurait pas d'emploi de salariés autre que l'emploi du chef d'entreprise lui-même sur sa propre activité ;

- d'autre part de la meilleure prise en compte de la fraude économique par l'ensemble des corps de contrôle et non plus seulement des services d'inspection du régime général de la sécurité sociale et du régime de la mutualité sociale agricole.

Le constat lié au défaut d'immatriculation de l'entreprise est la deuxième infraction constatée, avec 700 cas en 2017 et représente $26 \%$ de la dissimulation d'activité (32\% en 2016). Ce constat est en baisse depuis 2004 .

La fraude liée à l'absence de déclaration aux services fiscaux représente $15 \%$ de la dissimulation d'activité en 2017, comme en 2016.

Enfin, la fraude liée au non-respect de la décision de fermeture temporaire d'établissement pour travail illégal ${ }^{11}$ représente $0,1 \%$ de la dissimulation d'activité en 2017 (3 cas constatés contre 16 en 2016).

11 Infraction introduite en 2015. 


\section{Graphe 16 : Evolution des infractions de dissimulation d'activité depuis 2004}

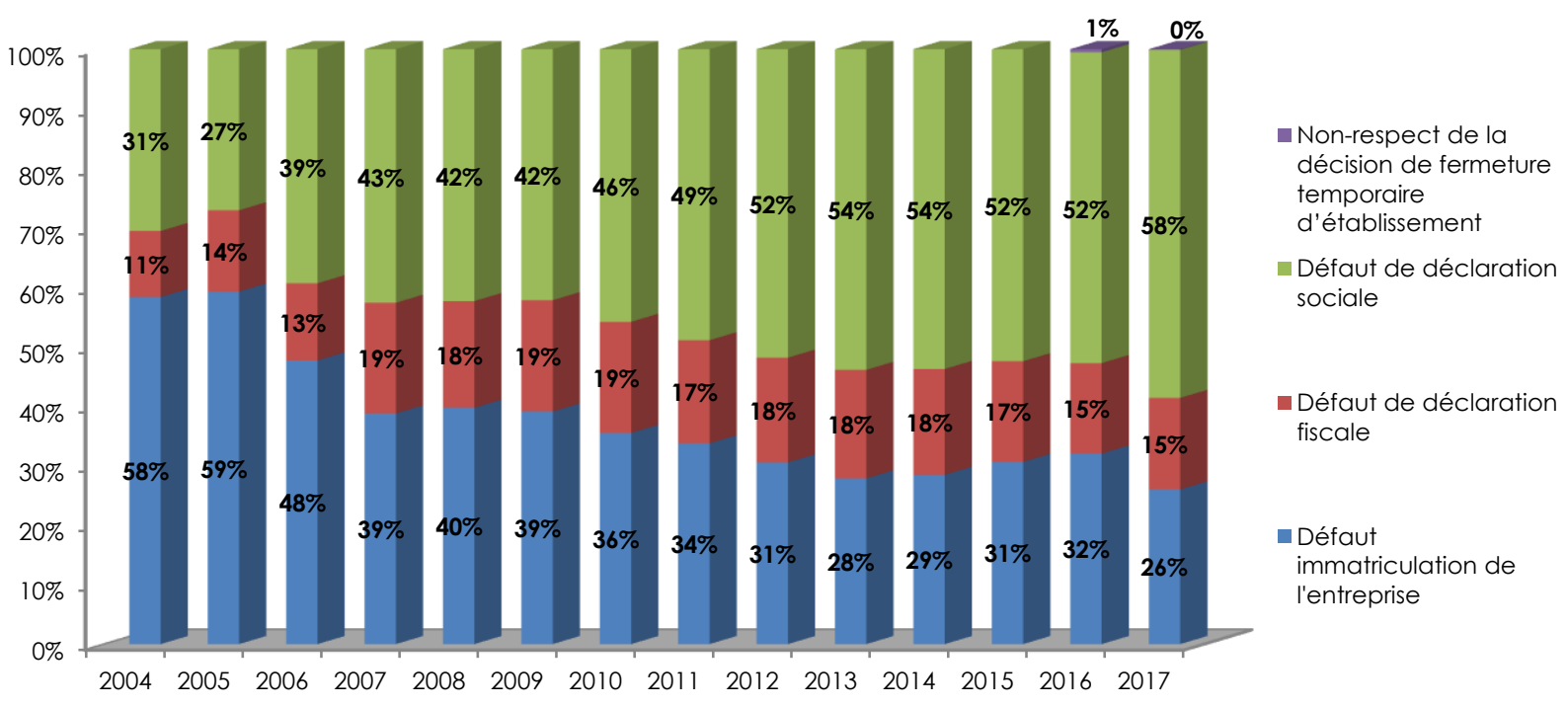

La dissimulation totale d'emploi salarié résulte de l'omission volontaire d'une formalité administrative obligatoire concernant l'emploi du salarié (notamment la déclaration préalable à l'embauche et souvent la remise d'un bulletin de paie). individuel des horaires de travail. II se peut alors qu'ils privilégient d'autres modes de suites données aux constats que la procédure pénale.

L'infraction de recours direct aux services de celui qui exerce un travail dissimulé est en baisse par rapport à l'année précédente et se situe à 375 infractions (418 en 2016), et représente $6 \%$ des constats de la dissimulation des salariés.

L'infraction de dissimulation de salariés avec défaut intentionnel de fiche de paie est en baisse $16 \%$ en 2017 et $7 \%$ en 2016). infractions ont été constatées en 2017. Elles représentent près de $54 \%$ des infractions de travail illégal et $69 \%$ des infractions de travail dissimulé.

L'infraction de dissimulation totale de salariés avec défaut intentionnel de déclaration préalable à l'embauche reste majeure avec plus des troisquarts des infractions de dissimulation d'emploi salarié, en augmentation de près de deux points par rapport à 2016.

La dissimulation partielle d'heures travaillées représente $4 \%$ des infractions en 2017, comme en 2016. Ce niveau est probablement en deçà des constats par les corps de contrôle. En effet, dans les retours qualitatifs, les agents mentionnent très régulièrement les manquements des employeurs ficulté d'établir l'intentionnalité de la fraude en l'absence de décompte paie)

En matière de dissimulation totale ou partielle d'emploi salarié, 6083 
Graphe 17 : Evolution des infractions de dissimulation d'emploi salarié depuis 2004

\subsubsection{Plus de 1400 infractions d'emploi d'étrangers sans titre de travail en 2017}

En 2017, 1416 infractions d'emploi d'un étranger sans titre de travail ont été constatées, soit un volume proche de celui observé en 2016 (1 423 en 2016). Cette infraction représente près de $13 \%$ du total des infractions en 2017.

Graphe 18 : Evolution de la part relative de l'infraction d'emploi d'étrangers sans titre de travail depuis 2004

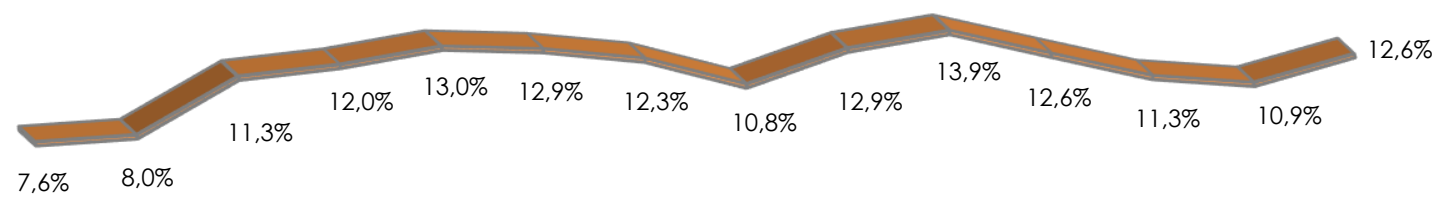

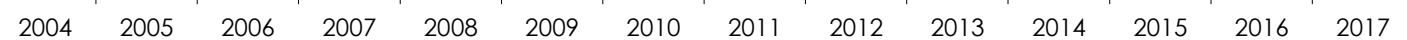

Recours par personne morale à une personne exerçant un travail dissimulé

L'infraction d'em dissimulé Jn étranger sans titre de travail concerne tous les ressortissants des pays tiers hors Union européenne.

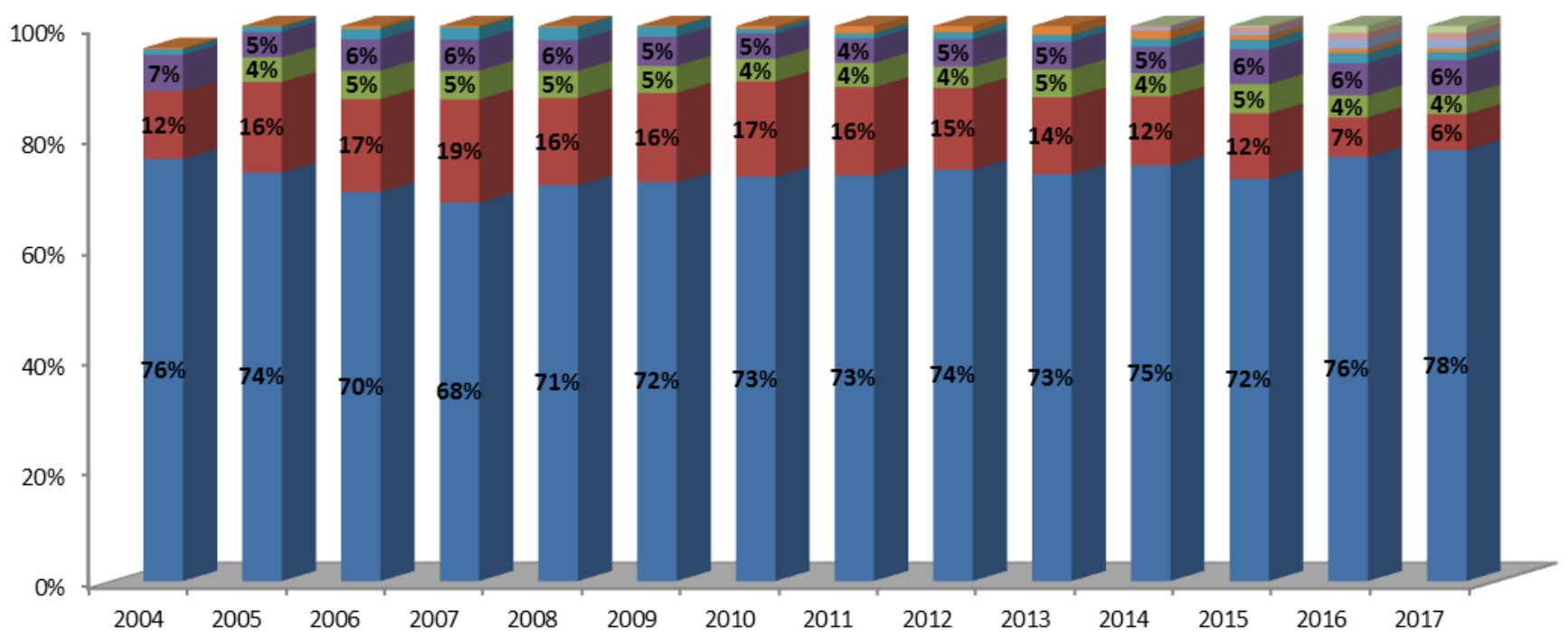

\# Diss. sal. par défaut de déclarations relatives aux salaires ou aux cotisations sociales assises sur ceux-ci auprès des org. de recouvrement des contributions et cotisations sociales ou de l'administration fiscale en vertu des dispositions légales

mecours à la sous-traitance sans faire accepter le sous-traitant et agréer ses conditions de paiement par le maitre d'ouvrage

necours par personne morale d'une personne exerçant un travail dissimulé

Publicité favorisant le travail diss.

Responsabilité personne morale

Recours au service de celui qui exerce un TD

niss. partielle d'heures travaillées

Défaut intentionnel de fiche de paie

Défaut intentionnel de D.P.A.E. 
Seuls les services de la police, de la gendarmerie, de l'inspection du travail et des douanes et droits indirects ont compétence pour relever, par procès-verbal, cette infraction. Ainsi, si les agents des URSSAF et des MSA peuvent vérifier qu'un travailleur étranger a été déclaré par son employeur, ils ne sont cependant pas habilités à contrôler l'admission au travail de cet étranger.

Pour l'ensemble des infractions de travail illégal, l'infraction d'emploi d'étrangers sans titre, telle qu'elle est appréhendée par cette statistique, se concentre principalement dans le secteur du BTP (33\%) puis des HCR (26\%) et du commerce (18\%).

\section{Graphe 19 : Répartition de l'infraction d'emploi d'étrangers sans titre de travail par secteur d'activité en} 2017

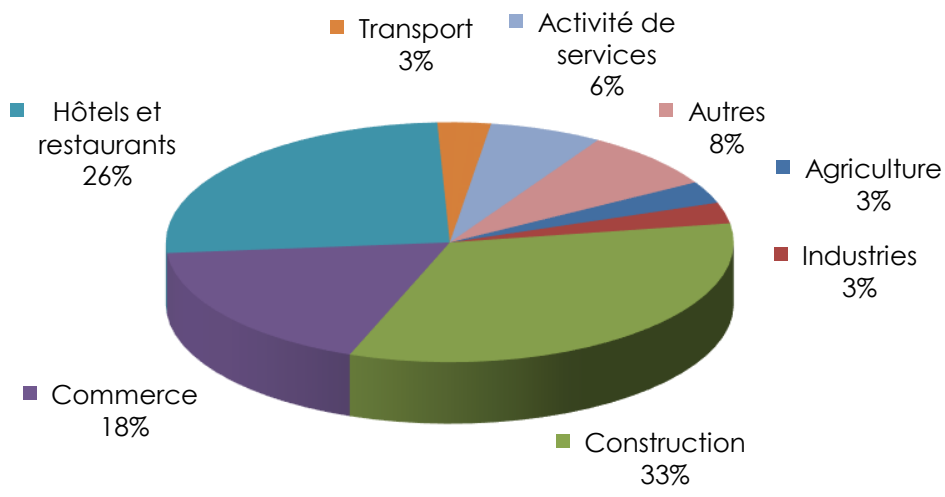

\subsubsection{Prêt illicite de main-d'œuvre et marchandage s'appréhendent difficilement}

Marchandage : depuis l'abrogation de l'article L.312-7 du code du travail qui interdisait la tenue de bureaux de placement payant, sont désormais autorisées toutes les opérations de fourniture de main-d'œuvre, autrement dit le placement des travailleurs auprès d'entreprises pour que celles-ci les embauchent et les emploient, que ces opérations soient réalisées dans un but lucratif ou non. Cependant, pour être légales, ces opérations de fourniture de main-d'œuvre doivent ne pas causer de préjudice au salarié fourni ni éluder l'application de la loi, du règlement ou de la convention collective. Dans le cas contraire, l'opérateur commet le délit de marchandage (L. 8231 - 1CT).

Prêt exclusif: seules les entreprises de travail temporaire déclarées à l'inspection du travail et titulaires d'une garantie financière sont autorisées par la loi à effectuer des opérations de prêt exclusif de main-d'œuvre dans un but lucratif. Dès lors, selon l'article L.8241 - 1 CT, toute opération à but lucratif de prêt exclusif de salariés effectuée par une entreprise qui fournit ce personnel à une entreprise utilisatrice en dehors des règles du travail temporaire est délictueuse. 
Passé de 2,4\% à 4,8\% entre 2004 et 2006, la part du prêt illicite de main d'œuvre n'a cessé de baisser jusqu'en 2010. Pendant quatre ans, la part de ces infractions augmente pour se situer à 3,7\% en 2014 . Depuis 2015, cette part diminue et s'établit à 1,9\% en 2017.

\section{Graphe 20 : Evolution de la part relative des infractions prêt illicite de main d'œuvre depuis 2004}

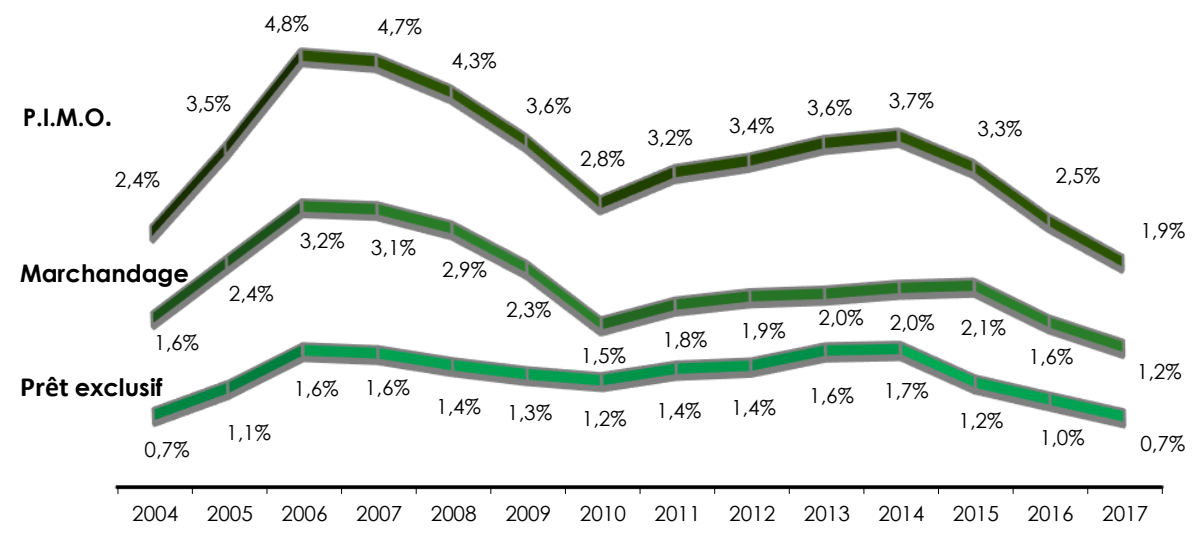

Ces infractions sont difficiles à appréhender du fait de trois difficultés principales:

- les montages juridiques complexes, la multitude d'entreprises sous-traitantes, la rapidité d'exécution des travaux, les entreprises éphémères, enfin la caractérisation de la relation de travail contraignent parfois à renoncer aux investigations malgré de fortes suspicions de cette infraction, au risque de ne pas obtenir un dossier suffisamment étayé pour engager une procédure pénale ;

- les entreprises se donnent une apparence juridique conforme aux règles régissant les relations de travail en déclarant les salariés mais en réalité recourent à la fausse prestation de service ou à la fausse sous-traitance pour dissimuler des opérations frauduleuses de prêt de personnel. Là encore, ces montages nécessitent des investigations lourdes et complexes pour caractériser l'infraction:

- d'après certains agents, la crise exacerberait la concurrence entre les entreprises, pouvant conduire certaines d'entre elles à tenter de diminuer leurs coûts et de préserver ou améliorer leur flexibilité en recourant à de la prestation illégale ou irrégulière (fausse sous-traitance, fausse entreprises de travail temporaire, sous rémunération ou sous déclaration des heures effectuées, etc

\subsubsection{Fraude aux revenus de remplacement et cumul irrégulier d'emplois}

La fraude aux revenus de remplacement définie à l'article L.5429-1 du code du travail est le fait de percevoir ou de tenter de percevoir indûment et en toute connaissance de cause par des procédés illégaux un revenu de remplacement comme l'assurance chômage ou le régime de solidarité. Les infractions à l'assurance chômage sont constatées et relevées par procès-verbal par les agents de contrôle de l'inspection du travail ainsi que les OPJ et APJ. Ces informations sont communiquées à Pôle emploi12. Cette situation se caractérise par le cumul d'une situation d'emploi - déclaré ou non - avec celle d'une perception d'allocation.

Ne représentant que $0,2 \%$ de l'ensemble des infractions de travail illégal en $2017(0,1 \%$ en 2016$)$, le faible nombre de cas recensés -qui ne préjuge pas de la réalité de la fraude aux revenus de remplacement- ne permet pas de mettre en évidence des évolutions significatives.

\footnotetext{
12 défini par l'article L. 114-15 CSS.
} 
Le cumul irrégulier d'emplois pour les salariés de droit privé concerne l'activité des salariés des professions industrielles, artisanales ou agricoles pour des travaux rémunérés au-delà de la durée maximale du travail dans sa profession (en principe 48h de travail par semaine cf. L 8261-1 CT). Depuis la loi du 2 février 2007, les règles concernant l'interdiction du cumul d'emplois pour les fonctionnaires ont été abrogées. De l'ordre d'une centaine d'infractions relevées jusqu'en 2008, cette infraction serait constatée 2 fois en 2017 (9 fois en 2016, 6 fois en 2015 et 12 fois en 2014).

\subsubsection{Les autres infractions liées au travail illégal}

Les autres infractions se composent d'infractions qui sont corrélées au travail illégal car fréquemment présentes lors de constat de travail illégal, mais sans en être directement. On peut les regrouper en cina catégories principales:

- les constats liés à l'entrée et à l'aide à l'entrée et au séjour irrégulier des étrangers pour $47 \%$ du total des autres infractions en 2017 (395 constats) ;

- les constats liés aux défauts de tenue, à la non présentation ou à l'absence de mentions obligatoires dans le registre unique du personnel, ou bien dans les déclarations préalables à l'embauche pour 11 \% du total des autres infractions en 2017 (92 constats) ;

- les constats liés au détachement et ayant été inclus dans des procès-verbaux de travail illégal, pour $6 \%$ du total des autres infractions en 2017 (47 constats) : défaut de déclaration de détachement de prestations de service internationales, défaut d'annexion de la déclaration de détachement au registre unique du personnel, non déclaration d'un AT d'un salarié détaché par le dirigeant d'une entreprise non établie en France, non présentation par l'employeur de salariés détachés de certains documents à l'agent de contrôle, non-respect par le donneur d'ordre ou maitre d'ouvrage de son obligation de vigilance au regard du respect des règles du noyau dur par un sous-traitant direct ou indirect ;

- les infractions dont la part se situe entre 0 et $5 \%$ en 2017 : délit d'outrage et d'obstacle à agent de contrôle 5,1 \% (43 constats) ; fraude pour l'obtention d'un titre de travail/placement par ETT de ressortissants de pays tiers hors de France 2,4\% (20 cas); fraude ou fausse déclaration pour l'obtention de prestation ou d'allocation indue versée par un organisme de protection sociale $1,8 \%$ (15 cas) ; infractions à la réglementation générale sur l'hygiène et la sécurité du travail 1,8\% (15 constats); usage (ou tentative) d'usage de faux documents 1,4\% (12 constats); défaut de déclaration hébergement collectif de salariés à l'inspection du travail 1,2\% (10 constats); abus de vulnérabilité sur rémunération et sur condition de travail ou d'hébergement $1,0 \%$ (8 constats) ; fraude ou aide à la fraude au revenu de solidarité active 0,8\% (7 constats); perception frauduleuse de prestations au titre de l'aide sociale 0,8 \% (7 cas) ; non remise non intentionnelle du bulletin de paie ou mention incomplète ou erronée dans la remise du bulletin de paie $0,8 \%$ (7 constats) ; défaut de déclaration à la préfecture d'un hébergement collectif de travailleurs $0,7 \%$ (6 constats) ; défaut d'affichage sur un chantier de BTP 0,5\% (4 constats) et traite ou tentative de traite d'êtres humains par le travail 0,5\% (4 cas).

- les autres infractions pour lesquelles il n'y a pas de précision (18\% du total des autres infractions soit 150 infractions). L'analyse des procédures indique par exemple les manquements en termes de permis de conduire, état d'ébriété, vente à la sauvette, escroquerie, etc. 


\section{Auteurs et employés}

\subsection{Près de 7000 auteurs et co-auteurs présumés recensés en 2017}

L'enquête de la verbalisation recense 6961 auteurs d'infractions de travail illégal en 2017, soit 1,18 auteur en moyenne par procédure (1,18 également en 2016).

Présomption d'innocence Toute personne suspectée ou poursuivie est présumée innocente tant que sa culpabilité n'a pas été établie. Cf. Article préliminaire du Code de procédure pénale. L'usage du mot "auteur" sans être accompagné du terme " présumé " dans ce rapport est une simplification de rédaction.

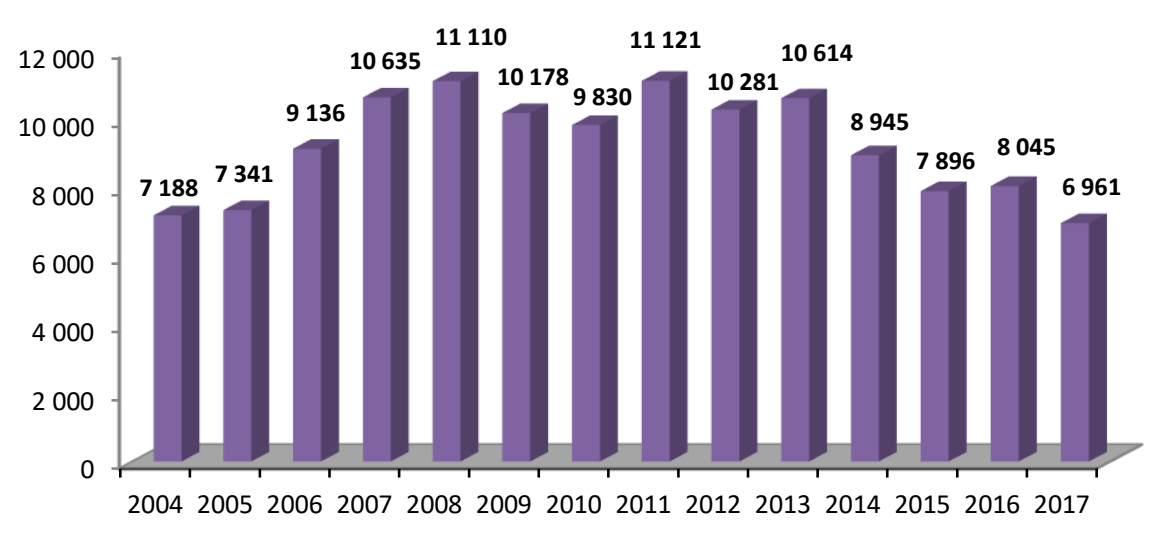

Graphe 21 : Nombre d'auteurs depuis 2004

L'enquête permet de séparer les procédures incriminant la personne morale et/ou la personne physique. L'incrimination de la personne physique reste prépondérante avec $57 \%$ des cas en 2017 (56\% en 2016). $10 \%$ des procédures impliquent la personne morale en 2017, comme en 2016 et $33 \%$ incriminent les personnes morale et physique (34\% en 2016).

Graphe 22 : Répartition des personnes morales et physiques depuis 2004

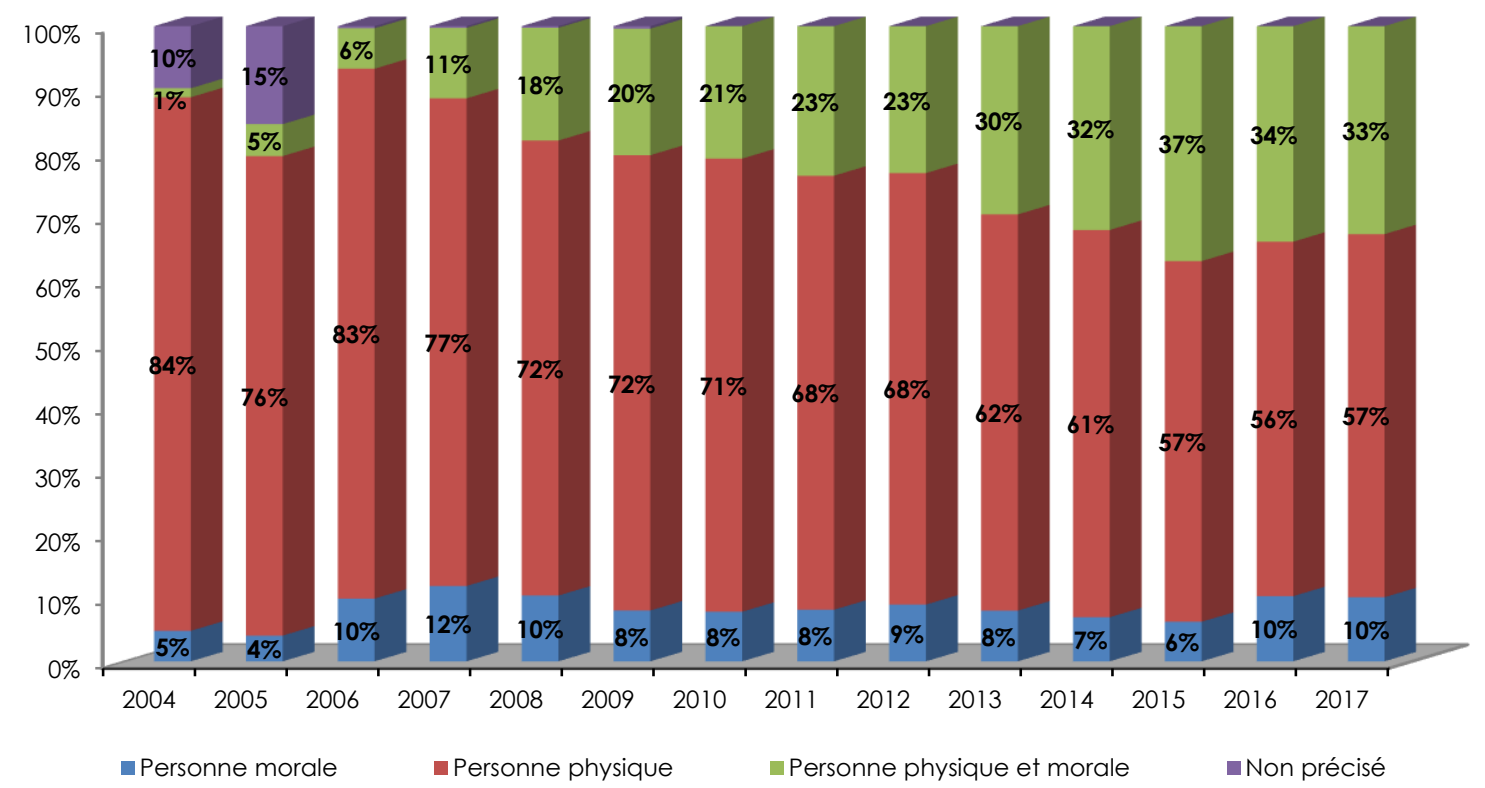


Cette enquête recense près de 100 nationalités distinctes en 2017. Sur l'ensemble des infractions constatées, 73 \% sont le fait d'auteurs présumés ressortissants de l'Union européenne.

Parmi les auteurs présumés de nationalité étrangère (Union européenne ou non), $82 \%$ des auteurs présumés relèvent des 10 premières nationalités recensées et $85 \%$ des vingt premières ${ }^{13}$.

La répartition des auteurs par nationalité est dans l'ensemble semblable à celle observée les années précédentes, même si l'ordre est légèrement modifié. Les auteurs présumés de nationalité française sont majoritaires dans toutes les catégories d'infraction.

Tableau 3 : Répartition des auteurs par nationalité en 2017

\begin{tabular}{|c|c|c|c|c|c|c|c|c|c|}
\hline \multirow[b]{2}{*}{$\begin{array}{l}\text { Nationalité } \\
\text { des auteurs }\end{array}$} & \multirow[b]{2}{*}{$\begin{array}{c}\text { Nombre } \\
\text { d'auteur } \\
\text { s }\end{array}$} & \multicolumn{8}{|c|}{ Nombre d'infractions } \\
\hline & & Total & $\begin{array}{l}\text { Dissimulation } \\
\text { d'activité }\end{array}$ & $\begin{array}{c}\text { Dissimulation } \\
\text { de salariés }\end{array}$ & E.S.T.T. & P.I.M.O. & $\begin{array}{l}\text { Fraude } \\
\text { revenus } \\
\text { de } \\
\text { remplact }\end{array}$ & $\begin{array}{l}\text { Cumul } \\
\text { irrégulier } \\
\text { d'emplois }\end{array}$ & Autres \\
\hline UE-28 & 5062 & 8109 & 2108 & 4345 & 880 & 173 & 16 & 2 & 585 \\
\hline dont France & 4799 & 7602 & 1979 & 4113 & 813 & 141 & 15 & 2 & 539 \\
\hline Pays tiers & 1088 & 1921 & 301 & 948 & 457 & 8 & 1 & 0 & 206 \\
\hline Non précisé & 811 & 1230 & 273 & 790 & 79 & 37 & 0 & 0 & 51 \\
\hline & 6961 & 11260 & 2682 & 6083 & 1416 & 218 & 17 & 2 & 842 \\
\hline UE-28 & $73 \%$ & $72 \%$ & $79 \%$ & $71 \%$ & $62 \%$ & $79 \%$ & $94 \%$ & $100 \%$ & $69 \%$ \\
\hline dont France & $69 \%$ & $68 \%$ & $74 \%$ & $68 \%$ & $57 \%$ & $65 \%$ & $88 \%$ & $100 \%$ & $64 \%$ \\
\hline Pays tiers & $16 \%$ & $17 \%$ & $11 \%$ & $16 \%$ & $32 \%$ & $4 \%$ & $6 \%$ & $0 \%$ & $24 \%$ \\
\hline Non précisé & $12 \%$ & $11 \%$ & $10 \%$ & $13 \%$ & $6 \%$ & $17 \%$ & $0 \%$ & $0 \%$ & $6 \%$ \\
\hline & $100 \%$ & $100 \%$ & $100 \%$ & $100 \%$ & $100 \%$ & $100 \%$ & $100 \%$ & $100 \%$ & $100 \%$ \\
\hline \multicolumn{10}{|c|}{ Dont les 20 premières nationalités } \\
\hline France & 4799 & 7602 & 1979 & 4113 & 813 & 141 & 15 & 2 & 539 \\
\hline Turquie & 248 & 409 & 91 & 219 & 71 & 1 & 0 & 0 & 27 \\
\hline Chine & 128 & 305 & 15 & 140 & 96 & 0 & 0 & 0 & 54 \\
\hline Tunisie & 117 & 198 & 19 & 106 & 51 & 1 & 1 & 0 & 20 \\
\hline Algérie & 114 & 189 & 22 & 103 & 52 & 2 & 0 & 0 & 10 \\
\hline Maroc & 107 & 182 & 23 & 96 & 43 & 3 & 0 & 0 & 17 \\
\hline Portugal & 81 & 160 & 36 & 72 & 21 & 20 & 0 & 0 & 11 \\
\hline Roumanie & 54 & 91 & 32 & 47 & 5 & 2 & 1 & 0 & 4 \\
\hline Pakistan & 54 & 88 & 13 & 44 & 23 & 0 & 0 & 0 & 8 \\
\hline Egypte & 35 & 64 & 9 & 30 & 21 & 0 & 0 & 0 & 4 \\
\hline Italie & 27 & 50 & 3 & 24 & 14 & 2 & 0 & 0 & 7 \\
\hline Cameroun & 25 & 46 & 20 & 9 & 4 & 0 & 0 & 0 & 13 \\
\hline Sri Lanka & 26 & 43 & 2 & 16 & 17 & 0 & 0 & 0 & 8 \\
\hline Bulgarie & 23 & 40 & 16 & 14 & 2 & 6 & 0 & 0 & 2 \\
\hline Espagne & 21 & 40 & 10 & 15 & 8 & 2 & 0 & 0 & 5 \\
\hline $\begin{array}{l}\text { Côte } \\
\text { d'Ivoire }\end{array}$ & 17 & 35 & 8 & 7 & 12 & 0 & 0 & 0 & 8 \\
\hline Suriname & 19 & 34 & 8 & 15 & 3 & 0 & 0 & 0 & 8 \\
\hline Congo & 18 & 33 & 8 & 16 & 7 & 0 & 0 & 0 & 2 \\
\hline Haïti & 15 & 29 & 5 & 18 & 4 & 0 & 0 & 0 & 2 \\
\hline Bangladesh & 13 & 25 & 0 & 10 & 10 & 0 & 0 & 0 & 5 \\
\hline
\end{tabular}

$1386 \%$ en $2016,86 \%$ en $2015,84 \%$ en 2014 et 2013 , 83\% en 2012 . 
En 2017, 65 \% des infractions de prêt illicite de main d'œuvre (P.I.M.O.) sont le fait d'auteurs présumés de nationalité française (68\% en 2016). Si l'on tient compte de l'ensemble des auteurs de nationalité européenne (dont française), la part des auteurs de nationalité française est de $82 \%$ (84\% en 2016). Ce volume est cohérent avec le développement de la prestation de services internationale qui est principalement européenne. La présence des auteurs de nationalité étrangère pour l'infraction de prêt illicite de main d'œuvre, de $18 \%$, est due au phénomène de sous-traitance en cascade, sachant que cette sous-traitance se réalise en partie avec des entreprises étrangères (de deuxième, troisième rang ou plus encore), la surreprésentation des auteurs étrangers dans ce type d'infraction est implicite. Pour autant, il convient de souligner le poids de $17 \%$ de nationalité non précisée qui pourrait venir modifier la lecture de cette répartition.

La part des auteurs de nationalité française dans l'infraction d'emploi d'étrangers sans titre représente $57 \%$ en 2017 (61 \% en 2016). La part des étrangers comme auteurs de ce type d'infraction, de $37 \%$, suggère l'existence d'un phénomène de filières, notamment au sein d'une même nationalité.

Le fait qu'un procès-verbal recense plusieurs auteurs recouvre trois cas de figure distincts :

- une co-responsabilité de fait au sein d'une entreprise ;

- une incrimination du client ou du donneur d'ordre direct, qui en recourant sciemment au travail dissimulé par le prestataire, peut également être sanctionné ;

- une incrimination des personnes qui ont recours par personne interposée ou par un intermédiaire à l'auteur d'un travail dissimulé. Cette incrimination vise le dirigeant de fait derrière l'homme de paille ou le prête nom, le maître d'ouvrage, le donneur d'ouvrage, l'entrepreneur titulaire, le fabricant, le client, c'est-à-dire les véritables bénéficiaires de la prestation.

Le nombre d'auteurs mentionnés dans le procès-verbal est un indicateur de la complexité croissante des montages dans lesquels les infractions sont les plus difficiles à démontrer et auxquels sont confrontés les agents de l'inspection du travail.

\subsection{Plus de 27200 salariés sont concernés par les infractions de travail illégal}

Les salariés concernés sont les personnes retrouvées en situation de travail et auxquelles les situations d'infractions de travail illégal qui ont été relevées et verbalisées portent préjudice en regard aux droits attachés au statut salarial.
L'enquête recense 27260 salariés concernés par les infractions de travail illégal en 2017 (-3\% par rapport à 2016). Cette diminution résulte notamment de la baisse enregistrée des procédures.

Le nombre moyen de salariés par procès-verbal augmente et s'établit à 4,61 salariés par procédure en 2017 (4,11 en 2016).

\section{Graphe 23 : \\ Nombre de salariés concernés depuis 2004}

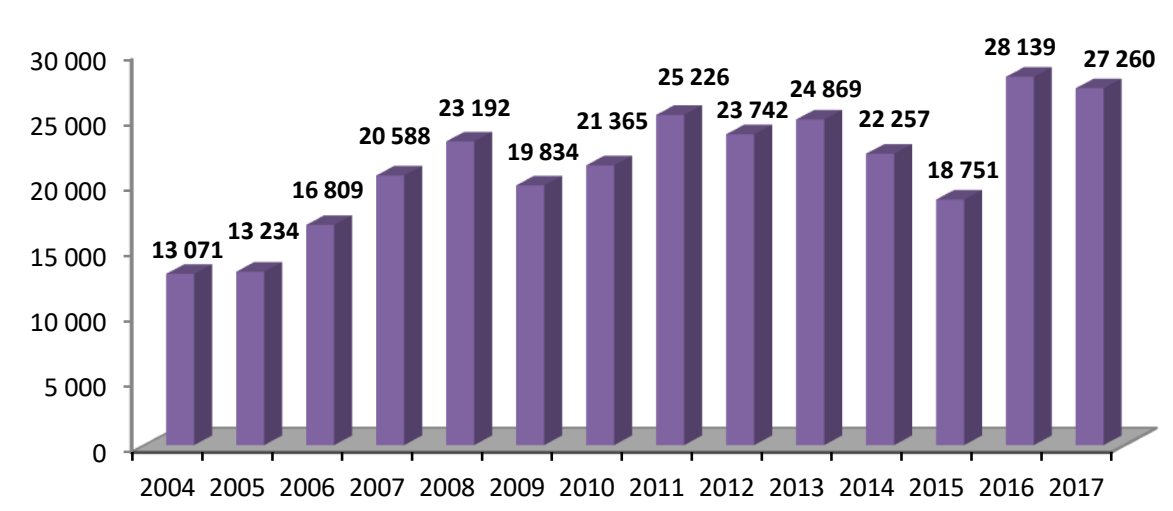


En 2017, 110 nationalités sont présentes dans l'ensemble des procédures. Sur l'ensemble des infractions constatées, $37 \%$ concernent des salariés ressortissants de l'Union européenne.

Les 10 premières nationalités recensées concentrent $44 \%$ des salariés concernés par les infractions (54\% en 2016), et $48 \%$ pour les vingt premières (57\% en 2016).

Depuis le 1er août 2011, l'employeur qui recrute un nouveau salarié doit remplir la déclaration préalable à l'embauche DPAE. Elle regroupe en une seule déclaration l'ensemble des déclarations et des demandes que l'employeur doit faire lors de l'embauche d'un salarié.

Lors de cette modification, l'indication de la nationalité du salarié a été supprimée et remplacée par celle de son sexe.
Dans le tableau ci-après, le poids majeur de la rubrique des nationalités pour lesquelles l'information n'est pas précisée nécéssite des précisions. Représentant $51 \%$ des nationalités pour l'ensemble des infractions, l'imprécision de cette ventilation résulte de plusieurs causes:

- l'information n'est pas toujours connue des services notamment en l'absence de documents d'identité ;

- la nationalité n'est pas toujours demandée par les services en effet ni la nationalité des salariés ni le nombre n'importent pour la caractérisation des infractions de travail illégal, les salariés qu'ils soient français ou non ayant les mêmes droits au regard du code du travail ;

- quand le nombre de salariés concerné par les infractions est conséquent, cette information n'est pas relevée car jugée trop fastidieuse.

Par ailleurs, l'analyse des nationalités des salariés pour l'infraction d'emploi d'étrangers sans titre de travail amène deux remarques:

- cette infraction concerne $20 \%$ des employés des pays de l'Union européenne en 2017. Cependant, le tableau montre des discordances entre la nationalité des salariés européens (et notamment 124 «Français ») et le constat de cette infraction ${ }^{14}$.

- le ratio «nombre de salariés concernés par les infractions de travail illégal de nationalité européenne / nombre total de salariés concernés par les infractions de travail illégal ॥ est en baisse (37\% en 2017 et $47 \%$ 2016). Cette baisse est notamment due à la part non négligeable des nationalités non précisées (49\% en 2017 et $39 \%$ en 2016). Néanmoins, l'évolution de la prestation de services internationale peut être un argument explicatif de ces hauts niveaux constatés.

\footnotetext{
14 L'erreur de saisie est par principe inévitable. Mais les agents de contrôle signalaient, dès 2010, des organisations de fraude par usurpation des identités (fraude documentaire). II a paru intéressant de maintenir cette « information » dans le tableau pour souligner le phénomène de fraude documentaire, plutôt que d'effectuer les redressements idoines. II convient cependant de lire ces valeurs avec beaucoup de précaution.
} 
Tableau 4 : Répartition des salariés concernés par nationalité en 2017

\begin{tabular}{|c|c|c|c|c|c|c|c|c|c|}
\hline \multirow[b]{2}{*}{$\begin{array}{l}\text { Nationalité } \\
\text { des salariés }\end{array}$} & \multirow[b]{2}{*}{$\begin{array}{l}\text { Nombre } \\
\text { de } \\
\text { salariés }\end{array}$} & \multicolumn{8}{|c|}{ Nombre d'infractions } \\
\hline & & Total & $\begin{array}{l}\text { Dissimulation } \\
\text { d'activité }\end{array}$ & $\begin{array}{l}\text { Dissimulation } \\
\text { de salariés }\end{array}$ & E.S.T.T. & P.I.M.O. & $\begin{array}{l}\text { Fraude } \\
\text { revenus } \\
\text { de } \\
\text { remplact }\end{array}$ & $\begin{array}{l}\text { Cumul } \\
\text { irrégulier } \\
\text { d'emplois }\end{array}$ & Autres \\
\hline UE-28 & 9998 & 15250 & 4567 & 9736 & 465 & 272 & 3 & 1 & 206 \\
\hline $\begin{array}{r}\text { dont } \\
\text { France }\end{array}$ & 7279 & 10636 & 2966 & 7354 & 124 & 86 & 3 & 1 & 102 \\
\hline Pays tiers & 3875 & 7611 & 1271 & 3907 & 1793 & 499 & 1 & 0 & 140 \\
\hline $\begin{array}{r}\text { Non } \\
\text { précisé }\end{array}$ & 13387 & 23514 & 8021 & 15046 & 86 & 308 & 2 & 0 & 51 \\
\hline & 27260 & 46375 & 13859 & 28689 & 2344 & 1079 & 6 & 1 & 397 \\
\hline UE-28 & $37 \%$ & $33 \%$ & $33 \%$ & $34 \%$ & $20 \%$ & $25 \%$ & $50 \%$ & $100 \%$ & $52 \%$ \\
\hline $\begin{array}{r}\text { dont } \\
\text { France }\end{array}$ & $27 \%$ & $23 \%$ & $21 \%$ & $26 \%$ & $5 \%$ & $8 \%$ & $50 \%$ & $100 \%$ & $26 \%$ \\
\hline Pays tiers & $14 \%$ & $16 \%$ & $9 \%$ & $14 \%$ & $76 \%$ & $46 \%$ & $17 \%$ & $0 \%$ & $35 \%$ \\
\hline $\begin{array}{r}\text { Non } \\
\text { précisé }\end{array}$ & $49 \%$ & $51 \%$ & $58 \%$ & $52 \%$ & $4 \%$ & $29 \%$ & $33 \%$ & $0 \%$ & $13 \%$ \\
\hline & $100 \%$ & $100 \%$ & $100 \%$ & $100 \%$ & $100 \%$ & $100 \%$ & $100 \%$ & $100 \%$ & $100 \%$ \\
\hline \multicolumn{10}{|c|}{ Dont les 20 premières nationalités } \\
\hline France & 7279 & 10636 & 2966 & 7354 & 124 & 86 & 3 & 1 & 102 \\
\hline Portugal & 823 & 2342 & 749 & 1007 & 156 & 359 & 0 & 0 & 71 \\
\hline Turquie & 1055 & 1941 & 680 & 1142 & 103 & 13 & 0 & 0 & 3 \\
\hline Roumanie & 907 & 1403 & 702 & 482 & 28 & 127 & 0 & 0 & 64 \\
\hline Maroc & 461 & 884 & 83 & 482 & 261 & 53 & 0 & 0 & 5 \\
\hline Pakistan & 407 & 794 & 185 & 414 & 188 & 6 & 0 & 0 & 1 \\
\hline Tunisie & 352 & 572 & 20 & 312 & 212 & 2 & 1 & 0 & 25 \\
\hline Chine & 272 & 494 & 33 & 300 & 157 & 0 & 0 & 0 & 4 \\
\hline Algérie & 280 & 467 & 36 & 267 & 154 & 0 & 0 & 0 & 10 \\
\hline Pologne & 207 & 440 & 99 & 295 & 0 & 43 & 0 & 0 & 3 \\
\hline Espagne & 242 & 337 & 91 & 237 & 5 & 0 & 0 & 0 & 4 \\
\hline Egypte & 167 & 311 & 13 & 138 & 131 & 3 & 0 & 0 & 26 \\
\hline Bulgarie & 214 & 269 & 34 & 206 & 0 & 29 & 0 & 0 & 0 \\
\hline Bangladesh & 127 & 200 & 6 & 88 & 105 & 0 & 0 & 0 & 1 \\
\hline Haiiti & 70 & 129 & 3 & 94 & 32 & 0 & 0 & 0 & 0 \\
\hline Sri Lanka & 73 & 105 & 7 & 56 & 42 & 0 & 0 & 0 & 0 \\
\hline Inde & 56 & 101 & 8 & 50 & 43 & 0 & 0 & 0 & 0 \\
\hline Brésil & 42 & 82 & 10 & 34 & 30 & 8 & 0 & 0 & 0 \\
\hline Equateur & 36 & 80 & 0 & 24 & 34 & 22 & 0 & 0 & 0 \\
\hline Ukraine & 42 & 78 & 4 & 25 & 41 & 8 & 0 & 0 & 0 \\
\hline
\end{tabular}




\section{Annexe}

\section{Annexe 1 - Contours de l'enquête sur l'infraction d'emploi d'étrangers sans titre de travail}

Contours de l'enquête sur l'infraction d'emploi d'étrangers sans titre de travail

Les deux principales infractions relatives à l'emploi de travailleurs salariés étrangers sont l'emploi d'un étranger démuni de titre de travail (L.8251-1 du code du travail) et l'aide au séjour irrégulier d'un étranger par la fourniture d'un travail (L.622-1 du code de l'entrée et du séjour des étrangers et du droit d'asile (CESEDA). L'exercice par un étranger d'une activité professionnelle salariée en France est réglementé par des dispositions qui relèvent à la fois de la législation sociale (dispositions du code du travail et du code de la sécurité sociale relatives à l'emploi et à la protection sociale des étrangers) et de la législation au séjour des étrangers (dispositions du CESEDA relatives aux conditions d'exercice par un étranger d'une activité professionnelle) *

L'enquête concerne exclusivement l'infraction liée au travail et non pas celle de non possession du titre de séjour. Ainsi, la situation d'irrégularité au regard du séjour, constatée en dehors de tout exercice d'un travail dans un lieu quelconque n'est pas intégrée dans cette statistique.

A contrario, dès qu'un ressortissant étranger non autorisé au travail est trouvé en situation de travail, l'infraction, si elle amène à la rédaction d'une procédure pénale, sera intégrée dans l'enquête. En outre, la situation d'irrégularité au travail sans l'être au séjour couvre également les cas des "faux " stagiaires étrangers, des demandeurs d'asile et des ressortissants étrangers en résidence temporaire sur le territoire national ayant un visa de moins de trois mois qui n'ouvre pas le droit de travailler, par exemple.

Un cas hybride s'est présenté avec des ressortissants munis d'une «fausse ॥ autorisation de travail liée à une irrégularité au séjour, mais déclarés par leurs employeurs auprès des organismes sociaux et fiscaux. Ce cas de figure a été mis en exergue lors des manifestations des sans-papiers en avril 2008. Cette situation entraîne la codification de l'infraction d'emploi d'étranger sans titre de travail sans qu'elle soit concomitante à celle de travail dissimulé.

* Ces dispositions reposent sur le principe de la nécessité pour l'étranger de posséder une autorisation administrative lui donnant le droit de travailler pour le compte d'un employeur, soit dans le cadre légal de la procédure d'introduction sur le territoire français, soit dans celui d'un séjour permanent régulier. Ce principe existe depuis la loi du 11 août 1926 relative à la protection du marché du travail national qui avait instauré un droit au travail pour les étrangers titulaires d'une carte d'identité d'étranger. L'ancien article 7 de l'ordonnance du 2 novembre 1945 avait repris ce principe, qui a été ensuite incorporé dans le code du travail à l'article L. 5221-5 (Loi n 73-4 du 2 janvier 1973 relative au code du travail). Aux termes de cet article « un étranger ne peut exercer une activité professionnelle salariée en France sans avoir obtenu au préalable l'autorisation mentionnée à l'article L. 341-2». 


\section{Annexe 2 - Analyse sectorielle}

\section{Note méthodologique}

La nomenclature d'activités relative à l'établissement utilisée dans le cadre de l'enquête reprend les 21 grands groupes ou "sections ॥ définis par l'Insee et pour certains d'entre eux, propose des sous-classes spécifiques aux secteurs prioritaires de lutte contre le travail illégal.

Les tableaux détaillés sont présentés autant que faire se peut sous la même forme et selon la même succession des infractions. Cependant, pour des raisons de lisibilité, les infractions présentes dans les tableaux sont uniquement celles pour lesquelles des infractions ont été constatées dans les procèsverbaux. Egalement, certaines infractions ont été renommées ou ont été regroupées. Par exemple, les infractions "Défaut de tenue du Registre Unique du Personnel (R.U.P.) ", "Non présentation du R.U.P." et "Absences de mentions obligatoires dans R.U.P. ॥, ont été regroupées sous la dénomination "Défaut, non présentation, absences de mentions obligatoires dans R.U.P. ॥. Ce principe a été reproduit à différents endroits (DPAE, séjour irrégulier des étrangers, RSA et délit et outrage à agent).

Enfin, les chiffres et conclusions énoncés ci-après ne sont pas exempts d'un contexte organisationnel et réglementaire. Il est alors important de rappeler que, plus encore que pour la partie précédente, toute exploitation des données sectorielles exige la plus grande prudence.

\section{Agriculture}

Données principales relatives à la verbalisation du travail illégal dans le secteur agricole depuis 2012

\begin{tabular}{|c|c|c|c|c|c|c|c|c|c|c|c|c|}
\hline Nombre de: & \multicolumn{2}{|c|}{2012} & \multicolumn{2}{|c|}{2013} & \multicolumn{2}{|c|}{2014} & \multicolumn{2}{|c|}{2015} & \multicolumn{2}{|c|}{2016} & \multicolumn{2}{|c|}{2017} \\
\hline Etablissements & \multicolumn{2}{|c|}{618} & \multicolumn{2}{|c|}{455} & \multicolumn{2}{|c|}{485} & \multicolumn{2}{|c|}{361} & \multicolumn{2}{|c|}{384} & \multicolumn{2}{|c|}{298} \\
\hline dont en Op. Conj. COLTI* & \multicolumn{2}{|c|}{139} & \multicolumn{2}{|c|}{104} & \multicolumn{2}{|c|}{134} & \multicolumn{2}{|c|}{99} & \multicolumn{2}{|c|}{92} & \multicolumn{2}{|c|}{78} \\
\hline Auteurs & \multicolumn{2}{|c|}{669} & \multicolumn{2}{|c|}{515} & \multicolumn{2}{|c|}{556} & \multicolumn{2}{|c|}{399} & \multicolumn{2}{|c|}{436} & \multicolumn{2}{|c|}{336} \\
\hline Salariés & \multicolumn{2}{|c|}{1474} & \multicolumn{2}{|c|}{1063} & \multicolumn{2}{|c|}{2117} & \multicolumn{2}{|c|}{1394} & \multicolumn{2}{|c|}{807} & \multicolumn{2}{|c|}{849} \\
\hline Infractions & \multicolumn{2}{|c|}{999} & \multicolumn{2}{|c|}{839} & \multicolumn{2}{|c|}{838} & \multicolumn{2}{|c|}{564} & & & & \\
\hline dont infractions : & & & & & & & & & & & & \\
\hline Travail dissimulé & 747 & $75 \%$ & 648 & $77 \%$ & 684 & $82 \%$ & 469 & $83 \%$ & 511 & $79 \%$ & 436 & $80 \%$ \\
\hline dont TD d'activité & 185 & $19 \%$ & 198 & $24 \%$ & 195 & $23 \%$ & 119 & $21 \%$ & 136 & $21 \%$ & 144 & $27 \%$ \\
\hline dont TD sur salarié & 562 & $56 \%$ & 450 & $54 \%$ & 489 & $58 \%$ & 350 & $62 \%$ & 375 & $58 \%$ & 292 & $54 \%$ \\
\hline E.S.T.T. & 103 & $10 \%$ & 93 & $11 \%$ & 79 & $9 \%$ & 50 & $9 \%$ & 67 & $10 \%$ & 42 & $8 \%$ \\
\hline P.I.M.O. & 90 & $9 \%$ & 63 & $8 \%$ & 29 & $3 \%$ & 19 & $3 \%$ & 10 & $2 \%$ & 22 & $4 \%$ \\
\hline $\begin{array}{l}\text { Fraude revenus } \\
\text { remplacement }\end{array}$ & 1 & $0 \%$ & 0 & $0 \%$ & 1 & $0 \%$ & 1 & $0 \%$ & 1 & $0 \%$ & 3 & $1 \%$ \\
\hline Cumul irrégulier d'emplois & 1 & $0 \%$ & 1 & $0 \%$ & 0 & $0 \%$ & 2 & $0 \%$ & 3 & $0 \%$ & 0 & $0 \%$ \\
\hline Autres infractions & 57 & $6 \%$ & 34 & $4 \%$ & 45 & $5 \%$ & 23 & $4 \%$ & 53 & $8 \%$ & 39 & $7 \%$ \\
\hline dont Inf. contrav.TI & 18 & $2 \%$ & 7 & $1 \%$ & 13 & $2 \%$ & 7 & $1 \%$ & 18 & $3 \%$ & 5 & $1 \%$ \\
\hline dont délits connexes & 28 & $3 \%$ & 16 & $2 \%$ & 22 & $3 \%$ & 16 & $3 \%$ & 28 & $4 \%$ & 29 & $5 \%$ \\
\hline Total Infractions & 999 & $100 \%$ & 839 & $100 \%$ & 838 & $100 \%$ & 564 & $100 \%$ & 645 & $100 \%$ & 542 & $100 \%$ \\
\hline
\end{tabular}

*Nombre d'établissements impliqués dans le cadre d’opérations conjointes décidées en comité de lutte contre le travail illégal. 
Données principales et détail des infractions par sous-secteur dans l'agriculture en 2017

\begin{tabular}{|c|c|c|c|c|c|c|c|}
\hline & $\begin{array}{c}\text { Cultures non } \\
\text { permanentes, } \\
\text { permanentes } \\
\text { et } \\
\text { reproduction } \\
\text { de plantes } \\
\end{array}$ & $\begin{array}{c}\text { Production } \\
\text { animale, } \\
\text { culture et } \\
\text { élevage } \\
\text { associés }\end{array}$ & $\begin{array}{c}\text { Chasse et } \\
\text { autres } \\
\text { activités } \\
\text { de soutien } \\
\text { à } \\
\text { agriculture } \\
\end{array}$ & $\begin{array}{l}\text { Sylviculture } \\
\text { et } \\
\text { exploitation } \\
\text { forestière }\end{array}$ & $\begin{array}{l}\text { Pêche et } \\
\text { aquaculture }\end{array}$ & Total & $\begin{array}{l}\% \text { du } \\
\text { Total }\end{array}$ \\
\hline Etablissements & 142 & 45 & 38 & 51 & 22 & 298 & - \\
\hline Auteurs & 150 & 56 & 43 & 62 & 25 & 336 & - \\
\hline Salariés & 368 & 65 & 159 & 240 & 17 & 849 & - \\
\hline Infractions & 216 & 87 & 83 & 109 & 47 & 542 & $100,0 \%$ \\
\hline Dont Infractions délictueuses de travail illégal & 205 & 83 & 75 & 99 & 41 & 503 & $92,8 \%$ \\
\hline Diss. de sal. avec défaut intentionnel de DPAE & 114 & 32 & 25 & 28 & 14 & 213 & $39,3 \%$ \\
\hline $\begin{array}{l}\text { Défaut de déclaration aux organismes de protection } \\
\text { sociale }\end{array}$ & 26 & 21 & 11 & 19 & 4 & 81 & $14,9 \%$ \\
\hline Emploi d'étranger sans titre de travail & 24 & 2 & 2 & 8 & 3 & 39 & $7,2 \%$ \\
\hline Défaut d'immatriculation de l'entreprise & 10 & 7 & 4 & 13 & 3 & 37 & $6,8 \%$ \\
\hline Défaut de déclaration à l'administration fiscale & 7 & 7 & 4 & 6 & 2 & 26 & $4,8 \%$ \\
\hline $\begin{array}{l}\text { Diss. de sal. par dissimulation d'heures avec mention sur } \\
\text { fiche de paie }\end{array}$ & 3 & 4 & 6 & 7 & & 20 & $3,7 \%$ \\
\hline $\begin{array}{l}\text { Diss. de sal. avec défaut intentionnel de délivrance fiche } \\
\text { de paie }\end{array}$ & 3 & 4 & 4 & 4 & & 15 & $2,8 \%$ \\
\hline $\begin{array}{l}\text { Prêt illicite de main d'œuvre / Prêt exclusif de MO à but } \\
\text { lucratif }\end{array}$ & 4 & & 6 & 3 & & 13 & $2,4 \%$ \\
\hline $\begin{array}{l}\text { Diss. de sal. par défaut de déclarations salaires ou } \\
\text { cotisations sociales }\end{array}$ & 3 & & 2 & 5 & 1 & 11 & $2,0 \%$ \\
\hline Responsabilité pénale personne morale exerçant un TD & 3 & 2 & 2 & 2 & 2 & 11 & $2,0 \%$ \\
\hline Marchandage & 4 & & 5 & & & 9 & $1,7 \%$ \\
\hline Recours aux services de celui qui exerce un TD & 1 & 3 & 3 & 1 & 1 & 9 & $1,7 \%$ \\
\hline $\begin{array}{l}\text { Recours par personne morale d'une personne exerçant } \\
\text { un TD }\end{array}$ & 2 & & & & 4 & 6 & $1,1 \%$ \\
\hline $\begin{array}{l}\text { Emploi d'un étranger non muni d'une autorisation de } \\
\text { travail }\end{array}$ & 1 & & & 1 & 1 & 3 & $0,6 \%$ \\
\hline $\begin{array}{l}\text { Recours à la sous-traitance sans faire accepter le sous- } \\
\text { traitant et agréer ses conditions de paiement par le } \\
\text { MOA }\end{array}$ & & & 1 & & 2 & 3 & $0,6 \%$ \\
\hline $\begin{array}{l}\text { Obtention frauduleuse d'allocations à travailleur privé } \\
\text { d'emploi }\end{array}$ & & 1 & & 1 & & 2 & $0,4 \%$ \\
\hline Publicité tendant à favoriser volontairement le TD & & & & & 2 & 2 & $0,4 \%$ \\
\hline $\begin{array}{l}\text { Recours par personne interposée aux services de celui } \\
\text { qui exerce un TD }\end{array}$ & & & & & 2 & 2 & $0,4 \%$ \\
\hline $\begin{array}{l}\text { Obtention frauduleuse d'allocations visées à l'article } \\
\text { L5123-2 }\end{array}$ & & & & 1 & & 1 & $0,2 \%$ \\
\hline Dont Infractions contraventionnelles & 1 & 0 & 1 & 1 & 2 & 5 & $0,9 \%$ \\
\hline $\begin{array}{l}\text { Défaut non intentionnel/non présentation du récépissé } \\
\text { de DPAE }\end{array}$ & 1 & & & & 2 & 3 & $0,6 \%$ \\
\hline Défaut de déclaration de détachement en PSI & & & & 1 & & 1 & $0,2 \%$ \\
\hline $\begin{array}{l}\text { Non remise, mention incomplète/erronée non } \\
\text { intentionnel bulletin de paie }\end{array}$ & & & 1 & & & 1 & $0,2 \%$ \\
\hline Dont Délits connexes au travail illégal & 9 & 3 & 6 & 8 & 3 & 29 & $5,4 \%$ \\
\hline Entrée/aide à l'entrée et séjour irrégulier d'un étranger & 8 & 1 & & 4 & 3 & 16 & $3,0 \%$ \\
\hline Délit d'obstacle ou outrage à agent de contrôle & 1 & 1 & 2 & & & 4 & $0,7 \%$ \\
\hline $\begin{array}{l}\text { Infraction à la réglementation générale sur hygiène et } \\
\text { sécurité du travail }\end{array}$ & & & & 3 & & 3 & $0,6 \%$ \\
\hline $\begin{array}{l}\text { Défaut déclaration hébergement collectif de salariés à } \\
\text { l'IT }\end{array}$ & & & 2 & & & 2 & $0,4 \%$ \\
\hline $\begin{array}{l}\text { Défaut déclaration hébergement collectif de travailleurs } \\
\text { au préfet }\end{array}$ & & & 2 & & & 2 & $0,4 \%$ \\
\hline Abus vulnérabilité sur rémunération & & 1 & & & & 1 & $0,2 \%$ \\
\hline $\begin{array}{l}\text { Fraude/fausse déclaration pour obtention } \\
\text { prestation/allocation sociale }\end{array}$ & & & & 1 & & 1 & $0,2 \%$ \\
\hline Dont Autres infractions & 1 & 1 & 1 & 1 & 1 & 5 & $0,9 \%$ \\
\hline
\end{tabular}




\section{Construction}

Données principales relatives à la verbalisation du travail illégal dans le secteur de la construction depuis 2012

\begin{tabular}{|c|c|c|c|c|c|c|c|c|c|c|c|c|}
\hline Nombre de: & \multicolumn{2}{|c|}{2012} & \multicolumn{2}{|c|}{2013} & \multicolumn{2}{|c|}{2014} & \multicolumn{2}{|c|}{2015} & \multicolumn{2}{|c|}{2016} & \multicolumn{2}{|c|}{2017} \\
\hline Etablissements & \multicolumn{2}{|c|}{2613} & \multicolumn{2}{|c|}{2987} & \multicolumn{2}{|c|}{2369} & \multicolumn{2}{|c|}{2197} & \multicolumn{2}{|c|}{2016} & \multicolumn{2}{|c|}{1847} \\
\hline dont en Op. Conj. COLTI* & \multicolumn{2}{|c|}{328} & \multicolumn{2}{|c|}{510} & \multicolumn{2}{|c|}{312} & \multicolumn{2}{|c|}{252} & \multicolumn{2}{|c|}{263} & \multicolumn{2}{|c|}{275} \\
\hline Auteurs & \multicolumn{2}{|c|}{2963} & \multicolumn{2}{|c|}{3394} & \multicolumn{2}{|c|}{2687} & \multicolumn{2}{|c|}{2446} & \multicolumn{2}{|c|}{2272} & \multicolumn{2}{|c|}{2069} \\
\hline Salariés & \multicolumn{2}{|c|}{7197} & \multicolumn{2}{|c|}{8282} & \multicolumn{2}{|c|}{7707} & \multicolumn{2}{|c|}{6248} & \multicolumn{2}{|c|}{11844} & \multicolumn{2}{|c|}{13620} \\
\hline Infractions & \multicolumn{2}{|c|}{5528} & \multicolumn{2}{|c|}{6204} & \multicolumn{2}{|c|}{4892} & \multicolumn{2}{|c|}{3752} & 38 & & 33 & \\
\hline dont infractions: & & & & & & & & & & & & \\
\hline Travail dissimulé & 3785 & $68 \%$ & 4355 & $70 \%$ & 3444 & $70 \%$ & 2782 & $74 \%$ & 2960 & $77 \%$ & 2596 & $76 \%$ \\
\hline dont TD d'activité & 887 & $16 \%$ & 1074 & $17 \%$ & 867 & $18 \%$ & 758 & $20 \%$ & 840 & $22 \%$ & 776 & $23 \%$ \\
\hline dont TD sur salarié & 2898 & $52 \%$ & 3281 & $53 \%$ & 2577 & $53 \%$ & 2024 & $54 \%$ & 2120 & $55 \%$ & 1820 & $54 \%$ \\
\hline E.S.T.T. & 1007 & $18 \%$ & 1096 & $18 \%$ & 755 & $15 \%$ & 494 & $13 \%$ & 430 & $11 \%$ & 471 & $14 \%$ \\
\hline P.I.M.O. & 305 & $6 \%$ & 358 & $6 \%$ & 316 & $6 \%$ & 253 & $7 \%$ & 174 & $5 \%$ & 109 & $3 \%$ \\
\hline $\begin{array}{l}\text { Fraude revenus } \\
\text { remplacement }\end{array}$ & 9 & $0 \%$ & 11 & $0 \%$ & 30 & $1 \%$ & 12 & $0 \%$ & 4 & $0 \%$ & 1 & $0 \%$ \\
\hline Cumul irrégulier d'emplois & 8 & $0 \%$ & 8 & $0 \%$ & 3 & $0 \%$ & 1 & $0 \%$ & 0 & $0 \%$ & 1 & $0 \%$ \\
\hline Autres infractions & 414 & $7 \%$ & 376 & $6 \%$ & 344 & $7 \%$ & 210 & $6 \%$ & 269 & $7 \%$ & 218 & $6 \%$ \\
\hline dont Inf. contrav.TI & 114 & $2 \%$ & 96 & $2 \%$ & 54 & $1 \%$ & 59 & $2 \%$ & 92 & $2 \%$ & 49 & $1 \%$ \\
\hline dont délits connexes & 257 & $5 \%$ & 222 & $4 \%$ & 240 & $5 \%$ & 208 & $6 \%$ & 151 & $4 \%$ & 135 & $4 \%$ \\
\hline Total Infractions & 5528 & $100 \%$ & 6204 & $100 \%$ & 4892 & $100 \%$ & 3752 & $100 \%$ & 3837 & $100 \%$ & 3396 & $100 \%$ \\
\hline
\end{tabular}

*Nombre d'établissements impliqués dans le cadre d'opérations conjointes décidées en comité de lutte contre le travail illégal. 
Données principales et détail des infractions par sous-secteur de la construction en 2017

\begin{tabular}{|c|c|c|c|c|c|c|c|c|}
\hline & \multirow[b]{2}{*}{$\begin{array}{l}\text { Construction } \\
\text { bâtiment }\end{array}$} & \multirow[b]{2}{*}{$\begin{array}{l}\text { Génie } \\
\text { civil }\end{array}$} & \multicolumn{4}{|c|}{ Travaux de construction spécialisés } & \multirow[b]{2}{*}{ Total } & \multirow[b]{2}{*}{$\begin{array}{l}\% \text { du } \\
\text { Total }\end{array}$} \\
\hline & & & $\begin{array}{l}\text { Démolition, } \\
\text { réparation } \\
\text { sites }\end{array}$ & $\begin{array}{c}\text { Travaux } \\
\text { d'installation } \\
\text { électrique, } \\
\text { plomberie } \\
\text { et autres } \\
\end{array}$ & $\begin{array}{l}\text { Travaux } \\
\text { de } \\
\text { finition }\end{array}$ & Autres & & \\
\hline Etablissements & 517 & 14 & 40 & 147 & 572 & 557 & 1847 & - \\
\hline Auteurs & 570 & 17 & 46 & 165 & 639 & 632 & 2069 & - \\
\hline Salariés & 2591 & 45 & 256 & 1087 & 3796 & 5845 & 13620 & - \\
\hline Infractions & 927 & 28 & 76 & 278 & 1091 & 996 & 3396 & $100,0 \%$ \\
\hline Dont Infractions délictueuses de travail illégal & 858 & 22 & 72 & 266 & 1022 & 938 & 3178 & $93,6 \%$ \\
\hline Diss. de sal. avec défaut intentionnel de DPAE & 390 & 10 & 37 & 111 & 413 & 463 & 1424 & $41,9 \%$ \\
\hline Défaut de déclaration aux organismes de protection sociale & 122 & 2 & 4 & 45 & 200 & 163 & 536 & $15,8 \%$ \\
\hline Emploi d'étranger sans titre de travail & 110 & 4 & 9 & 44 & 152 & 112 & 431 & $12,7 \%$ \\
\hline Recours aux services de celui qui exerce un TD & 38 & 1 & 4 & 14 & 37 & 33 & 127 & $3,7 \%$ \\
\hline Défaut d'immatriculation de l'entreprise & 32 & 2 & 1 & 15 & 39 & 36 & 125 & $3,7 \%$ \\
\hline Défaut de déclaration à l'administration fiscale & 19 & & 2 & 5 & 53 & 36 & 115 & $3,4 \%$ \\
\hline Diss. de sal. avec défaut intentionnel de délivrance fiche de paie & 31 & & 1 & 13 & 34 & 18 & 97 & $2,9 \%$ \\
\hline Prêt illicite de main d'œuvre / Prêt exclusif de MO à but lucratif & 27 & & 7 & 2 & 18 & 14 & 68 & $2,0 \%$ \\
\hline $\begin{array}{l}\text { Recours à la sous-traitance sans faire accepter le sous-traitant et agréer ses } \\
\text { conditions de paiement par le MOA }\end{array}$ & 15 & & & 2 & 14 & 15 & 46 & $1,4 \%$ \\
\hline Diss. de sal. par dissimulation d'heures avec mention sur fiche de paie & 15 & & & 7 & 13 & 8 & 43 & $1,3 \%$ \\
\hline Marchandage & 23 & & 5 & 2 & 8 & 3 & 41 & $1,2 \%$ \\
\hline Emploi d'un étranger non muni d'une autorisation de travail & 14 & 2 & & 5 & 13 & 6 & 40 & $1,2 \%$ \\
\hline Recours par personne interposée aux services de celui qui exerce un TD & 11 & & & 1 & 8 & 5 & 25 & $0,7 \%$ \\
\hline Recours par personne morale d'une personne exerçant un TD & 3 & & & & 6 & 9 & 18 & $0,5 \%$ \\
\hline Responsabilité pénale personne morale exerçant un TD & 3 & & 1 & & 7 & 7 & 18 & $0,5 \%$ \\
\hline Diss. de sal. par défaut de déclarations salaires ou cotisations sociales & 3 & & & & 3 & 3 & 9 & $0,3 \%$ \\
\hline Info. mensongère identification d'un professionnel lors d'une annonce & & & 1 & & 3 & 4 & 8 & $0,2 \%$ \\
\hline Publicité tendant à favoriser volontairement le TD & & 1 & & & 1 & 3 & 5 & $0,1 \%$ \\
\hline Obtention frauduleuse d'allocations à travailleur privé d'emploi & 1 & & & & & & 1 & $0,0 \%$ \\
\hline Recours par un employeur à une personne en cumul illicite d'emploi & 1 & & & & & & 1 & $0,0 \%$ \\
\hline Dont Infractions contraventionnelles & 23 & 2 & 0 & 0 & 12 & 12 & 49 & $1,4 \%$ \\
\hline Défaut de déclaration de détachement en PSI & 8 & 2 & & & 2 & 1 & 13 & $0,4 \%$ \\
\hline Défaut non intentionnel/non présentation du récépissé de DPAE & 5 & & & & 4 & 4 & 13 & $0,4 \%$ \\
\hline $\begin{array}{l}\text { Non présentation par l'employeur de sal. détachés de doc. à agent de } \\
\text { contrôle }\end{array}$ & 4 & & & & 2 & 2 & 8 & $0,2 \%$ \\
\hline Défaut tenue/non présentation/absence de mentions obligatoires RUP & 1 & & & & 1 & 3 & 5 & $0,1 \%$ \\
\hline Défaut d'affichage sur un chantier de BTP & 1 & & & & 1 & 1 & 3 & $0,1 \%$ \\
\hline Non remise, mention incomplète/erronée non intentionnel bulletin de paie & 3 & & & & & & 3 & $0,1 \%$ \\
\hline $\begin{array}{l}\text { Non-respect par le donneur d'ordre/MOA de son obligation de vigilance du } \\
\text { respect des règles du noyau dur par un sous-traitant }\end{array}$ & 1 & & & & 2 & & 3 & $0,1 \%$ \\
\hline Non déclaration d'un AT d'un salarié détaché & & & & & & 1 & 1 & $0,0 \%$ \\
\hline Dont Délits connexes au travail illégal & 41 & 4 & 4 & 10 & 46 & 30 & 135 & $4,0 \%$ \\
\hline Entrée/aide à l'entrée et séjour irrégulier d'un étranger & 23 & 4 & 4 & 7 & 37 & 19 & 94 & $2,8 \%$ \\
\hline Délit d'obstacle ou outrage à agent de contrôle & 10 & & & & 4 & 5 & 19 & $0,6 \%$ \\
\hline Infraction à la réglementation générale sur hygiène et sécurité du travail & 3 & & & & 1 & 2 & 6 & $0,2 \%$ \\
\hline Fraude/fausse déclaration pour obtention prestation/allocation sociale & 2 & & & & 1 & 1 & 4 & $0,1 \%$ \\
\hline Fraude pour l'obtention d'un titre de travail & 2 & & & & 1 & & 3 & $0,1 \%$ \\
\hline Usage (ou tentative) de faux documents & & & & 1 & 1 & & 2 & $0,1 \%$ \\
\hline Abus vulnérabilité sur rémunération & & & & & & 1 & 1 & $0,0 \%$ \\
\hline Défaut déclaration hébergement collectif de salariés à l'IT & & & & & & 1 & 1 & $0,0 \%$ \\
\hline Défaut déclaration hébergement collectif de travailleurs au préfet & & & & 1 & & & 1 & $0,0 \%$ \\
\hline Fraude/aide à la fraude au RSA & & & & & & 1 & 1 & $0,0 \%$ \\
\hline $\begin{array}{l}\text { Perception de fonds ou biens pour l'emploi ou l'introduction de travailleur } \\
\text { étranger }\end{array}$ & & & & 1 & & & 1 & $0,0 \%$ \\
\hline Perception frauduleuse de prestations au titre de l'aide sociale & 1 & & & & & & 1 & $0,0 \%$ \\
\hline Traite (ou tentative) des êtres humains & & & & & 1 & & 1 & $0,0 \%$ \\
\hline Dont Autres infractions & 5 & 0 & 0 & 2 & 11 & 16 & 34 & $1,0 \%$ \\
\hline
\end{tabular}




\section{Hébergement et restauration}

Données principales relatives à la verbalisation du travail illégal dans le secteur de l'hébergement et de la restauration depuis 2012

\begin{tabular}{|c|c|c|c|c|c|c|c|c|c|c|c|c|}
\hline Nombre de: & \multicolumn{2}{|c|}{2012} & \multicolumn{2}{|c|}{2013} & \multicolumn{2}{|c|}{2014} & \multicolumn{2}{|c|}{2015} & \multicolumn{2}{|c|}{2016} & \multicolumn{2}{|c|}{2017} \\
\hline Etablissements & \multicolumn{2}{|c|}{1991} & \multicolumn{2}{|c|}{1920} & \multicolumn{2}{|c|}{1578} & \multicolumn{2}{|c|}{1415} & \multicolumn{2}{|c|}{1348} & \multicolumn{2}{|c|}{1233} \\
\hline dont en Op. Conj. COLTI* & \multicolumn{2}{|c|}{417} & \multicolumn{2}{|c|}{489} & \multicolumn{2}{|c|}{441} & \multicolumn{2}{|c|}{373} & \multicolumn{2}{|c|}{428} & \multicolumn{2}{|c|}{407} \\
\hline Auteurs & \multicolumn{2}{|c|}{2237} & \multicolumn{2}{|c|}{2184} & \multicolumn{2}{|c|}{1800} & \multicolumn{2}{|c|}{1566} & \multicolumn{2}{|c|}{1546} & \multicolumn{2}{|c|}{1369} \\
\hline Salariés & \multicolumn{2}{|c|}{4655} & \multicolumn{2}{|c|}{3610} & \multicolumn{2}{|c|}{2938} & \multicolumn{2}{|c|}{2685} & \multicolumn{2}{|c|}{2698} & \multicolumn{2}{|c|}{2109} \\
\hline Infractions & \multicolumn{2}{|c|}{3745} & \multicolumn{2}{|c|}{3742} & \multicolumn{2}{|c|}{2921} & \multicolumn{2}{|c|}{2423} & 24 & & 21 & \\
\hline dont infractions: & & & & & & & & & & & & \\
\hline Travail dissimulé & 2979 & $80 \%$ & 3013 & $81 \%$ & 2335 & $80 \%$ & 1973 & $81 \%$ & 1878 & $76 \%$ & 1587 & $73 \%$ \\
\hline dont TD d'activité & 609 & $16 \%$ & 591 & $16 \%$ & 434 & $15 \%$ & 385 & $16 \%$ & 358 & $15 \%$ & 303 & $14 \%$ \\
\hline dont TD sur salarié & 2370 & $63 \%$ & 2422 & $65 \%$ & 1901 & $65 \%$ & 1588 & $66 \%$ & 1520 & $62 \%$ & 1284 & $59 \%$ \\
\hline E.S.T.T. & 478 & $13 \%$ & 505 & $13 \%$ & 410 & $14 \%$ & 333 & $14 \%$ & 358 & $15 \%$ & 364 & $17 \%$ \\
\hline P.I.M.O. & 3 & $0 \%$ & 13 & $0 \%$ & 6 & $0 \%$ & 11 & $0 \%$ & 10 & $0 \%$ & 8 & $0 \%$ \\
\hline $\begin{array}{l}\text { Fraude revenus } \\
\text { remplacement }\end{array}$ & 9 & $0 \%$ & 9 & $0 \%$ & 6 & $0 \%$ & 3 & $0 \%$ & 3 & $0 \%$ & 1 & $0 \%$ \\
\hline Cumul irrégulier d'emplois & 1 & $0 \%$ & 1 & $0 \%$ & 4 & $0 \%$ & 0 & $0 \%$ & 0 & $0 \%$ & 1 & $0 \%$ \\
\hline Autres infractions & 275 & $7 \%$ & 201 & $5 \%$ & 160 & $5 \%$ & 103 & $4 \%$ & 209 & $9 \%$ & 226 & $10 \%$ \\
\hline dont Inf. contrav.TI & 121 & $3 \%$ & 92 & $2 \%$ & 49 & $2 \%$ & 32 & $1 \%$ & 62 & $3 \%$ & 43 & $2 \%$ \\
\hline dont délits connexes & 128 & $3 \%$ & 87 & $2 \%$ & 88 & $3 \%$ & 71 & $3 \%$ & 126 & $5 \%$ & 163 & $7 \%$ \\
\hline Total Infractions & 3745 & $100 \%$ & 3742 & $100 \%$ & 2921 & $100 \%$ & 2423 & $100 \%$ & 2458 & $100 \%$ & 2187 & $100 \%$ \\
\hline
\end{tabular}

*Nombre d'établissements impliqués dans le cadre d’opérations conjointes décidées en comité de lutte contre le travail illégal. 
Données principales et détail des infractions par sous-secteur de l'hébergement et de la restauration en 2017

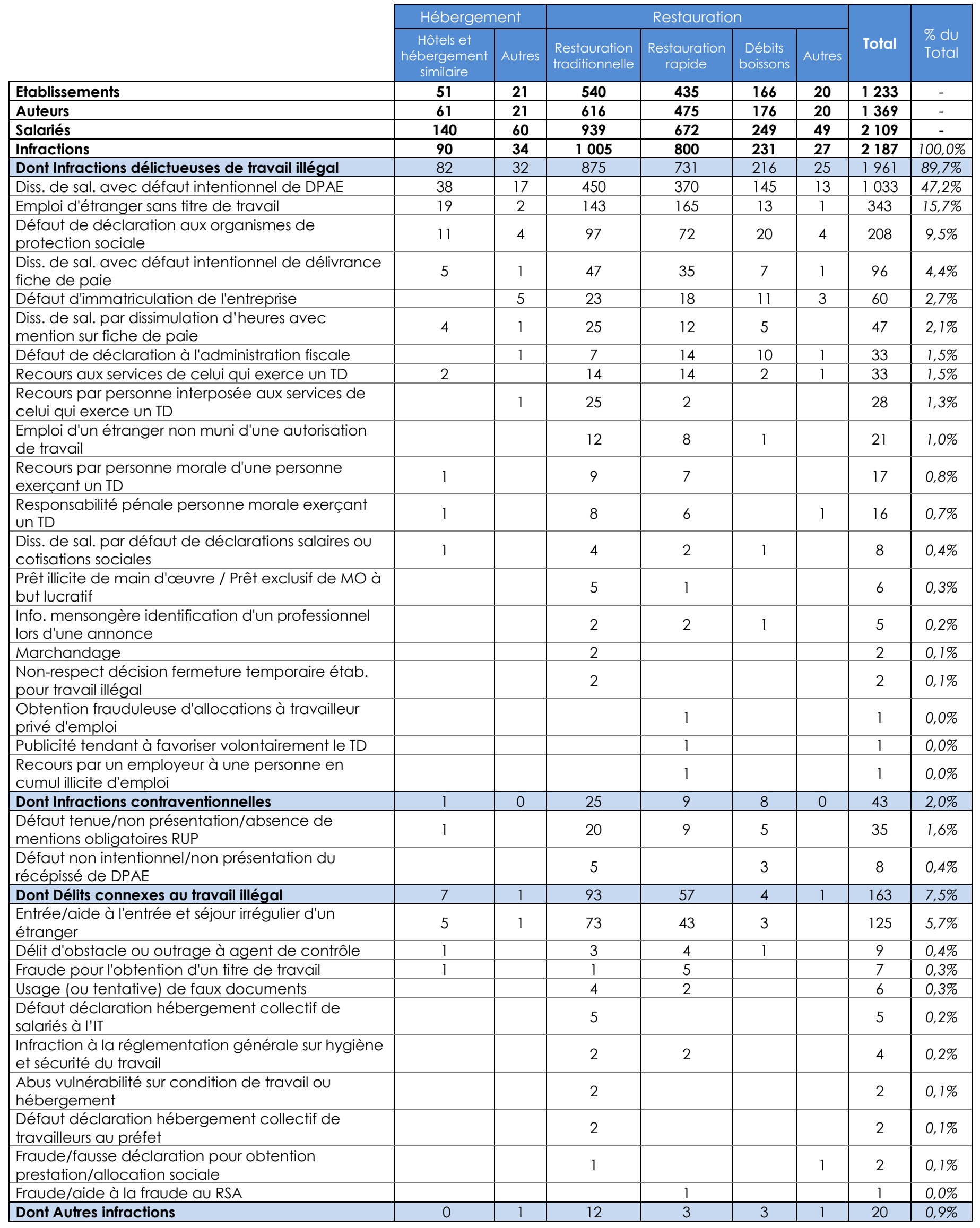




\section{Commerce et réparation d'automobiles et de motocycles}

Données principales relatives à la verbalisation du travail illégal dans le secteur du commerce et de la réparation d'automobiles et de motocycles depuis 2012

\begin{tabular}{|c|c|c|c|c|c|c|c|c|c|c|c|c|}
\hline Nombre de: & \multicolumn{2}{|c|}{2012} & \multicolumn{2}{|c|}{2013} & \multicolumn{2}{|c|}{2014} & \multicolumn{2}{|c|}{2015} & \multicolumn{2}{|c|}{2016} & \multicolumn{2}{|c|}{2017} \\
\hline Etablissements & \multicolumn{2}{|c|}{1512} & \multicolumn{2}{|c|}{1492} & \multicolumn{2}{|c|}{1337} & \multicolumn{2}{|c|}{1161} & \multicolumn{2}{|c|}{1080} & \multicolumn{2}{|c|}{940} \\
\hline dont en Op. Conj. COLTI* & \multicolumn{2}{|c|}{231} & \multicolumn{2}{|c|}{236} & \multicolumn{2}{|c|}{256} & \multicolumn{2}{|c|}{240} & \multicolumn{2}{|c|}{224} & \multicolumn{2}{|c|}{252} \\
\hline Auteurs & \multicolumn{2}{|c|}{1638} & \multicolumn{2}{|c|}{1681} & \multicolumn{2}{|c|}{1496} & \multicolumn{2}{|c|}{1288} & \multicolumn{2}{|c|}{1186} & \multicolumn{2}{|c|}{1075} \\
\hline Salariés & \multicolumn{2}{|c|}{2853} & \multicolumn{2}{|c|}{2431} & \multicolumn{2}{|c|}{2181} & \multicolumn{2}{|c|}{2112} & \multicolumn{2}{|c|}{2430} & \multicolumn{2}{|c|}{2098} \\
\hline Infractions & \multicolumn{2}{|c|}{2855} & \multicolumn{2}{|c|}{2882} & \multicolumn{2}{|c|}{2567} & \multicolumn{2}{|c|}{2127} & 19 & & $1 \varepsilon$ & \\
\hline dont infractions : & & & & & & & & & & & & \\
\hline Travail dissimulé & 2328 & $82 \%$ & 2262 & $78 \%$ & 2079 & $81 \%$ & 1738 & $82 \%$ & 1520 & $80 \%$ & 1459 & $79 \%$ \\
\hline dont TD d'activité & 750 & $26 \%$ & 667 & $23 \%$ & 678 & $26 \%$ & 596 & $28 \%$ & 496 & $26 \%$ & 483 & $26 \%$ \\
\hline dont TD sur salarié & 1578 & $55 \%$ & 1595 & $55 \%$ & 1401 & $55 \%$ & 1142 & $54 \%$ & 1024 & $54 \%$ & 976 & $53 \%$ \\
\hline E.S.T.T. & 315 & $11 \%$ & 383 & $13 \%$ & 325 & $13 \%$ & 249 & $12 \%$ & 233 & $12 \%$ & 253 & $14 \%$ \\
\hline P.I.M.O. & 11 & $0 \%$ & 42 & $1 \%$ & 21 & $1 \%$ & 17 & $1 \%$ & 10 & $1 \%$ & 2 & $0 \%$ \\
\hline Fraude revenus remplacement & 12 & $0 \%$ & 11 & $0 \%$ & 11 & $0 \%$ & 11 & $1 \%$ & 4 & $0 \%$ & 3 & $0 \%$ \\
\hline Cumul irrégulier d'emplois & 2 & $0 \%$ & 4 & $0 \%$ & 4 & $0 \%$ & 0 & $0 \%$ & 0 & $0 \%$ & 0 & $0 \%$ \\
\hline Autres infractions & 187 & $7 \%$ & 180 & $6 \%$ & 127 & $5 \%$ & 112 & $5 \%$ & 142 & $7 \%$ & 132 & $7 \%$ \\
\hline dont Inf. contrav.TI & 53 & $2 \%$ & 53 & $2 \%$ & 30 & $1 \%$ & 13 & $1 \%$ & 31 & $2 \%$ & 20 & $1 \%$ \\
\hline dont délits connexes & 108 & $4 \%$ & 95 & $3 \%$ & 62 & $2 \%$ & 99 & $5 \%$ & 77 & $4 \%$ & 87 & $5 \%$ \\
\hline Total Infractions & 2855 & $100 \%$ & 2882 & $100 \%$ & 2567 & $100 \%$ & 2127 & $100 \%$ & 1909 & $100 \%$ & 1849 & $100 \%$ \\
\hline
\end{tabular}

*Nombre d'établissements impliqués dans le cadre d’opérations conjointes décidées en comité de lutte contre le travail illégal. 
Données principales et détail des infractions par sous-secteur du commerce et de la réparation d'automobiles et de motocycles en 2017

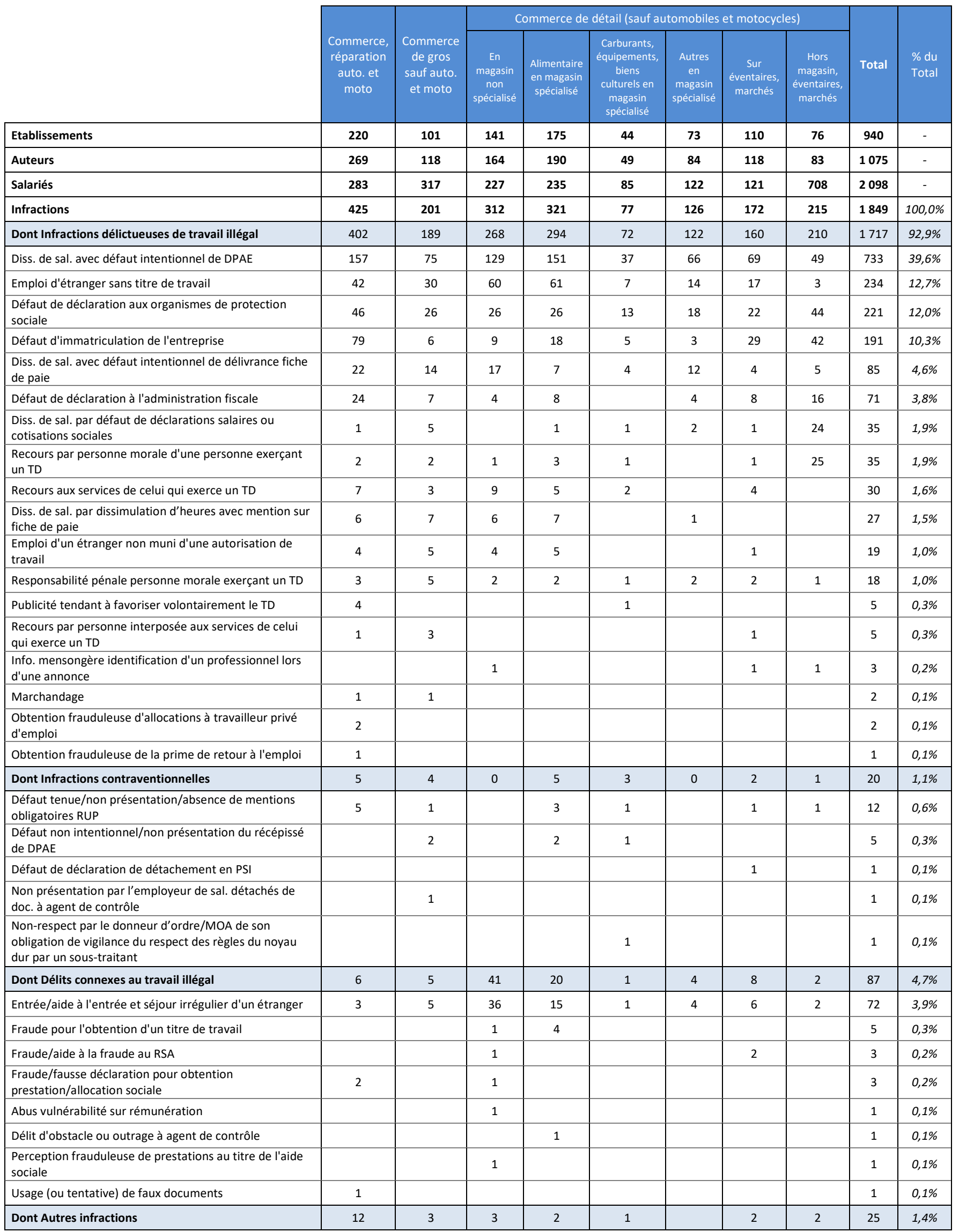




\section{Industries extractives et industrie manufacturière}

Données principales relatives à la verbalisation du travail illégal dans le secteur de l'industrie depuis 2012

\begin{tabular}{|c|c|c|c|c|c|c|c|c|c|c|c|c|}
\hline Nombre de: & \multicolumn{2}{|c|}{2012} & \multicolumn{2}{|c|}{2013} & \multicolumn{2}{|c|}{2014} & \multicolumn{2}{|c|}{2015} & \multicolumn{2}{|c|}{2016} & \multicolumn{2}{|c|}{2017} \\
\hline Etablissements & \multicolumn{2}{|c|}{280} & \multicolumn{2}{|c|}{295} & \multicolumn{2}{|c|}{232} & \multicolumn{2}{|c|}{192} & \multicolumn{2}{|c|}{227} & \multicolumn{2}{|c|}{175} \\
\hline dont en Op. Conj. COLTI* & \multicolumn{2}{|c|}{331} & \multicolumn{2}{|c|}{352} & \multicolumn{2}{|c|}{275} & \multicolumn{2}{|c|}{220} & \multicolumn{2}{|c|}{35} & \multicolumn{2}{|c|}{27} \\
\hline Auteurs & \multicolumn{2}{|c|}{1005} & \multicolumn{2}{|c|}{927} & \multicolumn{2}{|c|}{688} & \multicolumn{2}{|c|}{579} & \multicolumn{2}{|c|}{261} & \multicolumn{2}{|c|}{211} \\
\hline Salariés & \multicolumn{2}{|c|}{50} & \multicolumn{2}{|c|}{32} & \multicolumn{2}{|c|}{29} & \multicolumn{2}{|c|}{19} & \multicolumn{2}{|c|}{1893} & \multicolumn{2}{|c|}{788} \\
\hline Infractions & \multicolumn{2}{|c|}{601} & \multicolumn{2}{|c|}{621} & \multicolumn{2}{|c|}{449} & \multicolumn{2}{|c|}{379} & & & & \\
\hline dont infractions: & & & & & & & & & & & & \\
\hline Travail dissimulé & 427 & $71 \%$ & 467 & $75 \%$ & 328 & $73 \%$ & 293 & $77 \%$ & 332 & $75 \%$ & 268 & $79 \%$ \\
\hline dont TD d'activité & 94 & $16 \%$ & 111 & $18 \%$ & 68 & $15 \%$ & 75 & $20 \%$ & 86 & $20 \%$ & 94 & $28 \%$ \\
\hline dont TD sur salarié & 333 & $55 \%$ & 356 & $57 \%$ & 260 & $58 \%$ & 218 & $58 \%$ & 246 & $56 \%$ & 174 & $51 \%$ \\
\hline E.S.T.T. & 91 & $15 \%$ & 80 & $13 \%$ & 57 & $13 \%$ & 38 & $10 \%$ & 53 & $12 \%$ & 40 & $12 \%$ \\
\hline P.I.M.O. & 45 & $7 \%$ & 34 & $5 \%$ & 37 & $8 \%$ & 28 & $7 \%$ & 25 & $6 \%$ & 14 & $4 \%$ \\
\hline Fraude revenus remplacement & 0 & $0 \%$ & 5 & $1 \%$ & 0 & $0 \%$ & 2 & $1 \%$ & 0 & $0 \%$ & 0 & $0 \%$ \\
\hline Cumul irrégulier d'emplois & 0 & $0 \%$ & 0 & $0 \%$ & 0 & $0 \%$ & 0 & $0 \%$ & 0 & $0 \%$ & 0 & $0 \%$ \\
\hline Autres infractions & 38 & $6 \%$ & 35 & $6 \%$ & 27 & $6 \%$ & 18 & $5 \%$ & 30 & $7 \%$ & 19 & $6 \%$ \\
\hline dont Inf. contrav.TI & 8 & $1 \%$ & 14 & $2 \%$ & 14 & $3 \%$ & 5 & $1 \%$ & 9 & $2 \%$ & 3 & $1 \%$ \\
\hline dont délits connexes & 20 & $3 \%$ & 18 & $3 \%$ & 10 & $2 \%$ & 13 & $3 \%$ & 18 & $4 \%$ & 12 & $4 \%$ \\
\hline Total Infractions & 601 & $100 \%$ & 621 & $100 \%$ & 449 & $100 \%$ & 379 & $100 \%$ & 440 & $100 \%$ & 341 & $100 \%$ \\
\hline
\end{tabular}

*Nombre d'établissements impliqués dans le cadre d'opérations conjointes décidées en comité de lutte contre le travail illégal. 
Données principales et détail des infractions par sous-secteur des industries extractives et de l'industrie manufacturière en 2017

\begin{tabular}{|c|c|c|c|c|c|c|c|}
\hline & \multicolumn{5}{|c|}{ Industrie manufacturière } & \multirow[b]{2}{*}{ Total } & \multirow[b]{2}{*}{$\begin{array}{l}\% \text { du } \\
\text { Total }\end{array}$} \\
\hline & $\begin{array}{l}\text { Industries } \\
\text { extractives }\end{array}$ & $\begin{array}{l}\text { Industries } \\
\text { alimentaires }\end{array}$ & $\begin{array}{l}\text { Fabrication } \\
\text { de textiles }\end{array}$ & $\begin{array}{c}\text { Industrie de } \\
\text { I'habillement, } \\
\text { cuir et } \\
\text { chaussure }\end{array}$ & Autres & & \\
\hline Etablissements & 0 & 59 & 3 & 13 & 100 & 175 & - \\
\hline Auteurs & 0 & 68 & 4 & 28 & 111 & 211 & - \\
\hline Salariés & 0 & 106 & 7 & 48 & 627 & 788 & - \\
\hline Infractions & 0 & 95 & 7 & 39 & 200 & 341 & $100,0 \%$ \\
\hline Dont Infractions délictueuses de travail illégal & 0 & 93 & 7 & 36 & 186 & 322 & $94,4 \%$ \\
\hline Diss. de sal. avec défaut intentionnel de DPAE & & 51 & 4 & 8 & 63 & 126 & $37,0 \%$ \\
\hline Défaut de déclaration aux organismes de protection sociale & & 12 & & 7 & 30 & 49 & $14,4 \%$ \\
\hline Emploi d'étranger sans titre de travail & & 15 & 3 & 4 & 15 & 37 & $10,9 \%$ \\
\hline Défaut d'immatriculation de l'entreprise & & 4 & & 2 & 23 & 29 & $8,5 \%$ \\
\hline Recours aux services de celui qui exerce un TD & & & & 13 & 8 & 21 & $6,2 \%$ \\
\hline Défaut de déclaration à l'administration fiscale & & 1 & & & 15 & 16 & $4,7 \%$ \\
\hline $\begin{array}{l}\text { Prêt illicite de main d'œuvre / Prêt exclusif de MO à but } \\
\text { lucratif }\end{array}$ & & & & & 10 & 10 & $2,9 \%$ \\
\hline $\begin{array}{l}\text { Diss. de sal. avec défaut intentionnel de délivrance fiche de } \\
\text { paie }\end{array}$ & & 4 & & 1 & 4 & 9 & $2,6 \%$ \\
\hline $\begin{array}{l}\text { Diss. de sal. par dissimulation d'heures avec mention sur fiche } \\
\text { de paie }\end{array}$ & & 2 & & & 4 & 6 & $1,8 \%$ \\
\hline $\begin{array}{l}\text { Recours par personne morale d'une personne exerçant un } \\
\text { TD }\end{array}$ & & & & & 5 & 5 & $1,5 \%$ \\
\hline Marchandage & & & & & 4 & 4 & $1,2 \%$ \\
\hline Responsabilité pénale personne morale exerçant un TD & & & & & 4 & 4 & $1,2 \%$ \\
\hline Emploi d'un étranger non muni d'une autorisation de travail & & 3 & & & & 3 & $0,9 \%$ \\
\hline $\begin{array}{l}\text { Diss. de sal. par défaut de déclarations salaires ou cotisations } \\
\text { sociales }\end{array}$ & & 1 & & & & 1 & $0,3 \%$ \\
\hline $\begin{array}{l}\text { Info. mensongère identification d'un professionnel lors d'une } \\
\text { annonce }\end{array}$ & & & & 1 & & 1 & $0,3 \%$ \\
\hline $\begin{array}{l}\text { Recours par personne interposée aux services de celui qui } \\
\text { exerce un TD }\end{array}$ & & & & & 1 & 1 & $0,3 \%$ \\
\hline Dont Infractions contraventionnelles & 0 & 0 & 0 & 0 & 3 & 3 & $0,9 \%$ \\
\hline Défaut de déclaration de détachement en PSI & & & & & 1 & 1 & $0,3 \%$ \\
\hline Non déclaration d'un AT d'un salarié détaché & & & & & 1 & 1 & $0,3 \%$ \\
\hline $\begin{array}{l}\text { Non présentation par l'employeur de sal. détachés de doc. } \\
\text { à agent de contrôle }\end{array}$ & & & & & 1 & 1 & $0,3 \%$ \\
\hline Dont Délits connexes au travail illégal & 0 & 2 & 0 & 2 & 8 & 12 & $3,5 \%$ \\
\hline Entrée/aide à l'entrée et séjour irrégulier d'un étranger & & 2 & & 2 & 6 & 10 & $2,9 \%$ \\
\hline Délit d'obstacle ou outrage à agent de contrôle & & & & & 1 & 1 & $0,3 \%$ \\
\hline $\begin{array}{l}\text { Placement par ETT de ressortissants de pays tiers hors de } \\
\text { France }\end{array}$ & & & & & 1 & 1 & $0,3 \%$ \\
\hline Dont Autres infractions & 0 & 0 & 0 & 1 & 3 & 4 & $1,2 \%$ \\
\hline
\end{tabular}




\section{Transports}

\section{Données principales relatives à la verbalisation du travail illégal dans le secteur des transports depuis}

2012

\begin{tabular}{|c|c|c|c|c|c|c|c|c|c|c|c|c|}
\hline Nombre de: & \multicolumn{2}{|c|}{2012} & \multicolumn{2}{|c|}{2013} & \multicolumn{2}{|c|}{2014} & \multicolumn{2}{|c|}{2015} & \multicolumn{2}{|c|}{2016} & \multicolumn{2}{|c|}{2017} \\
\hline Etablissements & \multicolumn{2}{|c|}{447} & \multicolumn{2}{|c|}{481} & \multicolumn{2}{|c|}{460} & \multicolumn{2}{|c|}{450} & \multicolumn{2}{|c|}{653} & \multicolumn{2}{|c|}{503} \\
\hline dont en Op. Conj. COLTI* & \multicolumn{2}{|c|}{28} & \multicolumn{2}{|c|}{34} & \multicolumn{2}{|c|}{56} & \multicolumn{2}{|c|}{28} & \multicolumn{2}{|c|}{80} & \multicolumn{2}{|c|}{62} \\
\hline Auteurs & \multicolumn{2}{|c|}{488} & \multicolumn{2}{|c|}{525} & \multicolumn{2}{|c|}{545} & \multicolumn{2}{|c|}{486} & \multicolumn{2}{|c|}{697} & \multicolumn{2}{|c|}{547} \\
\hline Salariés & \multicolumn{2}{|c|}{771} & \multicolumn{2}{|c|}{822} & \multicolumn{2}{|c|}{1097} & \multicolumn{2}{|c|}{623} & \multicolumn{2}{|c|}{1423} & \multicolumn{2}{|c|}{1296} \\
\hline Infractions & \multicolumn{2}{|c|}{803} & \multicolumn{2}{|c|}{812} & \multicolumn{2}{|c|}{881} & \multicolumn{2}{|c|}{663} & & & & \\
\hline dont infractions: & & & & & & & & & & & & \\
\hline Travail dissimulé & 655 & $82 \%$ & 685 & $84 \%$ & 716 & $81 \%$ & 578 & $87 \%$ & 902 & $90 \%$ & 661 & $86 \%$ \\
\hline dont TD d'activité & 199 & $25 \%$ & 196 & $24 \%$ & 161 & $18 \%$ & 208 & $31 \%$ & 306 & $31 \%$ & 160 & $21 \%$ \\
\hline dont TD sur salarié & 456 & $57 \%$ & 489 & $60 \%$ & 555 & $63 \%$ & 370 & $56 \%$ & 596 & $60 \%$ & 501 & $65 \%$ \\
\hline E.S.T.T. & 64 & $8 \%$ & 63 & $8 \%$ & 65 & $7 \%$ & 41 & $6 \%$ & 36 & $4 \%$ & 43 & $6 \%$ \\
\hline P.I.M.O. & 19 & $2 \%$ & 16 & $2 \%$ & 63 & $7 \%$ & 5 & $1 \%$ & 8 & $1 \%$ & 16 & $2 \%$ \\
\hline $\begin{array}{l}\text { Fraude revenus } \\
\text { remplacement }\end{array}$ & 7 & $1 \%$ & 2 & $0 \%$ & 4 & $0 \%$ & 2 & $0 \%$ & 0 & $0 \%$ & 1 & $0 \%$ \\
\hline Cumul irrégulier d'emplois & 2 & $0 \%$ & 1 & $0 \%$ & 0 & $0 \%$ & 0 & $0 \%$ & 3 & $0 \%$ & 0 & $0 \%$ \\
\hline Autres infractions & 56 & $7 \%$ & 45 & $6 \%$ & 33 & $4 \%$ & 37 & $6 \%$ & 51 & $5 \%$ & 45 & $6 \%$ \\
\hline dont Inf. contrav.TI & 13 & $2 \%$ & 9 & $1 \%$ & 6 & $1 \%$ & 2 & $0 \%$ & 4 & $0 \%$ & 7 & $1 \%$ \\
\hline dont délits connexes & 27 & $3 \%$ & 21 & $3 \%$ & 15 & $2 \%$ & 34 & $5 \%$ & 32 & $3 \%$ & 27 & $4 \%$ \\
\hline Total Infractions & 803 & $100 \%$ & 812 & $100 \%$ & 881 & $100 \%$ & 663 & $100 \%$ & 1000 & $100 \%$ & 766 & $100 \%$ \\
\hline
\end{tabular}

*Nombre d'établissements impliqués dans le cadre d'opérations conjointes décidées en comité de lutte contre le travail illégal. 
Données principales et détail des infractions par sous-secteurs des transports en 2017

\begin{tabular}{|c|c|c|c|c|c|c|c|c|}
\hline & $\begin{array}{l}\text { Transport } \\
\text { ferroviaire }\end{array}$ & $\begin{array}{l}\text { Transports } \\
\text { de } \\
\text { voyageurs } \\
\text { par taxis }\end{array}$ & $\begin{array}{l}\text { Transports } \\
\text { routiers de } \\
\text { fret }\end{array}$ & $\begin{array}{l}\text { Services de } \\
\text { déménagement }\end{array}$ & $\begin{array}{l}\text { Transport } \\
\text { maritime } \\
\text { et fluvial }\end{array}$ & Autres & Total & $\begin{array}{l}\% \text { du } \\
\text { Total }\end{array}$ \\
\hline Etablissements & 2 & 180 & 250 & 30 & 11 & 30 & 503 & - \\
\hline Auteurs & 2 & 188 & 278 & 32 & 13 & 34 & 547 & - \\
\hline Salariés & 1 & 152 & 837 & 60 & 14 & 232 & 1296 & - \\
\hline Infractions & 2 & 259 & 364 & 50 & 41 & 50 & 766 & $100,0 \%$ \\
\hline Dont Infractions délictueuses de travail illégal & 2 & 245 & 341 & 47 & 41 & 45 & 721 & $94,1 \%$ \\
\hline Diss. de sal. avec défaut intentionnel de DPAE & 1 & 152 & 186 & 27 & 11 & 18 & 395 & $51,6 \%$ \\
\hline $\begin{array}{l}\text { Défaut de déclaration aux organismes de protection } \\
\text { sociale }\end{array}$ & & 26 & 35 & 4 & 4 & 7 & 76 & $9,9 \%$ \\
\hline Défaut d'immatriculation de l'entreprise & & 33 & 10 & 1 & 6 & 4 & 54 & $7 \%$ \\
\hline Emploi d'étranger sans titre de travail & & & 30 & 4 & & 3 & 37 & $5 \%$ \\
\hline $\begin{array}{l}\text { Diss. de sal. par dissimulation d'heures avec mention sur } \\
\text { fiche de paie }\end{array}$ & & 2 & 28 & & & 3 & 33 & $4,3 \%$ \\
\hline Défaut de déclaration à l'administration fiscale & & 18 & 7 & & 4 & 1 & 30 & $3,9 \%$ \\
\hline Recours aux services de celui qui exerce un TD & 1 & 5 & 13 & 4 & 4 & 3 & 30 & $3,9 \%$ \\
\hline $\begin{array}{l}\text { Recours par personne morale d'une personne exerçant } \\
\text { un TD }\end{array}$ & & 4 & 5 & & & 3 & 12 & $1,6 \%$ \\
\hline $\begin{array}{l}\text { Diss. de sal. avec défaut intentionnel de délivrance } \\
\text { fiche de paie }\end{array}$ & & 1 & 6 & 2 & & & 9 & $1,2 \%$ \\
\hline $\begin{array}{l}\text { Prêt illicite de main d'œuvre / Prêt exclusif de MO à but } \\
\text { lucratif }\end{array}$ & & 1 & 4 & & 4 & & 9 & $1,2 \%$ \\
\hline Marchandage & & & 3 & & 4 & & 7 & $0,9 \%$ \\
\hline $\begin{array}{l}\text { Emploi d'un étranger non muni d'une autorisation de } \\
\text { travail }\end{array}$ & & & 5 & & & 1 & 6 & $0,8 \%$ \\
\hline $\begin{array}{l}\text { Recours par personne interposée aux services de celui } \\
\text { qui exerce un TD }\end{array}$ & & & 2 & & 4 & & 6 & $0,8 \%$ \\
\hline Responsabilité pénale personne morale exerçant un TD & & 1 & 3 & & & 2 & 6 & $0,8 \%$ \\
\hline $\begin{array}{l}\text { Diss. de sal. par défaut de déclarations salaires ou } \\
\text { cotisations sociales }\end{array}$ & & 1 & 3 & 1 & & & 5 & $0,7 \%$ \\
\hline $\begin{array}{l}\text { Recours à la sous-traitance sans faire accepter le sous- } \\
\text { traitant et agréer ses conditions de paiement par le } \\
\text { MOA }\end{array}$ & & & & 3 & & & 3 & $0,4 \%$ \\
\hline $\begin{array}{l}\text { Info. mensongère identification d'un professionnel lors } \\
\text { d'une annonce }\end{array}$ & & & 1 & & & & 1 & $0,1 \%$ \\
\hline $\begin{array}{l}\text { Obtention frauduleuse d'allocations à travailleur privé } \\
\text { d'emploi }\end{array}$ & & & & 1 & & & 1 & $0,1 \%$ \\
\hline Publicité tendant à favoriser volontairement le TD & & 1 & & & & & 1 & $0,1 \%$ \\
\hline Dont Infractions contraventionnelles & 0 & 0 & 5 & 1 & 0 & 1 & 7 & $0,9 \%$ \\
\hline $\begin{array}{l}\text { Défaut tenue/non présentation/absence de mentions } \\
\text { obligatoires RUP }\end{array}$ & & & 4 & & & & 4 & $0,5 \%$ \\
\hline Non déclaration d'un AT d'un salarié détaché & & & 1 & & & 1 & 2 & $0,3 \%$ \\
\hline $\begin{array}{l}\text { Défaut non intentionnel/non présentation du récépissé } \\
\text { de DPAE }\end{array}$ & & & & 1 & & & 1 & $0,1 \%$ \\
\hline Dont Délits connexes au travail illégal & 0 & 14 & 9 & 1 & 0 & 3 & 27 & $3,5 \%$ \\
\hline Entrée/aide à l'entrée et séjour irrégulier d'un étranger & & 14 & 5 & 1 & & 2 & 22 & $2,9 \%$ \\
\hline Délit d'obstacle ou outrage à agent de contrôle & & & 2 & & & 1 & 3 & $0,4 \%$ \\
\hline $\begin{array}{l}\text { Placement par ETT de ressortissants de pays tiers hors de } \\
\text { France }\end{array}$ & & & 1 & & & & 1 & $0,1 \%$ \\
\hline Usage (ou tentative) de faux documents & & & 1 & & & & 1 & $0,1 \%$ \\
\hline Dont Autres infractions & 0 & 0 & 9 & 1 & & 1 & 11 & $1,4 \%$ \\
\hline
\end{tabular}


Activités financières, immobilières, spécialisées, scientifiques, techniques, et de services administratifs et de soutien

Données principales relatives à la verbalisation du travail illégal dans le secteur des activités financières, immobilières, spécialisées, scientifiques, techniques, de services administratifs et de soutien depuis 2012

\begin{tabular}{|c|c|c|c|c|c|c|c|c|c|c|c|c|}
\hline Nombre de: & \multicolumn{2}{|c|}{2012} & \multicolumn{2}{|c|}{2013} & \multicolumn{2}{|c|}{2014} & \multicolumn{2}{|c|}{2015} & \multicolumn{2}{|c|}{2016} & \multicolumn{2}{|c|}{2017} \\
\hline Etablissements & \multicolumn{2}{|c|}{609} & \multicolumn{2}{|c|}{622} & \multicolumn{2}{|c|}{499} & \multicolumn{2}{|c|}{505} & \multicolumn{2}{|c|}{500} & \multicolumn{2}{|c|}{486} \\
\hline dont en Op. Conj. COLTI* & \multicolumn{2}{|c|}{48} & \multicolumn{2}{|c|}{54} & \multicolumn{2}{|c|}{58} & \multicolumn{2}{|c|}{33} & \multicolumn{2}{|c|}{52} & \multicolumn{2}{|c|}{51} \\
\hline Auteurs & \multicolumn{2}{|c|}{692} & \multicolumn{2}{|c|}{743} & \multicolumn{2}{|c|}{578} & \multicolumn{2}{|c|}{569} & \multicolumn{2}{|c|}{581} & \multicolumn{2}{|c|}{569} \\
\hline Salariés & \multicolumn{2}{|c|}{3236} & \multicolumn{2}{|c|}{5364} & \multicolumn{2}{|c|}{2904} & \multicolumn{2}{|c|}{3272} & \multicolumn{2}{|c|}{4062} & \multicolumn{2}{|c|}{3058} \\
\hline Infractions & \multicolumn{2}{|c|}{1231} & \multicolumn{2}{|c|}{1387} & \multicolumn{2}{|c|}{1008} & \multicolumn{2}{|c|}{894} & & & & \\
\hline dont infractions: & & & & & & & & & & & & \\
\hline Travail dissimulé & 952 & $77 \%$ & 1022 & $74 \%$ & 764 & $76 \%$ & 748 & $84 \%$ & 785 & $83 \%$ & 785 & $83 \%$ \\
\hline dont TD d'activité & 304 & $25 \%$ & 344 & $25 \%$ & 233 & $23 \%$ & 270 & $30 \%$ & 292 & $31 \%$ & 317 & $34 \%$ \\
\hline dont TD sur salarié & 648 & $53 \%$ & 678 & $49 \%$ & 531 & $53 \%$ & 478 & $53 \%$ & 493 & $52 \%$ & 456 & $48 \%$ \\
\hline E.S.T.T. & 118 & $10 \%$ & 162 & $12 \%$ & 98 & $10 \%$ & 62 & $7 \%$ & 53 & $6 \%$ & 77 & $8 \%$ \\
\hline P.I.M.O. & 78 & $6 \%$ & 125 & $9 \%$ & 62 & $6 \%$ & 40 & $4 \%$ & 44 & $5 \%$ & 35 & $4 \%$ \\
\hline $\begin{array}{l}\text { Fraude revenus } \\
\text { remplacement }\end{array}$ & 3 & $0 \%$ & 2 & $0 \%$ & 4 & $0 \%$ & 8 & $1 \%$ & 0 & $0 \%$ & 3 & $0 \%$ \\
\hline Cumul irrégulier d'emplois & 3 & $0 \%$ & 4 & $0 \%$ & 1 & $0 \%$ & 1 & $0 \%$ & 1 & $0 \%$ & 0 & $0 \%$ \\
\hline Autres infractions & 77 & $6 \%$ & 72 & $5 \%$ & 79 & $8 \%$ & 35 & $4 \%$ & 66 & $7 \%$ & 53 & $6 \%$ \\
\hline dont Inf. contrav.TI & 15 & $1 \%$ & 19 & $1 \%$ & 29 & $3 \%$ & 8 & $1 \%$ & 22 & $2 \%$ & 11 & $1 \%$ \\
\hline dont délits connexes & 34 & $3 \%$ & 42 & $3 \%$ & 39 & $4 \%$ & 3 & $0 \%$ & 32 & $3 \%$ & 36 & $4 \%$ \\
\hline Total Infractions & 1231 & $100 \%$ & 1387 & $100 \%$ & 1008 & $100 \%$ & 894 & $100 \%$ & 949 & $100 \%$ & 941 & $100 \%$ \\
\hline
\end{tabular}

*Nombre d'établissements impliqués dans le cadre d'opérations conjointes décidées en comité de lutte contre le travail illégal. 
Données principales et détail des infractions par sous-secteur des activités financières, immobilières, spécialisées, scientifiques, techniques, de services administratifs et de soutien en 2017

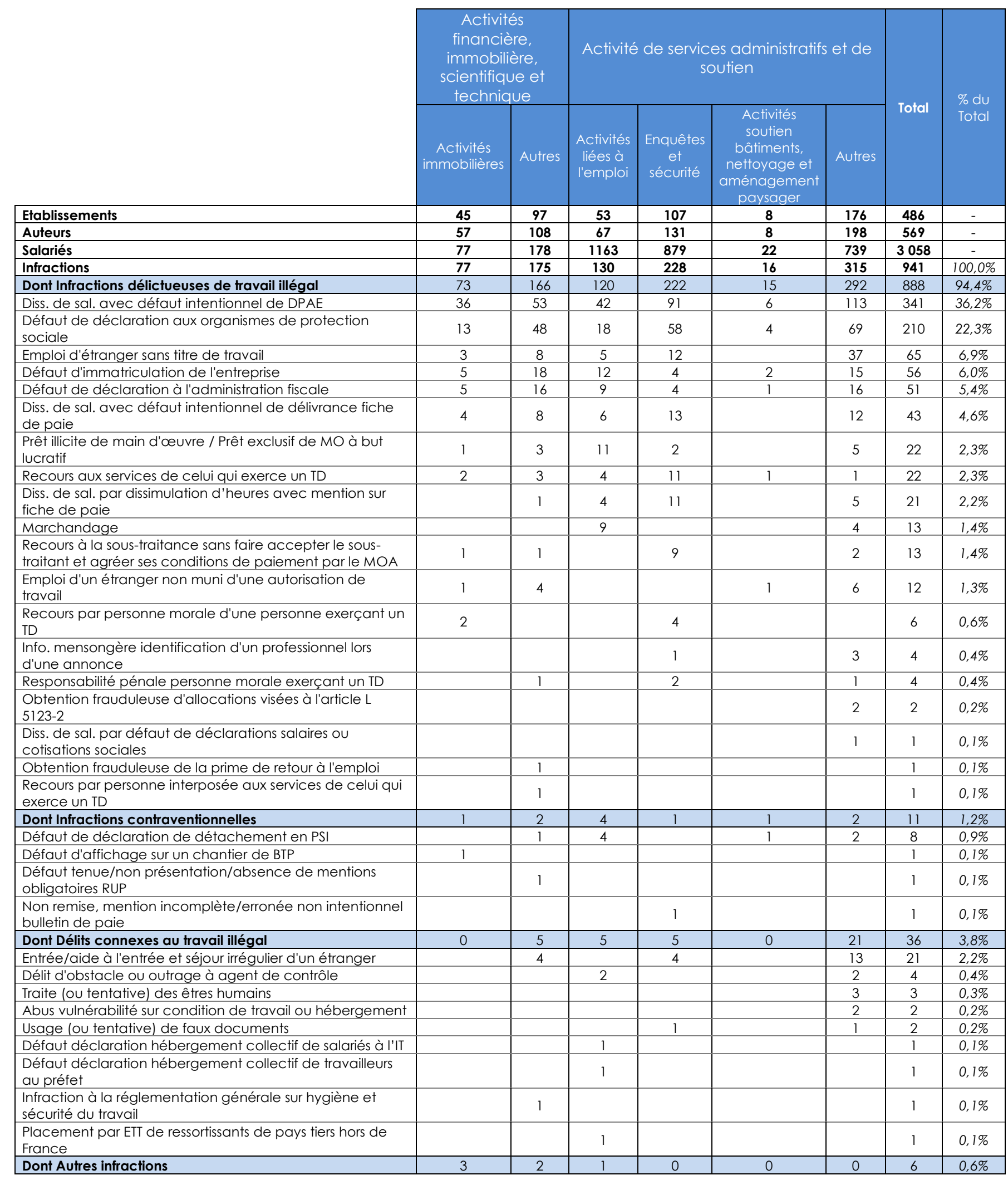




\section{Information et communication et arts, spectacles et activités récréatives}

Données principales relatives à la verbalisation du travail illégal dans le secteur de l'information et de la communication, et des arts, des spectacles et des activités récréatives depuis 2012

\begin{tabular}{|c|c|c|c|c|c|c|c|c|c|c|c|c|}
\hline Nombre de: & \multicolumn{2}{|c|}{2012} & \multicolumn{2}{|c|}{2013} & \multicolumn{2}{|c|}{2014} & \multicolumn{2}{|c|}{2015} & \multicolumn{2}{|c|}{2016} & \multicolumn{2}{|c|}{2017} \\
\hline Etablissements & \multicolumn{2}{|c|}{232} & \multicolumn{2}{|c|}{212} & \multicolumn{2}{|c|}{164} & \multicolumn{2}{|c|}{160} & \multicolumn{2}{|c|}{196} & \multicolumn{2}{|c|}{163} \\
\hline dont en Op. Conj. COLTI* & \multicolumn{2}{|c|}{69} & \multicolumn{2}{|c|}{59} & \multicolumn{2}{|c|}{31} & \multicolumn{2}{|c|}{25} & \multicolumn{2}{|c|}{47} & \multicolumn{2}{|c|}{41} \\
\hline Auteurs & \multicolumn{2}{|c|}{265} & \multicolumn{2}{|c|}{224} & \multicolumn{2}{|c|}{189} & \multicolumn{2}{|c|}{186} & \multicolumn{2}{|c|}{207} & \multicolumn{2}{|c|}{189} \\
\hline Salariés & \multicolumn{2}{|c|}{1066} & \multicolumn{2}{|c|}{834} & \multicolumn{2}{|c|}{577} & \multicolumn{2}{|c|}{438} & \multicolumn{2}{|c|}{1127} & \multicolumn{2}{|c|}{2536} \\
\hline Infractions & \multicolumn{2}{|c|}{475} & \multicolumn{2}{|c|}{369} & \multicolumn{2}{|c|}{319} & \multicolumn{2}{|c|}{292} & & & & \\
\hline dont infractions: & & & & & & & & & & & & \\
\hline Travail dissimulé & 427 & $90 \%$ & 334 & $91 \%$ & 280 & $88 \%$ & 264 & $90 \%$ & 300 & $90 \%$ & 252 & $89 \%$ \\
\hline dont TD d'activité & 119 & $25 \%$ & 95 & $26 \%$ & 96 & $30 \%$ & 93 & $32 \%$ & 95 & $28 \%$ & 94 & $33 \%$ \\
\hline dont TD sur salarié & 308 & $65 \%$ & 239 & $65 \%$ & 184 & $58 \%$ & 171 & $59 \%$ & 205 & $61 \%$ & 158 & $56 \%$ \\
\hline E.S.T.T. & 21 & $4 \%$ & 21 & $6 \%$ & 12 & $4 \%$ & 16 & $5 \%$ & 16 & $5 \%$ & 14 & $5 \%$ \\
\hline P.I.M.O. & 8 & $2 \%$ & 1 & $0,3 \%$ & 3 & $1 \%$ & 2 & $1 \%$ & 4 & $1 \%$ & 2 & $1 \%$ \\
\hline $\begin{array}{l}\text { Fraude revenus } \\
\text { remplacement }\end{array}$ & 3 & $1 \%$ & 0 & $0 \%$ & 2 & $1 \%$ & 0 & $0 \%$ & 1 & $0 \%$ & 0 & $0 \%$ \\
\hline Cumul irrégulier d'emplois & 0 & $0 \%$ & 0 & $0 \%$ & 0 & $0 \%$ & 0 & $0 \%$ & 0 & $0 \%$ & 0 & $0 \%$ \\
\hline Autres infractions & 16 & $3 \%$ & 13 & $4 \%$ & 22 & $7 \%$ & 10 & $3 \%$ & 14 & $4 \%$ & 14 & $5 \%$ \\
\hline dont Inf. contrav.TI & 4 & $1 \%$ & 9 & $2 \%$ & 8 & $3 \%$ & 1 & $0 \%$ & 7 & $2 \%$ & 6 & $2 \%$ \\
\hline dont délits connexes & 6 & $1 \%$ & 3 & $1 \%$ & 7 & $2 \%$ & 5 & $2 \%$ & 5 & $1 \%$ & 3 & $1 \%$ \\
\hline Total Infractions & 475 & $100 \%$ & 369 & $100 \%$ & 319 & $100 \%$ & 292 & $100 \%$ & 335 & $100 \%$ & 282 & $100 \%$ \\
\hline
\end{tabular}

*Nombre d'établissements impliqués dans le cadre d’opérations conjointes décidées en comité de lutte contre le travail illégal. 
Données principales et détail des infractions par sous-secteur de l'information et de la communication, et des arts, des spectacles et des activités récréatives en 2017

\begin{tabular}{|c|c|c|c|c|c|c|c|c|c|}
\hline & \multicolumn{3}{|c|}{ Information et communication } & \multicolumn{4}{|c|}{$\begin{array}{l}\text { Arts, spectacles et activités } \\
\text { récréatives } \\
\end{array}$} & \multirow[b]{2}{*}{ Total } & \multirow[b]{2}{*}{$\begin{array}{l}\% \text { du } \\
\text { Total }\end{array}$} \\
\hline & $\begin{array}{l}\text { Activités } \\
\text { cinématographiques, } \\
\text { vidéo et de télévision }\end{array}$ & $\begin{array}{l}\text { Télécom- } \\
\text { munications }\end{array}$ & Autres & $\begin{array}{l}\text { Activités } \\
\text { créatives, } \\
\text { artistiques } \\
\text { et de } \\
\text { spectacle }\end{array}$ & $\begin{array}{c}\text { Activités } \\
\text { sportives } \\
\text { et } \\
\text { centres } \\
\text { équestres }\end{array}$ & $\begin{array}{l}\text { Bal et } \\
\text { discothèqu } \\
e\end{array}$ & Autres & & \\
\hline Etablissements & 2 & 15 & 25 & 36 & 37 & 40 & 8 & 163 & - \\
\hline Auteurs & 2 & 15 & 29 & 41 & 45 & 48 & 9 & 189 & - \\
\hline Salariés & 2 & 10 & 2341 & 58 & 50 & 65 & 10 & $\begin{array}{c}2 \\
536\end{array}$ & - \\
\hline Infractions & 2 & 22 & 40 & 66 & 71 & 67 & 14 & 282 & $100,0 \%$ \\
\hline $\begin{array}{l}\text { Dont Infractions délictueuses de } \\
\text { travail illégal }\end{array}$ & 2 & 22 & 40 & 60 & 63 & 67 & 14 & 268 & $95,0 \%$ \\
\hline $\begin{array}{l}\text { Diss. de sal. avec défaut intentionnel } \\
\text { de DPAE }\end{array}$ & & 8 & 17 & 25 & 28 & 39 & 8 & 125 & $44,3 \%$ \\
\hline $\begin{array}{l}\text { Défaut de déclaration aux } \\
\text { organismes de protection sociale }\end{array}$ & 1 & 1 & 13 & 12 & 13 & 13 & 3 & 56 & $19,9 \%$ \\
\hline $\begin{array}{l}\text { Défaut d'immatriculation de } \\
\text { l'entreprise }\end{array}$ & 1 & 5 & 1 & 6 & 3 & 7 & & 23 & $8,2 \%$ \\
\hline $\begin{array}{l}\text { Défaut de déclaration à } \\
\text { l'administration fiscale }\end{array}$ & & & 5 & 2 & 3 & 2 & 3 & 15 & $5,3 \%$ \\
\hline $\begin{array}{l}\text { Diss. de sal. avec défaut intentionnel } \\
\text { de délivrance fiche de paie }\end{array}$ & & 1 & 2 & 3 & 2 & 4 & & 12 & $4,3 \%$ \\
\hline Emploi d'étranger sans titre de travail & & 3 & 1 & 2 & 4 & 1 & & 11 & $3,9 \%$ \\
\hline $\begin{array}{l}\text { Recours aux services de celui qui } \\
\text { exerce un TD }\end{array}$ & & & 1 & 2 & 3 & & & 6 & $2,1 \%$ \\
\hline $\begin{array}{l}\text { Responsabilité pénale personne } \\
\text { morale exerçant un TD }\end{array}$ & & 1 & & & 2 & 1 & & 4 & $1,4 \%$ \\
\hline $\begin{array}{l}\text { Diss. de sal. par dissimulation d'heures } \\
\text { avec mention sur fiche de paie }\end{array}$ & & & & 2 & 1 & & & 3 & $1,1 \%$ \\
\hline $\begin{array}{l}\text { Emploi d'un étranger non muni d'une } \\
\text { autorisation de travail }\end{array}$ & & 1 & & 1 & 1 & & & 3 & $1,1 \%$ \\
\hline $\begin{array}{l}\text { Publicité tendant à favoriser } \\
\text { volontairement le TD }\end{array}$ & & & & & 3 & & & 3 & $1,1 \%$ \\
\hline $\begin{array}{l}\text { Diss. de sal. par défaut de } \\
\text { déclarations salaires ou cotisations } \\
\text { sociales }\end{array}$ & & & & 2 & & & & 2 & $0,7 \%$ \\
\hline $\begin{array}{l}\text { Recours à la sous-traitance sans faire } \\
\text { accepter le sous-traitant et agréer ses } \\
\text { conditions de paiement par le MOA }\end{array}$ & & & & 2 & & & & 2 & $0,7 \%$ \\
\hline Marchandage & & 1 & & & & & & 1 & $0,4 \%$ \\
\hline $\begin{array}{l}\text { Prêt illicite de main d'œuvre / Prêt } \\
\text { exclusif de MO à but lucratif }\end{array}$ & & 1 & & & & & & 1 & $0,4 \%$ \\
\hline $\begin{array}{l}\text { Recours par personne morale d'une } \\
\text { personne exerçant un TD }\end{array}$ & & & & 1 & & & & 1 & $0,4 \%$ \\
\hline Dont Infractions contraventionnelles & 0 & 0 & 0 & 5 & 1 & 0 & 0 & 6 & $2,1 \%$ \\
\hline $\begin{array}{l}\text { Défaut tenue/non } \\
\text { présentation/absence de mentions } \\
\text { obligatoires RUP }\end{array}$ & & & & 3 & & & & 3 & $1,1 \%$ \\
\hline $\begin{array}{l}\text { Non déclaration d'un AT d'un salarié } \\
\text { détaché }\end{array}$ & & & & & 1 & & & 1 & $0,4 \%$ \\
\hline $\begin{array}{l}\text { Non présentation par l'employeur de } \\
\text { sal. détachés de doc. à agent de } \\
\text { contrôle }\end{array}$ & & & & 1 & & & & 1 & $0,4 \%$ \\
\hline $\begin{array}{l}\text { Non remise, mention } \\
\text { incomplète/erronée non intentionnel } \\
\text { bulletin de paie }\end{array}$ & & & & 1 & & & & 1 & $0,4 \%$ \\
\hline Dont Délits connexes au travail illégal & 0 & 0 & 0 & 1 & 2 & 0 & 0 & 3 & $1,1 \%$ \\
\hline $\begin{array}{l}\text { Entrée/aide à l'entrée et séjour } \\
\text { irrégulier d'un étranger }\end{array}$ & & & & & 2 & & & 2 & $0,7 \%$ \\
\hline $\begin{array}{l}\text { Fraude pour l'obtention d'un titre de } \\
\text { travail }\end{array}$ & & & & 1 & & & & 1 & $0,4 \%$ \\
\hline Dont Autres infractions & 0 & 0 & 0 & 0 & 5 & 0 & 0 & 5 & $1,8 \%$ \\
\hline
\end{tabular}




\section{Liste des tableaux et graphes}

\section{Tableaux}

Tableau 1 : Répartition des PV par nombre d'administrations présentes lors du contrôle depuis 2011

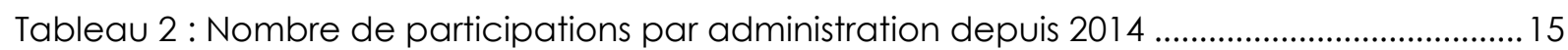

Tableau 3 : Répartition des auteurs par nationalité en 2017 ...........................................................32

Tableau 4 : Répartition des salariés concernés par nationalité en 2017 ......................................35

\section{Graphes}

Graphe 1 : Nombre de procès-verbaux reçus depuis 2004

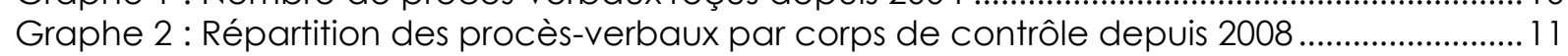

Graphe 3 : Répartition des PV entre contrôle conjoint et non conjoint depuis 2004 ......................12

Graphe 4 : Les alliances de collaboration des corps de contrôle en 2017 .....................................14

Graphe 5 : Comparaison entre taux de signature et taux de participation en 2017 .................16

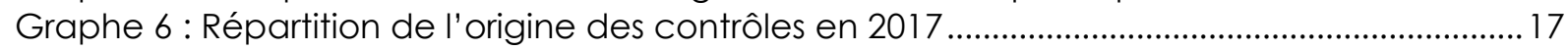

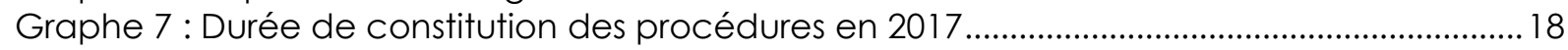

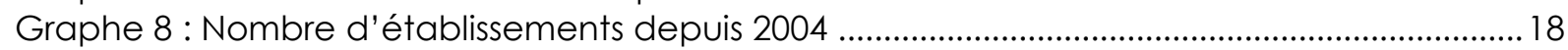

Graphe 9 : Catégorie juridique des établissements depuis 2004 ..................................................19

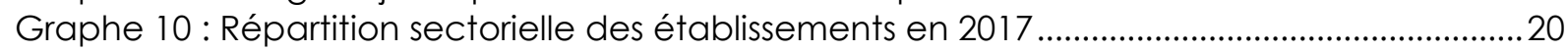

Graphe 11 : Répartition sectorielle des opérations décidées en comité en 2017 ........................20

Graphe 12 : La taille des entreprises verbalisées en 2017 ..............................................................21

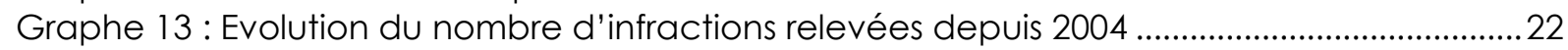

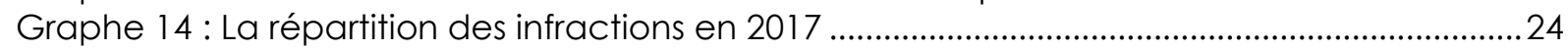

$7,5 \%$ des infractions concernent les autres infractions dont infractions contraventionnelles ou

délits connexes associés régulièrement au travail illégal en 2017, comme en 2016...........24

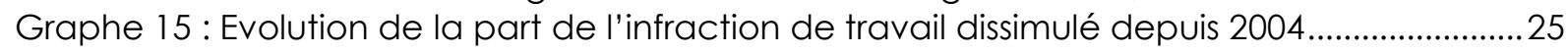

Graphe 16: Evolution des infractions de dissimulation d'activité depuis 2004 ............................26

Graphe 17 : Evolution des infractions de dissimulation d'emploi salarié depuis 2004 ….............27

Graphe 18: Evolution de la part relative de l'infraction d'emploi d'étrangers sans titre de

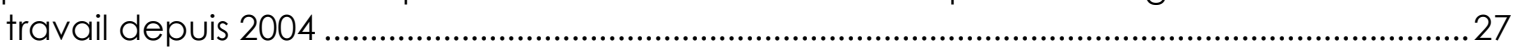

Graphe 19: Répartition de l'infraction d'emploi d'étrangers sans titre de travail par secteur

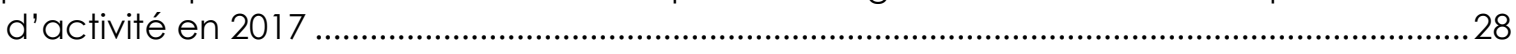

Graphe 20 : Evolution de la part relative des infractions prêt illicite de main d'œuvre depuis 2004.

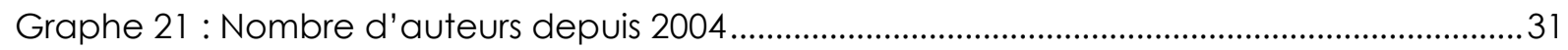

Graphe 22 : Répartition des personnes morales et physiques depuis 2004 .....................................31

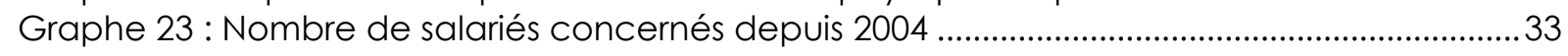




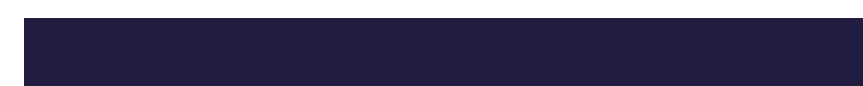

|54| DGT - Analyse de la verbalisation du travail illégal en 2017 

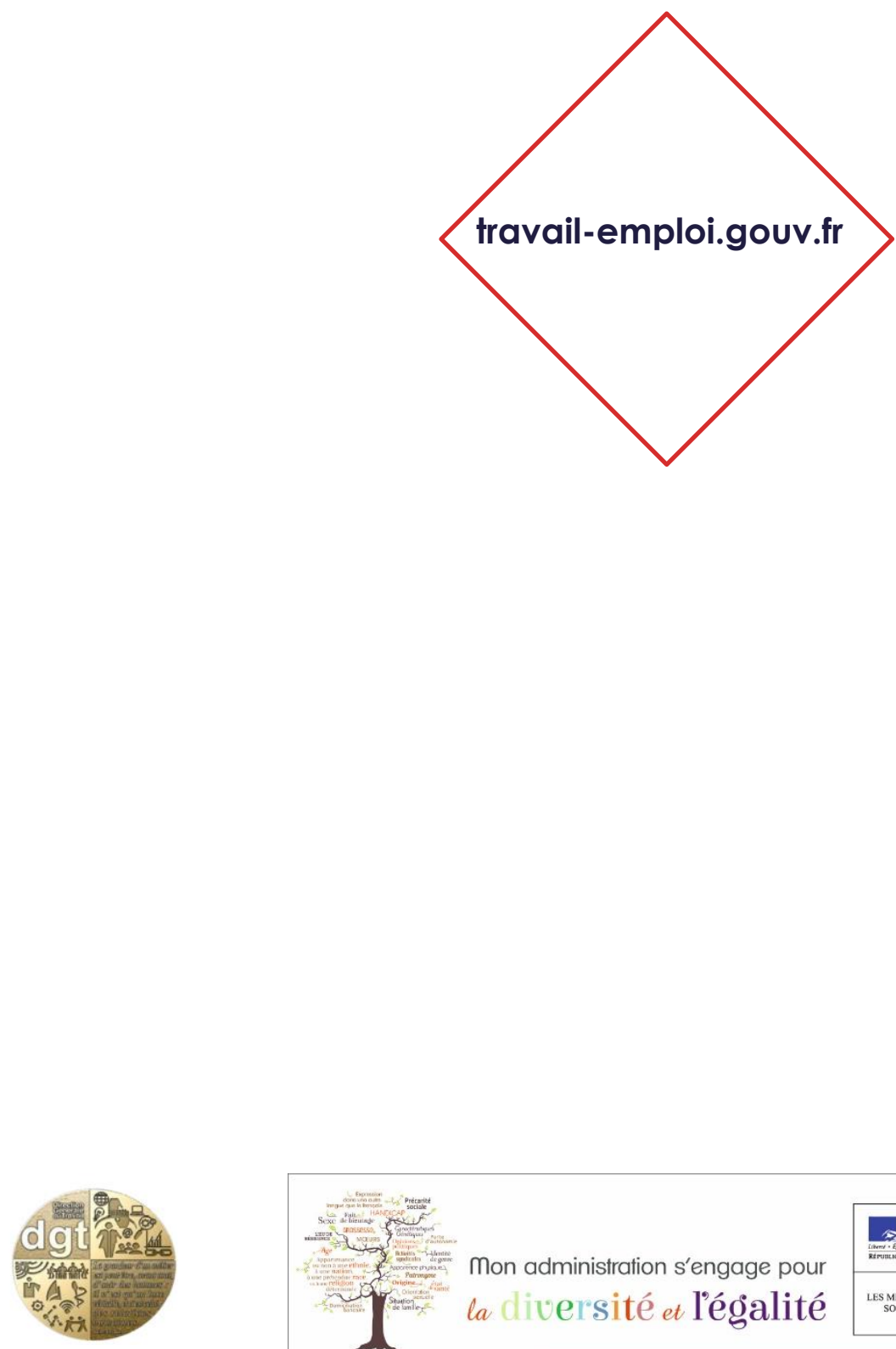